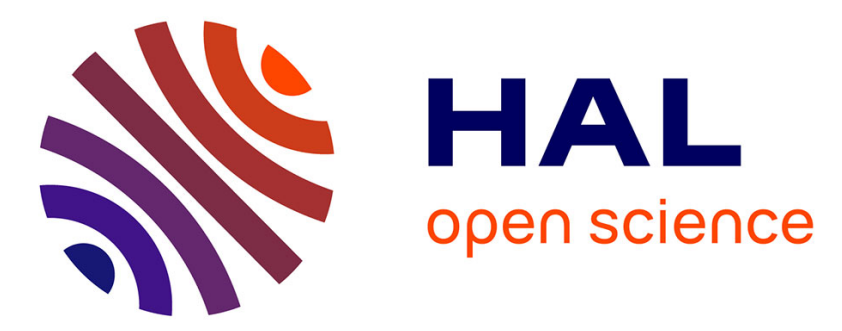

\title{
Comparative Analysis of Germline and Somatic Micro-lesion Mutational Spectra in 17 Human Tumour Suppressor Genes
}

Nadia Chuzhanova, Dobril Ivanov, Stephen Edward Hamby, Peter Stentson, Andrew D Phillips, Hildegard Kehrer-Sawatzki, David N. Cooper

\section{To cite this version:}

Nadia Chuzhanova, Dobril Ivanov, Stephen Edward Hamby, Peter Stentson, Andrew D Phillips, et al.. Comparative Analysis of Germline and Somatic Micro-lesion Mutational Spectra in 17 Human Tumour Suppressor Genes. Human Mutation, 2011, 10.1002/humu.21483 . hal-00625570

\section{HAL Id: hal-00625570 https://hal.science/hal-00625570}

Submitted on 22 Sep 2011

HAL is a multi-disciplinary open access archive for the deposit and dissemination of scientific research documents, whether they are published or not. The documents may come from teaching and research institutions in France or abroad, or from public or private research centers.
L'archive ouverte pluridisciplinaire HAL, est destinée au dépôt et à la diffusion de documents scientifiques de niveau recherche, publiés ou non, émanant des établissements d'enseignement et de recherche français ou étrangers, des laboratoires publics ou privés. 
Human Mutation

WILEY

\section{Comparative Analysis of Germline and Somatic Micro-lesion Mutational Spectra in 17 Human Tumour Suppressor Genes}

\begin{tabular}{|r|l|}
\hline Journal: & Human Mutation \\
\hline Manuscript ID: & humu-2010-0507.R1 \\
\hline Wiley - Manuscript type: & Research Article \\
\hline Duthor: & 10 -Jan-2011 \\
\hline Complete List of Authors: & $\begin{array}{l}\text { Chuzhanova, Nadia; Nottingham Trent University, School of Science } \\
\text { and Technology } \\
\text { Ivanov, Dobril; Cardiff University, Department of Psychological } \\
\text { Medicine and Neurology } \\
\text { Hamby, Stephen; Nottingham Trent University, School of Science } \\
\text { and Technology } \\
\text { Stentson, Peter } \\
\text { Phillips, Andrew; Cardiff University, Institute of Medical Genetics, } \\
\text { College of Medicine } \\
\text { Kehrer-Sawatzki, Hildegard; University of Ulm } \\
\text { Cooper, David; Cardiff University, Institute of Medical Genetics, } \\
\text { College of Medicine }\end{array}$ \\
\hline Key Words: & $\begin{array}{l}\text { germline and somatic mutational spectra, tumour suppressor } \\
\text { genes, recurrent mutation, mutation hotspot, non-B DNA, driver } \\
\text { mutations }\end{array}$ \\
\hline \hline
\end{tabular}

\section{SCHOLARONE ${ }^{\text {IM }}$ Manuscripts}


Comparative Analysis of Germline and Somatic Micro-lesion Mutational Spectra in

\title{
17 Human Tumour Suppressor Genes
}

\author{
Dobril Ivanov $^{1,2}$, Stephen E. Hamby ${ }^{3}$, Peter D. Stenson ${ }^{1}$, Andrew D. Phillips ${ }^{1}$, \\ Hildegard Kehrer-Sawatzki ${ }^{4}$, David N. Cooper ${ }^{1}$ and Nadia Chuzhanova ${ }^{3}$ \\ ${ }^{1}$ Institute of Medical Genetics, School of Medicine, Cardiff University, Cardiff, CF14 4XN, UK \\ ${ }^{2}$ MRC Centre for Neuropsychiatric Genetics and Genomics, Department of Psychological Medicine \\ and Neurology, Biostatistics and Bioinformatics Unit, School of Medicine, Cardiff University, \\ Cardiff, CF14 4XN, UK \\ ${ }^{3}$ School of Science and Technology, Nottingham Trent University, Nottingham, NG11 \\ $8 \mathrm{NS}, \mathrm{UK}$ \\ ${ }^{4}$ Institute of Human Genetics, University of Ulm, Albert-Einstein-Allee 11, $89081 \mathrm{Ulm}$, \\ Germany
}

\footnotetext{
*All correspondence to: Prof. Nadia Chuzhanova, School of Science and Technology

Nottingham Trent University, Clifton Lane, Nottingham NG11 8NS, UK

Tel: +44 (0) $01158488304 \quad$ E-mail: nadia.chuzhanova@ntu.ac.uk
} 


\begin{abstract}
Mutations associated with tumorigenesis may either arise somatically or can be inherited through the germline. In this study, we performed a comparison of somatic, germline and shared (found in both soma and germline) mutational spectra for 17 human tumour suppressor genes which included missense single base-pair substitutions and micro-deletions/micro-insertions. Somatic and germline mutational spectra were similar in relation to C.G $>$ T.A transitions but differed with respect to the frequency of A.T>G.C, A.T>T.A and C.G>A.T substitutions. Shared missense mutations were characterised by higher mutability rates, greater physicochemical differences between wild-type and mutant amino acid residues, and a tendency to occur in evolutionarily conserved amino acid residues and within $\mathrm{CpG} / \mathrm{CpHpG}$ oligonucleotides. Mononucleotide runs ( $\geq 4$ bp) were identified as hotspots for shared micro-deletions/micro-insertions. Both germline and somatic micro-deletions/micro-insertions were found to be significantly overrepresented within the 'indel hotspot' motif, GTAAGT. Using a naïve Bayes' classifier trained to discriminate between somatic, recurrent somatic, germline, shared and recurrent shared missense mutations, $63.1 \%$ of mutations in our dataset were correctly recognized. Using this classifier to analyse an independent dataset of probable driver mutations, we concluded that $~ 50 \%$ of these somatic missense mutations possess features consistent with their being either shared or recurrent, suggesting that a disproportionate number of such lesions are likely to be drivers of tumorigenesis.
\end{abstract}

Key Words: germline and somatic mutational spectra; tumour suppressor genes; recurrent mutation; mutation hotspot; non-B DNA; driver mutations 


\section{Introduction}

A major distinction to be made between somatic and germline mutations is that the former occur during mitotic cell cycles whereas the latter are generally meiotic in origin. In addition, whilst somatic cancer-causing gene lesions come to clinical attention by conferring a growth advantage upon the affected cells or tissue, germ-line gene mutations causing inherited disease normally come to attention by conferring a disadvantage upon the individual, usually through haploinsufficiency. Finally, whereas inherited disease usually implies only one or two pathological mutations at a specific locus, cancer is often characterized by multiple somatic mutations distributed genome-wide. Those somatic mutations which confer a growth advantage on the cells in which they occur, which are positively selected for in the emerging tumour mass and which have therefore been causally implicated in tumorigenesis, are termed 'driver' mutations [Stratton et al., 2009]. By contrast, those mutations which do not confer any growth advantage and have not been subject to selection during tumorigenesis, are termed 'passenger' mutations [Stratton et al., 2009]. Such passenger mutations may arise at high frequency as a consequence either of increased genomic instability or simply due to the considerable number of cell divisions required to convert a single transformed cell into a clinically detectable tumour [Lengauer et al., 1998; Boland and Ricciardiello, 1999; Simpson 2008; Parmigiani et al. 2009; Stratton et al., 2009].

Despite these basic differences, the mutational spectra (and hence the underlying mutational mechanisms) associated with single base-pair substitutions [Krawczak et al., 1995; Schmutte and Jones, 1998; Cole et al., 2008; Lobo et al., 2009], micro-deletions and micro-insertions [Jego et al., 1993; Greenblatt et al. 1996] and gross gene rearrangements [Oldenburg et al., 2000; Kolomietz et al., 2002] in specific genes often appear to exhibit marked similarities between the germline and the soma. Further, certain triplet repeats associated with a number of inherited human conditions are known to be unstable in both the germline and somatic tissues, a finding 
which serves to explain not only the phenomenon of genetic anticipation characteristic of these disorders but also their inherent inter-individual clinical variability [Giovannone et al., 1997; Leeflang et al., 1999; Martorell et al., 2000; Sharma et al., 2002; Pollard et al., 2004]. However, by contrast, highly variable human minisatellites can display markedly different degrees of instability between the soma and the germline [Buard et al., 2000; Stead and Jeffreys, 2000; Shanks et al., 2008]. These studies notwithstanding, few attempts have so far been made to compare the nature, location and relative frequency of germline and somatic mutations.

Human cancer genes usually harbour either somatic or germline mutations [Goode et al., 2002; Futreal et al., 2004; Vogelstein and Kinzler, 2004]. There is, however, one category of cancer gene, broadly termed tumour suppressors, that by virtue of their being mutated in both the germline and the soma, provides us with an ideal model system to compare somatic vs. germline mutational spectra [Futreal et al., 2004]. Tumour suppressor genes, defined as "genes that sustain loss-of-function mutations in the development of cancer" [Haber and Harlow, 1997], are involved in the regulation of a diverse array of different cellular functions including cell cycle checkpoint control, detection and repair of DNA damage, protein ubiquitination and degradation, mitogenic signalling, cell specification, differentiation and migration, and tumour angiogenesis [Sherr, 2004]. They encode proteins with a regulatory role in cell cycle progression (e.g. Rb), DNA-binding transcription factors (e.g. p53) and inhibitors of cyclin-dependent kinases required for cell cycle progression (e.g. p16). In inherited cancer syndromes, the mutational inactivation of both tumour suppressor alleles is required to change the phenotype of the cell. This 'two hit hypothesis' provides the basis for our mechanistic understanding of tumour suppressor gene mutagenesis: a first (inherited) mutation in one tumour suppressor allele is followed by the somatic loss of the remaining wild-type allele via a number of different mutational mechanisms [Knudson, 2001]. Whereas the inherited lesion is usually fairly subtle, the second (somatic) hit may also involve the deletional loss of the entire gene or even a substantial portion of the 
chromosome involved. Alternatively, both 'hits' may constitute somatic mutations: whatever the actual mechanism, the end result is the same - the loss or inactivation of both gene copies. Some interplay may however occur between the soma and the germline in that the location of the germline mutation can in some instances influence the nature, frequency and location of the subsequent somatic mutation [Lamlum et al., 1999; Groves et al., 2002; Latchford et al., 2007; Dallosso et al., 2009].

Tumour suppressor genes are often somatically inactivated by mutational mechanisms that are almost exclusively confined to the soma and which are found only infrequently in the germline (e.g. gross mutations characterized by loss of heterozygosity, epi-mutations such as methylationmediated promoter inactivation, and micro-lesions within highly repetitive sequence elements that are consequent to microsatellite instability). However, a typical spectrum of somatic mutations associated with tumorigenesis may also include gross rearrangements, copy number variation, and various types of micro-lesion (e.g. micro-deletions, micro-insertions and indels) including single base-pair substitutions [Loeb and Harris, 2008; Stratton et al., 2009]. Although the somatic micro-lesions are often quite similar to their germline counterparts, few studies of tumour suppressor genes have so far attempted to compare and contrast germline and somatic mutational spectra with respect to these relatively subtle types of mutation. However, such studies have indicated that germline and somatic micro-lesions can display remarkable similarities in terms of mutation type, location and relative frequency of occurrence, and hence by inference the putative underlying mechanisms of mutagenesis [Marshall et al., 1997; Ali et al., 1999; Gallou et al., 1999; Richter et al., 2003; Upadhyaya et al., 2004; Glazko et al., 2004; Tartaglia et al., 2006; Baser et al., 2006; Upadhyaya et al., 2008].

We attempt here a first formal comparison between germline and somatic micro-lesion mutational spectra for a total of 17 different human tumour suppressor genes [APC (MIM\# 611731), ATM (MIM\# 607585), BRCA1 (MIM\# 113705), BRCA2 (MIM\# 600185), CDH1 
(MIM\# 192090), CDKN2A (MIM\# 600160), NF1 (MIM\# 162200), NF2 (MIM\# 607379), PTCH1 (MIM\# 601309), PTEN (MIM\# 601728), RB1 (MIM\# 180200), STK11 (MIM\# 602216), TP53 (MIM\# 191170), TSC1 (MIM\# 605284), TSC2 (MIM\# 191092), VHL (MIM\# 608537) and WT1 (MIM\# 607102)].

\section{Materials and Methods}

Sources of germline and somatic mutation data

Data on germline and somatic micro-lesions (viz. missense mutations, micro-deletions and micro-insertions involving $\leq 20 \mathrm{bp}$ ) were collated for 17 different human tumour suppressor genes. Germline mutation data were obtained from the Human Gene Mutation Database [HGMD; http://www.hgmd.org; Stenson et al., 2009]. Somatic mutation data were compiled from a number of different sources including online somatic mutational databases viz. Catalogue of Somatic Mutations in Cancer (http://www.sanger.ac.uk/genetics/CGP/cosmic; RBI and PTEN), the Breast Cancer Information Core (http://research.nhgri.nih.gov/bic; BRCA1), the RB1 Gene Mutation Database (http://www.verandi.de/joomla; RB1), the International NF2 Mutation Database (http://www.hgmd.cf.ac.uk/nf2; NF2), the CDKN2A Database (https://biodesktop.uvm.edu/perl/p16; CDKN2A) and the IARC TP53 Mutation Database (http://www-p53.iarc.fr; TP53), the VHL Mutations Database (http://www.umd.be/VHL/), and data privately communicated by Eamonn Maher (VHL) and Gareth Evans (NF2). Additional somatic mutation data [for APC, ATM, BRCA1, BRCA2, CDH1, NF1, PTCH1, STK11, TSC1, TSC2 and WT1] were obtained by searching PubMed.

To be regarded as bona fide somatic mutations, and therefore suitable for inclusion in this analysis, reported lesions had to have been shown not only to be present in a tumour tissue but also to be absent from a non-tumour tissue (usually blood) from the same patient. Hence, mutational data derived from 'sporadic' patients were not included unless a non-tumour tissue 
had also been examined in order to exclude the possibility that the lesions detected were constitutional in origin. Depending upon the number of independent occurrences, $f$, of a given somatic or shared mutation described in the literature, these mutation types were further subdivided into two categories: recurrent mutations $(f>1)$ and non-recurrent mutations $(f=1)$. At the time this study was initiated (October 2006), the number of available germline and somatic missense mutations for each of the 17 studied tumour suppressor genes were as listed in Table 1 .

The analysis reported here focussed exclusively on missense mutations and micro-deletions/ micro-insertions. Nonsense mutations in tumour suppressor genes have already been addressed in the context of a general meta-analysis of this type of lesion [Mort et al., 2008]. Indels (representing a combination of micro-deletion and micro-insertion) were excluded from the analysis owing to their paucity.

\section{Control datasets of potential mutations}

For every tumour suppressor gene examined, all possible single base-pair substitutions in the gene coding sequence that (i) could potentially have given rise to a missense mutation and (ii) were not already included in either of the corresponding observed somatic and/or germline mutational spectra, were generated. These 'potential missense mutations' were used as a control dataset.

For each tumour suppressor gene, a matching control dataset of 'potential micro-deletions' was also generated by randomly selecting a first breakpoint and then choosing the length of the simulated micro-deletion (and therefore, the position of the second breakpoint) by reference to the probability distribution calculated for micro-deletions (from $1 \mathrm{bp}$ to $20 \mathrm{bp}$ ) observed in the corresponding dataset of mutations. A matching dataset of micro-insertions was generated in similar fashion, with the sites of insertion being randomly selected. Since some of the microdeletion/micro-insertion breakpoints occurred within an intron, extended cDNA sequences 
comprising exons and additional flanking intron sequences were used to generate corresponding control datasets.

\section{Grantham scores}

The 'Grantham score' or 'Grantham difference' [Grantham, 1974] measures the chemical difference between wild-type and mutated amino acid residues in terms of their side chain composition (i.e. the weight ratio of non-carbon components in end-groups or rings to carbons in side chains), polarity (i.e. basic, acidic or nonpolar depending upon side chain charge) and molecular volume.

On average, the physicochemical differences manifested by orthologous amino acid substitutions that have accumulated over evolutionary time will tend to be relatively small. By contrast, disease-causing substitutions are expected to exhibit higher Grantham scores, indicative of more dramatic physicochemical differences between the wild-type and mutated amino acid residues [Krawczak et al., 1998]. The values tabulated by Grantham [1974] were used in this study to calculate a median Grantham score for each set of missense mutations for each tumour suppressor gene.

\section{Degree of evolutionary conservation}

Amino acid residues that are highly conserved in orthologous proteins frequently represent sites of structural or functional importance. Hence, such highly conserved amino acid residues/protein regions often constitute hotspots for observed pathological mutations as a consequence of phenotype selection (rather than intrinsic mutability). To assess the degree of evolutionary conservation of those codons affected by somatic/germline mutations, orthologous tumour suppressor cDNA and protein sequences from different vertebrate species were retrieved from NCBI's Entrez Gene database (http://www.ncbi.nlm.nih.gov/sites/entrez?db=gene). The species 
used as a source of these cDNA and protein sequences are listed in Supp. Table 1 for each tumour suppressor gene/protein. ClustalX (http://www.clustal.org/) was used to align the protein sequences. A program was written to replace all amino acids in the protein alignments by cDNAderived codons, thereby avoiding the introduction of gaps within codons.

The evolutionary constraints acting upon the 17 human tumour suppressor genes at the codon level were inferred by calculating the $\frac{K a}{K a+K s}$ ratio for each codon where $K s$ and $K a$ are respectively the relative numbers of synonymous and nonsynonymous substitutions between codons in two aligned sequences [Walker et al., 1999]. If two aligned codons required more than one substitution to be transformed into each other, then the minimum number of substitutions was assumed, and the most parsimonious path was determined using a PAM100 matrix and the Nei \& Gojobori [1986] pathway method. Gaps inserted into the non-human vertebrate orthologous cDNA sequences during alignment were treated as being equivalent to a nonsynonymous substitution. Codons that were not present in the human cDNA sequence were not considered. A value representing the median level of evolutionary conservation across all codons was then derived for each mutational spectrum.

\section{Relative mutability rates}

To assess the likelihood of observing a certain nucleotide change in a given position and in a specific context, two tabulated measures of the nearest neighbour-dependent mutation rate were employed. The first was derived from 20,200 single base-pair substitutions inferred from alignments of paired human gene/pseudogene sequences [Hess et al., 1994]. This was termed the non-disease-associated mutability rate and, since it approximates to the neutral mutation frequency, it should reflect the intrinsic mutability of the underlying DNA sequence. One would expect the non-disease-associated mutation rates associated with pathological mutations to be 
low implying that these specific substitutions are much less likely to occur as neutral substitutions.

The nearest neighbour-dependent mutation rates derived from germline single base-pair substitutions [using data from the Human Gene Mutation Database (HGMD); Stenson et al., 2009] by Krawczak et al. [1998] were used as an approximation of the disease-associated mutability rate. This mutation rate is a function of selection for loss of biological function as well as the underlying intrinsic mutability of the DNA sequence.

\section{Repetitive sequence elements}

A variety of repetitive sequence elements have been reported in association with human gene mutations causing both inherited disease and cancer. Direct and inverted repeats and symmetric elements [see Chuzhanova et al. 2003 for definitions] of length $\geq 8$ bp, and less than 21 bp apart, capable of forming non-B DNA structures, were therefore sought within the extended cDNA sequences (comprising exons and up to \pm 85 bp of flanking sequence) using purposely designed software. In addition, DNA sequences were screened for the presence of mononucleotide runs of $\geq 4$ bp.

\section{Mutation descriptors}

Each missense mutation was ascribed various descriptors indicating (a) the type of mutation [i.e. shared mutation (i.e. found to occur both somatically and in the germline); exclusively somatic; exclusively germline; shared recurrent mutation (i.e. found to occur not only in the germline but also somatically on more than one occasion; somatic recurrent mutations (recorded in the soma more than once, but not in the germline); potential mutation (as defined above)] and (b) its location [i.e. $\mathrm{C} \rightarrow \mathrm{T}$ and $\mathrm{G} \rightarrow \mathrm{A}$ within a $\mathrm{CpG}$ dinucleotide or within a $\mathrm{CpHpG}$ trinucleotide (where $\mathrm{H}=\mathrm{A}, \mathrm{C}$ or $\mathrm{T}$ ) or in a repeat sequence (as described above)]. Mutations that have been 
reported as being exclusively somatic or exclusively germline will henceforth be referred to simply as 'somatic' and 'germline', respectively. The shared mutations, comprising the overlap between the somatic and germline mutations, may be visualized in the form of a Venn diagram (Figure 1). All somatic missense (including shared) mutations were further described as being either recurrent or non-recurrent (in the soma, see above; Figure 1). No such division was made for the relatively small number of recurrent micro-deletions and micro-insertions available; both recurrent and non-recurrent somatic mutations were therefore included in either the somatic or the shared datasets and labelled accordingly (Figure 1).

All micro-lesions (viz. missense mutations, micro-deletions and micro-insertions) in each gene were also labelled with respect to their occurrence within a region spanning a repetitive element or mononucleotide run including \pm 5 bp of flanking sequence. If a missense mutation (or at least one micro-deletion/micro-insertion breakpoint) was found to occur within this extended region, the micro-lesion was labelled as being found in association with the corresponding type of repeat.

Assessing the statistical significance of the results generated

To assess the similarity (or dissimilarity) of the germline and somatic mutational spectra with respect to (i) the frequency with which the missense mutations were located within $\mathrm{CpG} / \mathrm{non}$ $\mathrm{CpG}$ dinucleotides or $\mathrm{CpHpG} / \mathrm{non}-\mathrm{CpHpG}$ trinucleotides and (ii) the frequency with which the micro-deletions/micro-insertions were found within/outwith repeats, the various non-overlapping mutation datasets (bearing specific descriptors) were compared by means of the $\chi^{2}$ test. Since the normality assumption did not hold for the datasets studied, the Wilcoxon rank-sum test was used to compare and contrast missense mutational spectra with respect to the Grantham score, degree of evolutionary conservation, and both the non-disease- and disease-associated mutability rates. 
The permutation-based method [Olshen and Jain, 2002] was used to estimate the significance of our findings and to allow for multiple testing wherever appropriate. For each comparison, the null hypothesis [viz. no overall difference between two groups of mutations (e.g. somatic and potential) with respect to the specific property in question (e.g. occurrence in $\mathrm{CpG}$ or non-CpG nucleotides)], was tested for, either in the context of each gene or all genes combined. $\chi^{2}$ or ranksum statistics were calculated for the observed germline and somatic mutations as well as for 10,000 control sets of mutations created from the original sets by random permutation of the assigned mutational descriptors (e.g. randomly chosen mutations labelled as 'somatic' were relabelled as 'germline'; randomly chosen mutations labelled as 'shared' were re-labelled as 'somatic', etc.). The test statistic ( $\chi^{2}$ or rank-sum) for the original datasets that exceeded the 95th percentile of $\chi^{2}$ maxima for 10,000 control sets was deemed to be statistically significant; the corresponding p-value was termed the 'gene-wise' p-value. To allow for multiple testing in those cases where specific mutations in all genes were combined, a Bonferroni correction was applied; the corresponding p-value was termed the 'experiment-wise' p-value.

\section{Naïve Bayes classifier}

A decision tree classifier known as a Naïve Bayes tree [NBTree; Kohavi, 1996], implemented in the Weka machine learning package [Witten and Frank, 2005], was trained to discriminate between somatic, germline, shared, recurrent somatic and recurrent shared missense mutations. Each mutation was described by a total of six features including the degree of evolutionary conservation, the non-disease-associated and disease-associated relative mutability rates, Grantham score, and occurrence in $\mathrm{CpG} / \mathrm{CpHpG}$, non-CpG/non-CpHpG doublets/triplets or in repeats/mononucleotide runs. Ten-fold cross-validation was used to assess the accuracy of classification. The mutation datasets were balanced using random oversampling [Kotsiantis et 
al., 2006] by replicating random instances from the minority classes until all classes were represented by the same number of instances as the majority class.

\section{Results and Discussion}

The availability of both germline and somatic mutational spectra from tumour suppressor genes provides us with an ideal opportunity to study the nature of mutation of the same gene sequences in both the germline and the soma. The analysis reported here explores for the first time the similarities and differences exhibited by the germline, somatic (and shared) micro-lesion mutational spectra in 17 human tumour suppressor genes. The study presented here focussed upon missense mutations and micro-deletions as well as micro-insertions. Nonsense mutations in tumour suppressor genes have already been addressed elsewhere in the context of a general meta-analysis of this type of lesion [Mort et al., 2008].

\section{Characteristics of germline and somatic missense mutations with respect to mutation type} Taken together, the combined mutational spectra for all 17 tumour suppressor genes contained twice as many somatic $(61 \%)$ as germline $(31 \%)$ mutations. For five genes $(A P C, C D K N 2 A$, NF2, PTEN and TP53), a predominance of somatic over germline mutations was noted, with the TP53 gene having the highest proportion of somatic mutations (92\%). For the majority of genes, however (namely ATM, BRCA1, BRCA2, CDH1, NF1, PTCH1, RB1, STK11, TSC1, TSC2, VHL and $W T 1$ ), the analysed dataset included more germline than somatic mutations, with $>97 \%$ of all mutations in the BRCA1, NF1, TSC2 and WT1 genes being germline in origin.

Shared mutations are of particular interest because identical mutational mechanisms operating in the germline and the soma may be inferred for such lesions. The expected number of shared mutations for each gene was calculated as $p_{\text {somatic }} \times p_{\text {germline }} \times$ (total number of mutations), 
where $p$ denotes the relative frequencies of somatic and germline mutations. Although the proportion of shared mutations varies markedly between genes (from $0 \%$ to $25 \%$ of the total), only two genes (TP53 and VHL) were found to have a higher than expected number of shared mutations as calculated above.

\section{Patterns of germline and somatic missense mutations by mutation type}

Missense mutations were characterised by a predominance of transitions over transversions (Figure 2). The transition:transversion ratio was at its highest for shared recurrent mutations (3.5) and shared non-recurrent mutations (2.7). By contrast, the transition:transversion ratio for the control group (i.e. potential mutations) was 0.85 . Significant differences in the transition:transversion ratio were observed between all mutation types $(\mathrm{p}<0.05)$ with the exception of germline vs. shared mutations (Figure 2).

Not surprisingly, a strong positive correlation was noted between somatic and shared mutational spectra (Pearson's correlation $r=0.986, p=2.91 \times 10^{-4}$ ) with respect to the frequencies of six mutational changes viz. A.T>C.G, A.T>G.C, A.T>T.A, C.G>A.T, C.G>G.C and C.G $>$ T.A. Weaker negative correlations were found between somatic mutations and the control dataset of mutations $(\mathrm{r}=-0.887, \mathrm{p}=0.019)$ and between shared and the control $(\mathrm{r}=-0.837$, $\mathrm{p}=0.038)$ mutational spectra, indicative of the non-randomness of somatic mutation.

C.G $>$ T.A transitions constituted the most frequent type of mutation in shared (46\%), germline (29\%) and somatic (25\%) mutational spectra, significantly higher proportions than noted in the spectrum of mutations within our control dataset $(13 \%, \mathrm{p}<0.001)$ (Figure 2). Intriguingly, the number of A.T>G.C mutations was significantly higher (28\%) in the germline as compared to the somatic (16\%), shared (17\%) and control (16\%) mutational spectra (Figure 2). A.T>C.G mutations were significantly under-represented in the shared mutational spectrum $(7 \%, \mathrm{p}<0.001)$ as compared to the other spectra whereas A.T $>$ T.A mutations were under-represented (7\%, 
$\mathrm{p}<0.001)$ in both the germline and shared mutational spectra compared to both somatic and potential mutations (Figure 2). Finally, C.G $>$ A.T mutations were significantly underrepresented in the germline mutational spectrum $(10 \%)$ as compared to the somatic $\left(16 \%, \mathrm{p}=1.2 \times 10^{-5}\right)$ and potential $\left(15 \%, \mathrm{p}=2.6 \times 10^{-5}\right)$ spectra. Thus, the main similarity between the somatic and germline missense mutational spectra was in relation to C.G>T.A transitions whereas the main differences between these spectra involved the A.T>G.C, A.T>T.A and C.G>A.T mutations. It should be noted that the patterns of somatic nucleotide substitution exhibited by the 17 tumour suppressor genes studied here were markedly different from the genome-wide patterns of somatic nucleotide substitution previously observed in various cancer genome sequencing studies [Sjöblom et al., 2006; Greenman et al., 2007; Kan et al., 2010].

\section{CpG-and CpHpG-located missense mutations}

The $\mathrm{CpG}$ dinucleotide is a well known mutational hotspot in the human genome as a consequence of the spontaneous (and endogenous) deamination of 5-methylcytosine. In addition, Lister et al. [2009] reported abundant DNA methylation in $\mathrm{CpHpG}$ trinucleotides in the human genome, where $\mathrm{H}$ is either $\mathrm{A}, \mathrm{C}$ or $\mathrm{T}$, raising the possibility that $\mathrm{CpHpG}$ might also be a generalized mutation hotspot [Cooper et al., 2010].

The proportion of missense mutations that were either $\mathrm{C}>\mathrm{T}$ or $\mathrm{G}>\mathrm{A}$ within $\mathrm{CpG}$ or $\mathrm{CpHpG}$ oligonucleotides in the 17 tumour suppressor genes was found to vary between $0 \%$ and $100 \%$ (Table 2). This wide range in values may be attributed to the small size of some of the gene mutation datasets under study. Importantly, the $\mathrm{CpG}$ and $\mathrm{CpHpG}$ oligonucleotides were found to be disproportionately likely to harbour shared mutations; thus, 34\% of shared recurrent mutations and $21 \%$ of shared non-recurrent mutations were $\mathrm{C}>\mathrm{T}$ and $\mathrm{G}>\mathrm{A}$ mutations in $\mathrm{CpG}$ dinucleotides with an additional $10 \%$ and $9 \%$ of mutations, respectively, occurring within $\mathrm{CpHpG}$ trinucleotides. Since driver mutations tend to occur disproportionately frequently within 
CpG dinucleotides [Talavera et al., 2010], we postulate that missense mutations identified as being shared are highly likely to be driver mutations.

Significant differences were noted between the relative frequencies of $\mathrm{CpG}$ - and $\mathrm{CpHpG}-$ located mutations for somatic, germline, shared, somatic recurrent and shared recurrent missense mutations (Supp. Table 2).

We have previously shown that $18.2 \%$ and $9.9 \%$ of all missense/nonsense mutations recorded in the HGMD are $\mathrm{C}>\mathrm{T}$ and $\mathrm{G}>\mathrm{A}$ transitions in $\mathrm{CpG}$ and $\mathrm{CpHpG}$ oligonucleotides respectively [Cooper et al., 2010]. In the present study, we observed that the mutational spectra of shared and shared recurrent missense mutations in tumour suppressor genes were both found to be significantly enriched in CpG-located mutations ( $\chi^{2}$-test; $p$-values, 0.028 and $1.1 \times 10^{-9}$ respectively). This implies that the $\mathrm{CpG}$ dinucleotide is a generalized mutation hotspot in both the soma and the germline as a consequence of the endogenous mutational mechanism of methylation-mediated deamination of 5-methylcytosine. By contrast, the number of CpG-located mutations was significantly underrepresented $\left(\chi^{2}\right.$-test; $\mathrm{p}$-values $\left.<5 \times 10^{-14}\right)$ in the other mutational spectra (i.e. non-recurrent somatic, somatic recurrent and germline mutations) by comparison with HGMD data. To perform these comparisons, missense mutations (Table 2) and nonsense mutations [previously reported in Mort et al., 2008; see Table 6 therein] in all 17 tumour suppressor genes were combined. The proportion of shared recurrent missense mutations in tumour suppressor genes that were $\mathrm{CpHpG-located} \mathrm{was} \mathrm{found} \mathrm{to} \mathrm{be} \mathrm{significantly} \mathrm{higher}$ $(\mathrm{p}=0.023)$ than for mutations recorded in the HGMD whereas CpHpG-located somatic and recurrent somatic mutations were significantly under-represented $\left(\mathrm{p}<4 \times 10^{-10}\right)$. Significant enrichment in $\mathrm{CpHpG}$-located mutations was observed for germline mutations as compared to somatic mutations $\left(\mathrm{p}<3 \times 10^{-10}\right)$ consistent with the reported decrease in $\mathrm{CpHpG}$ methylation in differentiated cells [Lister et al., 2009]. In summary, germline and shared missense mutations were found to be significantly enriched at $\mathrm{CpG}$ and $\mathrm{CpHpG}$ oligonucleotides. 
The numbers of somatic and shared $\mathrm{C}>\mathrm{T}$ and $\mathrm{G}>\mathrm{A}$ transitions recorded within $\mathrm{CpG}$ dinucleotides for each gene (Table 2) did not correlate with the numbers of $\mathrm{CpG}$ dinucleotides found in these genes $(r<-0.5, p>0.127)$ and hence do not simply reflect intragenic $\mathrm{CpG}$ frequency. A weak positive correlation between CpG-located mutations and the number of genic CpG dinucleotides was however noted for germline mutations $(r=0.489, \mathrm{p}=0.046)$ indicating that CpG methylation is not entirely unrelated to the number of $\mathrm{CpG}$ dinucleotides, at least with respect to the germline; the relationship is however clearly more complex in the soma, possibly due to inter-tissue differences in gene methylation patterns [Tornaletti and Pfeifer, 1995] or transcription-coupled repair [Rubin and Green, 2009].

No correlation was found between the numbers of somatic, germline and shared mutations recorded within $\mathrm{CpHpG}$ trinucleotides and the corresponding numbers of $\mathrm{CpHpG}$ trinucleotides for these genes $(r=-0.316,0.373,-0.414 ; \mathrm{p}$-values $0.281,0.216$ and 0.098 , respectively) indicating that mutation within $\mathrm{CpHpG}$ trinucleotides is likely to be very much a gene-specific phenomenon (presumably dependent on both the extent and the degree of spatial localization of CpHpG methylation in the germline and/or soma).

Finally, the number of $\mathrm{CpG}$ dinucleotides in the various tumour suppressor genes studied (Table 2) was not found to correlate with gene length $(r=0.3, p$-value $=0.241)$. By contrast, we found a significant correlation $\left(r=0.885\right.$, $\mathrm{p}$-value $\left.=2.35 \times 10^{-6}\right)$ between tumour suppressor gene length and the number of $\mathrm{CpHpG}$ trinucleotides (excluding those with mutations), indicating that the tumour suppressor genes under study possess a similar density of $\mathrm{CpHpG}$ trinucleotides per unit length. We surmise that the factors that govern the establishment of the methylation pattern of $\mathrm{CpHpG}$ trinucleotides are likely to be quite complex.

Evolutionary conservation of tumour suppressor genes in relation to the sites of somatic and germline missense mutations 
For all 17 tumour suppressor genes, the degree of evolutionary conservation, as measured by $\mathrm{Ka} / \mathrm{Ks}$, was less than unity, indicating that these genes (and proteins) have been highly conserved evolutionarily as a consequence of the action of purifying selection. Indeed, the degree of evolutionary conservation displayed by most of the studied genes was markedly lower than the average $(\sim 0.18)$ noted in a comparison of 1880 human, rat and mouse gene orthologues [Makalowski and Boguski, 1998]. However, three genes (CDKN2A, BRCA1 and BRCA2) were found to exhibit a higher rate of evolutionary conservation than the average between human and rodents.

The evolutionary conservation of each mutated codon was inferred by calculating the $\frac{K a}{K a+K s}$ ratio; for each gene/spectrum, the mean value was then calculated across all mutations in the corresponding gene/spectrum. Shared recurrent missense mutations were found to occur disproportionately in highly conserved amino acid residues (mean degree of evolutionary conservation, 0.072 ) followed by shared non-recurrent mutations (0.138), somatic recurrent (0.169), germline (0.175), non-recurrent somatic $(0.265)$, and control dataset mutations $(0.255)$. The observed differences in the degree of evolutionary conservation for the different mutational spectra are shown in Supp. Table 2. These quite specific findings are consistent with the previously reported general tendency for cancer-associated mutations to occur frequently at evolutionarily conserved sites [Greenblatt et al., 2003; Tavtigian et al., 2009; Talavera et al., 2010].

Somatic non-recurrent mutations were found to occur in codons characterized by the highest mean value of $\frac{K a}{K a+K s}$ ratios as compared not only to the shared recurrent and shared nonrecurrent mutations (see above) but also to the mutations within the control dataset. This is consistent with the interpretation that a high proportion of non-recurrent somatic mutations, and 
most notably those which are located in less evolutionarily conserved regions, are likely to be 'passenger' mutations.

\section{Missense mutations in relation to the disease- and non-disease-associated substitution rates}

Employing alignments of paired human gene/pseudogene sequences, Hess et al. [1994] derived relative (non-disease-associated) nearest-neighbour-dependent mutability rates using the lowest frequency substitution type, $C(T>G) A / T(A>C) G$, as a baseline. These mutability rates were found to vary over a 52-fold range, with unity being assigned to the lowest frequency substitution type. This non-disease-associated mutability rate approximates to the neutral mutation frequency and hence reflects the intrinsic mutability of the underlying DNA sequence. Depending upon the observed nearest-neighbour context, we retrieved the corresponding nondisease-associated mutability rate (from the data of Hess et al. 1994) for each mutation (either observed or from the control dataset) and calculated the median value for each mutational spectrum. These median values are indicative of the relative mutability of each tumour suppressor gene. The median values were found to vary between 4 (NF2) and 8.9 (STK11) for somatic mutations, 4.1 (TP53) and 10.1 (WT1) for germline mutations, and $7.2(R B 1)$ and 11 $(P T E N)$ for shared mutations (values given only for genes with more than three mutations in the corresponding category; see Supp. Table 3, indicating that many of the median values are quite low and hence the corresponding mutations are unlikely to be neutral.

When data from all 17 genes were combined, shared recurrent mutations were found to be characterised by intrinsically low non-disease-associated mutability (median=11), followed by even lower median mutability values for shared non-recurrent mutations (7.9), germline mutations (7.2), somatic recurrent and non-recurrent (4.7) and control dataset mutations (4.1). Such low median mutability values across all groups indicates that at least half of the mutations within observed triplets are unlikely to be neutral in the sense defined by Hess et al. [1994] and 
hence are not simply explicable in terms of intrinsic DNA mutability. The low median mutability values for the control dataset of mutations within tumour suppressor genes reflect the high level of evolutionary conservation manifested by tumour suppressor gene coding sequences across different species, implying that any mutation within a triplet characterized by a low non-diseaseassociated mutation rate is very likely to have pathological consequences and would thus be subject to purifying selection.

In contrast to the non-disease-associated mutability rate (which is purely a reflection of the intrinsic DNA mutability), the disease-associated mutability rate reflects (in addition to the intrinsic DNA mutability) the increased likelihood of coming to clinical attention conferred by the loss of biological function. The $\mathrm{C}(\mathrm{G}>\mathrm{T}) \mathrm{T}$ mutation is one of the most frequent types of mutation associated with the loss of biological function [disease-associated mutability rate 10.255; Krawczak et al., 1998] but occurs much less frequently among neutral mutations [nondisease-associated mutability rate 4.4; Hess et al., 1994].

For each tumour suppressor gene and each mutational spectrum, the disease-associated median mutability values were calculated using mutability rates derived from Krawczak et al. [1998]. The disease-associated median value was found to be 0.85 for the germline mutations. The highest and lowest disease-associated median values for the mutation rates were noted for somatic mutations in the STK11 gene (1.7; Supp. Table 3) and for germline mutations in the TP53 (0.42) gene (values given only for genes with more than three mutations in the corresponding category). We found that shared recurrent and shared non-recurrent mutational spectra were characterized by higher median values of the disease-associated mutability rates (1.42 and 1.01 respectively) whereas somatic non-recurrent, somatic recurrent and control dataset mutations exhibited lower median mutability rates $(0.5,0.5$ and 0.4 respectively) as compared to germline mutations (0.85). The finding that the shared mutations (which, by definition, occur in both the germline and the soma) are characterized by higher disease- 
associated mutability rates is not surprising since mutations that occur with the highest probability are among those most likely to be shared.

We postulated that those mutations which occur both in the germline and the soma, and which are characterised by higher disease-associated mutability rates are disproportionately likely to be drivers of tumour development. Consistent with this postulate, somatic recurrent and nonrecurrent mutational spectra are characterized by lower median disease-associated mutability rates as compared to the germline spectrum. However, given that higher disease-associated mutability rates are a characteristic feature of driver mutations, a certain proportion of the somatic mutations, namely those characterised by higher disease-associated mutability rates, may correspond to functionally significant driver mutations.

In assessing the significance of our results, it was appropriate to consider the possibility that somatic mutations might display quite different nearest-neighbour-dependent disease-associated mutability rates from germline mutations. However, since a good correlation was observed between the mutability rates derived from inherited disease data [Krawczak et al., 1998] and the neighbour-dependent mutability rates calculated for the somatic mutations of the 17 tumoursuppressor genes studied here (Pearson's correlation $\mathrm{r}=0.703, \mathrm{p}=6.6 \times 10^{-30}$ ), this caveat appears not to be an issue.

\section{Distribution of Grantham scores with respect to tumour suppressor gene mutations}

Shared recurrent mutations were found to exhibit the largest median chemical difference value (Grantham scores) between the wild-type and mutated amino acid residues (100) followed by shared non-recurrent mutations and germline mutations (both 93), somatic recurrent (85), somatic non-recurrent (80) and potential mutations (78). Since there was an obvious trend for shared recurrent and non-recurrent mutations to cause the most dramatic chemical changes of the affected codon, we may infer that these types of lesion are also more likely to be driver 
mutations. However, bearing in mind that the range of theoretically possible values varies between 5 (Leu $\leftrightarrow$ Ile) and 215 (Cys $\leftrightarrow$ Trp), less elevated median values may simply indicate that a proportion of the mutations in each mutational spectrum are likely to be chemically less dramatic (Grantham scores <100).

\section{Missense mutations occurring within repeats and runs of identical nucleotides}

A number of studies have noted that single base-pair substitutions associated with inherited disease occur disproportionately either within, or in close proximity to, repetitive sequences [Jego et al., 1993; Greenblatt et al., 1996; Tappino et al., 2009; Thomas et al., 2010; Leclercq et al., 2010]. Hence, we wished to assess whether either germline or somatic mutations occurred disproportionately either within, or in the vicinity (see Mutation descriptors) of, direct, inverted and symmetric repeats or mononucleotide runs in the 17 tumour suppressor genes under study (Table 3, Supplementary Tables 4-6).

On average, direct repeats of length $\geq 8$ bp were found to cover $5.6 \%$ of the cDNA lengths of the 17 tumour suppressor genes, the coverage varying between $2.5 \%(B R C A 2)$ and $17 \%(P T E N)$ of the respective gene sequences. The corresponding proportion of the cDNA lengths for inverted repeats $\geq 8$ bp was $8.5 \%$, with proportions varying between $P T C H 1(4.5 \%)$ and $R B 1$ (15.7\%) while symmetric elements $\geq 8$ bp were found to encompass $25 \%$ of the cDNA lengths (varying between $15.5 \%$ for $A P C$ and $44 \%$ for $P T E N$ ).

On average, mononucleotide runs $\geq 4$ bp spanned $19.9 \%$ of the cDNA lengths, varying between 9.5\% (VHL) and 29\% (TP53). Approximately 24\% of non-recurrent somatic and $20 \%$ of germline missense mutations were found in mononucleotide runs; these proportions were significantly higher than noted for shared non-recurrent missense mutations $\left(4.9 \%, \mathrm{p} \leq 1.6 \times 10^{-4}\right)$. A greater proportion of non-recurrent somatic missense mutations was found in direct repeats (7\%) as compared to recurrent somatic missense mutations $\left(2 \%, \mathrm{p}=8.8 \times 10^{-7}\right)$, germline missense 
$(4 \%, \mathrm{p}=0.028)$ and potential missense mutations $\left(3.7 \%, \mathrm{p}=8.1 \times 10^{-7}\right)$. This result may reflect the disproportionate number of $\mathrm{CpG} / \mathrm{CpHpG}$ mutations among shared and recurrent somatic missense mutations. Further, for all mutational spectra examined (with the exception of the shared mutations), missense mutations were preferentially found in association with inverted and symmetric repeats as compared to the control dataset of mutations $(\mathrm{p}<0.05)$. However, no statistically significant differences were found between mutational spectra.

No correlation was observed between the number of mutations located within repeats and the fractional length of the cDNA covered by repeats, indicating that not every repeat sequence is mutation-prone. However, a strong correlation between the fractional length of the cDNA covered by repeats and cDNA length of genes $\left(r>0.87\right.$ and $\left.p<10^{-6}\right)$ served to demonstrate that repeat density per unit length was approximately the same for all tumour suppressor genes studied.

\section{Towards a classification of somatic and germline missense mutations}

All observed mutations within each mutational spectrum were re-categorized (Supp. Table 7) with respect to the location of mutations within $\mathrm{CpG} / \mathrm{CpHpG}$ oligonucleotides, within different types of repeat/mononucleotide runs, within both $\mathrm{CpG} / \mathrm{CpHpG}$ oligonucleotides and repeats. $4 \times 2$ contingency tables were then used to measure the strength of the pairwise associations between the various mutational distributions presented in Supp. Table 7, the significance of the associations being assessed by means of a Chi-square test. Significant $(\mathrm{p}<0.002)$ pairwise differences were noted between somatic and germline, somatic and shared, and between germline and shared mutational spectra $(\mathrm{p}<0.002)$ with respect to the features listed above and each of four types of repeat, indicating that these features have great discriminant potential.

All somatic, germline, shared non-recurrent, recurrent somatic and shared recurrent missense mutations (each described by a combination of different features (i.e. degree of evolutionary 
conservation, non-disease- and disease-associated mutability rates, Grantham score, $\mathrm{CpG} / \mathrm{CpHpG}$ location, occurrence within repeat/mononucleotide run) were then used to train a Naïve Bayes Tree classifier. $63.1 \%$ of somatic, germline, shared, recurrent somatic and shared recurrent mutations were correctly classified [the area under the Receiver Operating Characteristic (ROC) curve being 0.869 , indicating a reasonably good classification] implying that the mutation groupings differ with respect to the different features in a consistent fashion. The complete Naïve Bayes Tree classifier is depicted in Supp. Figure 1.

An additional non-overlapping dataset of 568 missense somatic mutations, identified in the 17 tumour suppressor genes under study, were extracted from a collection of 2,488 mutations identified as being probable driver mutations [Carter et al., 2009]. Features such as the degree of evolutionary conservation, Grantham score, mutability rates, $\mathrm{CpG} / \mathrm{CpHpG}$ location, occurrence within repeats/mononucleotide runs were again determined for each of these mutations.

Employing our classifier, $7 \%$ and $10 \%$ respectively of these 568 mutations were found to possess features consistent with their being shared recurrent and shared non-recurrent mutations. In addition, $32 \%$ of these probable driver mutations were found to bear features characteristic of recurrent somatic mutations (i.e. mutations documented in different tumours). A further $25 \%$ of the probable (somatic) driver mutations were classified as possessing features characteristic of germline mutations and hence could conceivably be treated as shared mutations missing from the original training dataset. The remaining $25 \%$ of mutations were classified as non-recurrent somatic mutations. Using this classifier, which is based on a very modest number (6) of predictive features, to analyse an independent dataset of probable driver mutations, we were able to predict that $\sim 50 \%$ of these somatic missense mutations exhibited features specific to either shared or recurrent mutations, indicating that a disproportionate number of such lesions are likely to be drivers of tumorigenesis. This percentage is certainly lower (79\%) than that obtained by Carter et al., [2009] through the application of a Random Forest Classifier based on 500 trees and 
$>50$ predictive features (using an out-of-the-bag error estimate similar to the cross-validation procedure) to the set of putative 2,488 driver mutations. However, based on the results of this study, we may conclude that, in general, the mutational spectrum of driver mutations is likely to contain a disproportionate number of somatic mutations that have germline counterparts $(\sim 17 \%)$ whilst an additional $32 \%$ of the driver mutations are likely to occur recurrently in the soma.

\section{Truncating vs non-truncating mutations in the germline and soma}

Somatic mutational spectra from the BRCA2, CDKN2A, STK11, TP53 and TSC1 genes were characterized by the predominance of non-truncating (i.e. missense) lesions over truncating lesions (i.e. nonsense mutations, frameshift micro-deletions, micro-insertions and indels) when nonsense mutations [reported in Mort et al. (2008)] and micro-indels (excluded from previous analyses) were also considered (Supp. Table 8). A similar predominance of non-truncating over truncating lesions was observed for the germline mutational spectra of the CDKN2A,TP53,VHL and WT1 genes. In general, the ratio of non-truncating to truncating lesions was found to be significantly higher in the soma $(0.85)$ than in the germline $(0.30 ; \mathrm{p}$-value<2.20E-16). All other mutational spectra were characterized by the predominance of truncating mutations.

\section{Occurrence of micro-deletions and micro-insertions within repeats and runs of identical nucleotides}

The mutational spectrum of micro-deletions, combined for all 17 tumour suppressor genes, comprised $55 \%$ germline, $43 \%$ somatic and $2 \%$ shared mutations. The mutational spectrum of micro-insertions was similar to that of micro-deletions and comprised $60 \%$ germline, $38 \%$ somatic and $2 \%$ shared mutations. Approximately $77 \%$ somatic, $87 \%$ germline and $91 \%$ shared micro-deletions and micro-insertions were $\leq 4 \mathrm{bp}$ in length. Strong $(\mathrm{r}=\sim 1)$ correlations were noted between the distributions of micro-deletions and micro-insertions with respect to the length 
of the deleted/inserted fragments, both gene-wise and for all genes combined $\left(r>0.9, \mathrm{p}<10^{-8}\right)$ for all mutational spectra.

Recent studies have revealed that simple repetitive DNA sequences are not only capable of adopting non-B DNA conformations and are highly mutagenic [Bacolla et al., 2004; Bacolla and Wells, 2004; Chuzhanova et al., 2009]. Indeed, both direct repeats and mononucleotide runs have long been known to be mutation hotspots in the TP53 gene [Jego et al., 1993; Greenblatt et al., 1996]. The number of micro-lesions occurring in the vicinity (see Mutation descriptors) of direct, symmetric and inverted repeats (capable respectively of slipped, triplex and cruciform non-B structure formation), or within mononucleotide runs (which often mediate microdeletions/micro-insertions) were therefore determined. The number of mutations found in the vicinity of all three types of repeat, and within mononucleotide runs, are given in Tables 3 and Supp. Tables 4-6.

The highest proportion of mutations in mononucleotide runs was found for the shared (39\%), germline (30\%) and somatic (25\%) mutational spectra. Significant differences were observed between shared and germline $(\mathrm{p}=0.0002)$, somatic and shared $(\mathrm{p}=0.045)$, and between all mutational spectra and potential mutations $(\mathrm{p}<0.0001)$ with respect to their occurrence within mononucleotide runs, confirming that these simple repeats constitute an important hotspot for micro-deletions and micro-insertions in both the soma and the germline. The preponderance of such mutations in mononucleotide runs is unsurprising in the context of the shared mutations since all mutations that occur with high frequency within mutation hotspots are more likely to be shared between the germline and the soma (as previously noted for $\mathrm{CpG}$ and $\mathrm{CpHpG}$ mutations). No other types of repeat were disproportionately associated (after correction for multiple testing) with micro-deletions and micro-insertions.

Hotspots in somatic and germline mutational spectra 
For the purposes of this analysis, a mutation hotspot was defined as a stretch of DNA of length $\leq 20 \mathrm{bp}$ where four or more independent mutational events have been reported and a significant degree $(p \leq 0.05)$ of clustering of these mutations was evident for a given stretch of DNA. In this definition of a hotspot, each recurrent mutation was considered only once. The order statistics, $r-$ scans, as described by Karlin and Macken [1991] and applied in Bacolla et al. [2006], were used to detect significant clustering of mutations by comparison with a Poisson distribution of mutations along the gene sequence. Overlapping hotspot regions were considered as a single hotspot.

The only mutational hotspot for somatic missense mutations was observed in the PTEN gene and comprised 18 mutations in the region between nucleotide positions 269 and 286. Several germline mutational hotspots were however detected for missense mutational spectra in the ATM, BRCA1, BRCA2, NF1, PTEN, RB1, STK11, TP53 and WT1 genes (Table 4). Several somatic mutational hotspots were found for micro-deletions/micro-insertions in the $A P C$ gene, the largest of which contained 33 mutations (positions 4303-4398) and forms part of a previously reported mutation cluster region [Miyoshi et al., 1992]. Hotspots identified in different mutational spectra were however unique to that spectrum. The only overlap noted between mutational hotspots identified in germline and somatic micro-deletion/micro-insertion mutational spectra was observed for the $A P C$ gene (the overlapping region comprising nucleotide positions 3919-3933). This micro-deletion/micro-insertion hotspot also includes codon 1309 (cDNA positions 3925-3927) found to be frequently mutated in Greek and French patients with familial adenomatous polyposis [Fostira et al. 2010; Lagarde et al. 2010].

Inspection of hotspot regions revealed that they are rich in repetitive elements, runs of identical nucleotides and $\mathrm{CpG} / \mathrm{CpHpG}$ oligonucleotides, offering immediate explanations for the elevated mutability. 


\section{Germline and somatic mutations located within specific hotspot motifs}

The cDNA sequences of 17 tumour suppressor genes were screened for the presence of nine specific motifs (and their complements) previously reported as being hotspots for mutation. These motifs included the putative somatic (cancer) mutation hotspot, WKVNRRRNVWK [the 'THEMIS motif'; Makridakis et al., 2009], the RGYW motif that correlates with the DNA polymerase eta error spectrum [Rogozin et al., 2001] and several so-called 'super hotspot' motifs originally found in germline micro-insertions and micro-deletions [Ball et al., 2005] and indels [Chuzhanova et al., 2003]. For the purposes of this analysis, the shared mutations were added to both the germline and somatic mutational spectra. Both germline and somatic micro-deletions and micro-insertions were found to be significantly overrepresented $(\mathrm{p} \leq 0.002)$ in the 'indel super hotspot' motif GTAAGT and its complement. Somatic micro-deletions and micro-insertions were also significantly overrepresented $(\mathrm{p}=0.009)$ with respect to the micro-deletion/microinsertion super hotspot AAATCT and its complement. The number of germline (but not somatic) micro-deletions/micro-insertions in the THEMIS motif were significantly overrepresented $(\mathrm{p}=0.003)$ as compared to the controls. No significant difference was however observed in the number of missense mutations occurring in any motifs analysed.

\section{Conclusions}

A number of important conclusions may be drawn from the results reported here. Firstly, it would appear that missense mutations that are found both in the soma and the germline (shared mutations) are disproportionately more likely to exert profound effects on tumour development and/or progression (i.e. more likely to be driver mutations) than exclusively somatic nonrecurrent missense mutations (at least for the TP53 and CDKN2A genes whose mutations contributed the bulk of the documented shared mutations in our tumour suppressor gene mutation dataset). Shared mutations also occur preferentially in $\mathrm{CpG} / \mathrm{CpHpG}$ oligonucleotides 
and are characterised by higher mutability rates (both non-disease- and disease-associated). Further, we found that shared mutations tend to occur in those codons that have been more highly conserved evolutionarily, and are associated with more dramatic chemical differences between the substituted (wild-type) and substituting amino acids. Taken together, it would thus appear that shared mutations are influenced to a greater extent by the local nucleotide sequence context than either germline or somatic non-recurrent missense mutations. Since this implies that shared mutations (the mutation category most likely to harbour driver mutations) have a tendency to arise through the action of similar endogenous mutational mechanisms, we may infer that endogenous mechanisms of mutagenesis exert a disproportionate effect on tumorigenesis. In an analysis of an unrelated dataset, we demonstrated that $17 \%$ of somatic missense mutations previously identified as being probable drivers [Carter et al., 2009] were found to possess the same features as shared (both recurrent and non-recurrent) mutations. A further $32 \%$ of these probable driver mutations shared the features expected of recurrent somatic mutations. Thus, we may conclude that $\sim 50 \%$ of these somatic missense mutations possess features consistent with their being either shared or recurrent, suggesting that a disproportionate number of such lesions are likely to be drivers of tumorigenesis.

A sizeable proportion of shared (39\%) and germline (30\%) micro-lesions were found to be located in runs of identical nucleotides $\geq 4 \mathrm{bp}$, making mononucleotide runs a hotspot for microdeletion and micro-insertions. The most likely underlying causative mechanism for these mutations is slipped mispairing at DNA replication mediating duplications and 'de-duplications' [Kondrashov \& Rogozin, 2004]. With regard to missense mutations, $\mathrm{CpG}$ and $\mathrm{CpHpG}$ oligonucleotides were found to be hotspots for shared recurrent and shared non-recurrent missense mutations; $34 \%(10 \%)$ and $21 \%$ (9\%) of respective mutations were found in $\mathrm{CpG}$ $(\mathrm{CpHpG})$ oligonucleotides. Further, 12\% of the 568 probable driver mutations [derived from Carter et al., 2009] were found to occur in $\mathrm{CpG} / \mathrm{CpHpG}$ oligonucleotides. $41 \%$ of probable 
driver mutations were found in repeats that were capable of non-B DNA structure formation (cf. $23 \%$ for potential mutations). Several hotspot regions were found in the mutational spectra of various genes; one of these, in the $A P C$ gene, was a hotspot for both somatic and germline micro-deletions/micro-insertions and corresponded to a previously recognized mutation hotspot [Miyoshi et al., 1992].

Taken together, the results and analysis presented herein strongly suggest that algorithms that attempt to predict the relative impact of tumour-associated micro-lesions on (tumour suppressor) gene and protein function [Tavtigian et al., 2008; Couch et al., 2008; Thusberg and Vihinen, 2009], should take into consideration the origin (i.e. somatic, germline or shared) of the mutations, their sequence context and repetitivity, as well as their frequency of occurrence.

\section{Acknowledgements}

We are most grateful to Eamonn Maher (Birmingham, UK), Gareth Evans (Manchester, UK) and the late Michael Baser for their provision of somatic mutation data. We are also very grateful to Larry Brody (NIH, Bethesda, MD, USA), Shiu-Ru Lin (Kaohsiung Medical University, Taiwan) and Tone Lovig (University of Oslo, Norway) for providing us with further information on specific somatic mutations and Rachel Karchin (Johns Hopkins University, Baltimore, USA) for making available her dataset of probable driver mutations. 


\section{References}

Ali IU, Schriml LM, Dean M. 1999. Mutational spectra of PTEN/MMAC1 gene: a tumor suppressor with lipid phosphatase activity. J Natl Cancer Inst 91:1922-1932.

Bacolla A, Jaworski A, Larson JE, Jakupciak JP, Chuzhanova NA, Abeysinghe SS, O’Connell CD, Cooper DN, Wells RD. 2004. Breakpoints of gross deletions coincide with non-B DNA conformations. Proc Natl Acad Sci USA 101:14162-14167.

Bacolla A, Wells RD. 2004. Non-B DNA conformations, genomic rearrangements, and human disease. J Biol Chem 279:47411-47414.

Bacolla A, Collins JR, Gold B, Chuzhanova N, Yi M, Stephens RM, Stefanov S, Olsh A, Jakupciak JP, Dean M, Lempicki RA, Cooper DN, Wells RD. 2006. Long homopurine•homopyrimidine sequences are characteristic of genes expressed in brain and the pseudoautosomal region. Nucleic Acids Res 34: 2663-2675.

Ball EV, Stenson PD, Krawczak M, Cooper DN, Chuzhanova NA. 2005. Micro-deletions and micro-insertions causing human genetic disease: common mechanisms of mutagenesis and the role of local DNA sequence complexity. Human Mutat 26:205-213.

Baser ME, Contributors to the International NF2 Mutation Database. Hum. Mutat. 27:297-306.

Boland CR, Ricciardiello L. 1999. How many mutations does it take to make a tumor? Proc Natl Acad Sci USA 96:14675-14677.

Buard J, Collick A, Brown J, Jeffreys AJ. 2000. Somatic versus germline mutation processes at minisatellite CEB1 (D2S90) in humans and transgenic mice. Genomics 65:95-103.

Carter H, Chen S, Isik L, Tyekucheva S, Velculescu VE, Kinzler KW, Vogelstein B, Karchin R. 2009. Cancer-specific high-throughput annotation of somatic mutations: computational prediction of driver missense mutations. Cancer Res 69:6660-6667. 
Chuzhanova NA, Anassis EJ, Ball E, Krawczak M, Cooper DN. 2003. Meta-analysis of indels causing human genetic disease: mechanisms of mutagenesis and the role of local DNA sequence complexity. Hum Mutat 21:28-44.

Chuzhanova N, Chen JM, Bacolla A, Patrinos GP, Férec C, Wells RD, Cooper DN. 2009. Gene conversion causing human inherited disease: the evidence for involvement of recombination-associated motifs and non-B DNA-forming sequences in DNA breakage. Hum Mutat 30:1189-1198.

Cole DN, Carlson JA, Wilson VL. 2008. Human germline and somatic cells have similar TP53 and Kirsten-RAS gene single base mutation frequencies. Environ. Mol. Mutagen. 2008 49:417-425.

Cooper DN, Mort M, Stenson PD, Ball EV, Chuzhanova NA. 2010. Methylation-mediated deamination of 5-methylcytosine appears to give rise to mutations causing human inherited disease in $\mathrm{CpNpG}$ trinucleotides as well as in $\mathrm{CpG}$ dinucleotides. Hum Genomics 4:406-410..

Couch FJ, Rasmussen LJ, Hofstra R, Monteiro AN, Greenblatt MS, de Wind N; IARC Unclassified Genetic Variants Working Group. 2008. Assessment of functional effects of unclassified genetic variants. Hum Mutat 29:1314-1326.

Dallosso AR, Jones S, Azzopardi D, Moskvina V, Al-Tassan N, Williams GT, Idziaszczyk S, Davies DR, Milewski P, Williams S, Beynon J, Sampson JR, Cheadle JP. 2009. The APC variant p.Glu1317Gln predisposes to colorectal adenomas by a novel mechanism of relaxing the target for tumorigenic somatic $A P C$ mutations. Hum Mutat 30:1412-1418.

Fostira F, Thodi G, Sandaltzopoulos R, Fountzilas G, Yannoukakos D. 2010. Mutational spectrum of APC and genotype-phenotype correlations in Greek FAP patients. BMC Cancer 10:389. 
Futreal PA, Coin L, Marshall M, Down T, Hubbard T, Wooster R, Rahman N, Stratton MR. 2004. A census of human cancer genes. Nat Rev Cancer 4:177-183.

Gallou C, Joly D, Mejean A, Staroz F, Martin N, Tarlet G, Orfanelli MT, Bouvier R, Droz D, Chretien Y, Maréchal JM, Richard S, Junien C, Béroud C. 1999. Mutations of the VHL gene in sporadic renal cell carcinoma: definition of a risk factor for VHL patients to develop an RCC. Hum Mutat 13:464-475.

Giovannone B, Sabbadini G, Di Maio L, Calabrese O, Castaldo I, Frontali M, Novelleto A, Squitieri F. 1997. Analysis of (CAG)n size heterogeneity in somatic and sperm cell DNA from intermediate and expanded Huntington disease gene carriers. Hum Mutat 10:458464.

Glazko GV, Koonin EV, Rogozin IB. 2004. Mutation hotspots in the p53 gene in tumors of different origin: correlation with evolutionary conservation and signs of positive selection. Biochim Biophys Acta 1679:95-106.

Goode EL, Ulrich CM, Potter JD. 2002. Polymorphisms in DNA repair genes and associations with cancer risk. Cancer Epidemiol Biomarkers Prev 11:1513-1530.

Grantham R. 1974. Amino acid difference formula to help explain protein evolution. Science $185: 862-864$.

Greenblatt MS, Grollman AP, Harris CC. 1996. Deletions and insertions in the p53 tumor suppressor gene in human cancers: confirmation of the DNA polymerase slippage/misalignment model. Cancer Res 56:2130-2136.

Greenblatt MS, Beaudet JG, Gump JR, Godin KS, Trombley L, Koh J, Bond JP. 2003. Detailed computational study of p53 and p16: using evolutionary sequence analysis and diseaseassociated mutations to predict the functional consequences of allelic variants. Oncogene 22:1150-1163. 
Greenman C, Stephens P, Smith R, Dalgliesh GL, Hunter C, Bignell G, Davies H, Teague J, Butler A, Stevens C, Edkins S, O'Meara S, Vastrik I, Schmidt EE, Avis T, Barthorpe S, Bhamra G, Buck G, Choudhury B, Clements J, Cole J, Dicks E, Forbes S, Gray K, Halliday K, Harrison R, Hills K, Hinton J, Jenkinson A, Jones D, Menzies A, Mironenko T, Perry J, Raine K, Richardson D, Shepherd R, Small A, Tofts C, Varian J, Webb T, West S, Widaa S, Yates A, Cahill DP, Louis DN, Goldstraw P, Nicholson AG, Brasseur F, Looijenga L, Weber BL, Chiew YE, DeFazio A, Greaves MF, Green AR, Campbell P, Birney E, Easton DF, Chenevix-Trench G, Tan MH, Khoo SK, Teh BT, Yuen ST, Leung SY, Wooster R, Futreal PA, Stratton MR. 2007. Patterns of somatic mutation in human cancer genomes. Nature 446:153-158.

Groves C, Lamlum H, Crabtree M, Williamson J, Taylor C, Bass S, Cuthbert-Heavens D, Hodgson S, Phillips R, Tomlinson I. 2002. Mutation cluster region, association between germline and somatic mutations and genotype-phenotype correlation in upper gastrointestinal familial adenomatous polyposis. Am J Pathol 160:2055-2061.

Haber D, Harlow E. 1997. Tumour-suppressor genes: evolving definitions in the genomic age. Nat Genet 16:320-322.

Hess ST, Blake JD, Blake RD. 1994. Wide variations in neighbor-dependent substitution rates. J Mol Biol 236:1022-1033.

Jego N, Thomas G, Hamelin R. 1993. Short direct repeats flanking deletions, and duplicating insertions in p53 gene in human cancers. Oncogene 8:209-213.

Kan Z, Jaiswal BS, Stinson J, Janakiraman V, Bhatt D, Stern HM, Yue P, Haverty PM, Bourgon R, Zheng J, Moorhead M, Chaudhuri S, Tomsho LP, Peters BA, Pujara K, Cordes S, Davis DP, Carlton VE, Yuan W, Li L, Wang W, Eigenbrot C, Kaminker JS, Eberhard DA, Waring P, Schuster SC, Modrusan Z, Zhang Z, Stokoe D, de Sauvage FJ, Faham M, 
Seshagiri S. 2010. Diverse somatic mutation patterns and pathway alterations in human cancers. Nature 466:869-873.

Karlin S, Macken C. 1991. Some statistical problems in the assessment of inhomogenesis of DNA sequence data. J Am Statist Assoc 86:27-35.

Knudson AG. 2001. Two genetic hits (more or less) to cancer. Nat Rev Cancer 1:157-162.

Kohavi R. 1996. Scaling up the accuracy of naive-Bayes classifiers: a decision-tree hHybrid. Proceedings of the Second International Conference on Knowledge Discovery and Data Mining. AAAI Press, pp 202-207.

Kolomietz E, Meyn MS, Pandita A, Squire JA. 2002. The role of Alu repeat clusters as mediators of recurrent chromosomal aberrations in tumors. Genes Chrom Cancer 35:97-112.

Kondrashov AS, Rogozin IB. 2004. Context of deletions and insertions in human coding sequences. Hum Mutat 23:177-185.

Kotsiantis S, Kanellopoulos D, Pintelas P. 2006. Handling imbalanced datasets: a review. GESTS International Transactions on Computer Science and Engineering 30:25-36.

Krawczak M, Smith-Sorensen B, Schmidtke J, Kakkar VV, Cooper DN, Hovig E. 1995. Somatic spectrum of cancer-associated single basepair substitutions in the TP53 gene is determined mainly by endogenous mechanisms of mutation and by selection. Hum Mutat $5: 48-57$.

Krawczak M, Ball EV, Cooper DN. 1998. Neighboring-nucleotide effects on the rates of germline single-base-pair substitution in human genes. Am J Hum Genet 63:474-488.

Lagarde A, Rouleau E, Ferrari A, Noguchi T, Qiu J, Briaux A, Bourdon V, Rémy V, Gaildrat P, Adélaïde J, Birnbaum D, Lidereau R, Sobol H, Olschwang S. 2010. Germline $A P C$ mutation spectrum derived from 863 genomic variations identified through a 15-year medical genetics service to French patients with FAP. J Med Genet [Epub ahead of print] PubMed PMID: 20685668. 
Lamlum H, Ilyas M, Rowan A, Clark S, Johnson V, Bell J, Frayling I, Efstathiou J, Pack K, Payne S, Roylance R, Gorman P, Sheer D, Neale K, Phillips R, Talbot I, Bodmer W, Tomlinson I. 1999. The type of somatic mutation at APC in familial adenomatous polyposis is determined by the site of the germline mutation: a new facet to Knudson's 'two-hit' hypothesis. Nat Med 5:1071-1075.

Latchford A Volikos E, Johnson V, Rogers P, Suraweera N, Tomlinson I, Phillips R, Silver A. 2007. APC mutations in FAP-associated desmoid tumours are non-random but not 'just right'. Hum Mol Genet 16:78-82.

Leclercq S, Rivals E, Jarne P. 2010. DNA slippage occurs at microsatellite loci without minimal threshold length in human: a comparative genomic approach. Genome Biol Evol 2:325335.

Leeflang EP, Tavare S, Marjoram P, Neal CO, Srinidhi J, MacFarlane H, MacDonald ME, Gusella JF, de Young M, Wexler NS, Arnheim N. 1999. Analysis of germline mutation spectra at the Huntington's disease locus supports a mitotic mutation mechanism. Hum Mol Genet 8:173-183.

Lengauer C, Kinzler KW, Vogelstein B. 1998. Genetic instabilities in human cancers. Nature 396:643-649.

Lister R, Pelizzola M, Dowen RH, Hawkins RD, Hon G, Tonti-Filippini J, Nery JR, Lee L, Ye Z, Ngo QM, Edsall L, Antosiewicz-Bourget J, Stewart R, Ruotti V, Millar AH, Thomson JA, Ren B, Ecker JR. 2009. Human DNA methylomes at base resolution show widespread epigenomic differences. Nature 19:315-322.

Lobo GP, Waite KA, Planchon SM, Romigh T, Nassif NT, Eng C. 2009. Germline and somatic cancer-associated mutations in the ATP-binding motifs of PTEN influence its subcellular localization and tumor suppressive function. Hum. Mol. Genet. 18:2851-2862. 
Loeb LA, Harris CC. 2008. Advances in chemical carcinogenesis: a historical review and prospective. Cancer Res 68: 6863-6872.

Makalowski W, Boguski MS. 1998. Evolutionary parameters of the transcribed mammalian genome: an analysis of 2,820 orthologous rodent and human sequences. Proc Natl Acad Sci USA 95:9407-9412.

Makridakis NM, Caldas Ferraz LF, Reichardt JK. 2009. Genomic analysis of cancer tissue reveals that somatic mutations commonly occur in a specific motif. Hum Mutat 30:39-48.

Marshall B, Isidro G, Carvalhas R, Boavida M. 1997. Germline versus somatic mutations of the APC gene: evidence for mechanistic differences. Hum Mutat 9:286-288.

Martorell L, Monckton DG, Gamez J, Baiget M. 2000. Complex patterns of male germline instability and somatic mosaicism in myotonic dystrophy type 1. Eur J Hum Genet 8: 423-430.

Miyoshi Y, Nagase H, Ando H, Horii A, Ichii S, Nakatsuru S, Aoki T, Miki Y, Mori T, Nakamura Y. 1992. Somatic mutations of the APC gene in colorectal tumors: mutation cluster region in the APC gene. Hum Mol Genet 1:229-33.

Mort M, Ivanov D, Cooper DN, Chuzhanova NA. 2008. A meta-analysis of nonsense mutations causing human genetic disease. Hum Mutat 29:1037-1047.

Nei M, Gojobori T. 1986. Simple methods for estimating the numbers of synonymous and nonsynonymous nucleotide substitutions. Mol Biol Evol 3:418-426.

Oldenburg J, Rost S, El-Maarri O, Leuer M, Olek K, Muller CR, Schwaab R. 2000. De novo factor VIII gene intron 22 inversion in a female carrier presents as a somatic mosaicism. Blood 96: 2905-2906.

Olshen AB, Jain AN. 2002. Deriving quantitative conclusions from microarray expression data. Bioinformatics 18:961-970. 
Parmigiani G, Boca S, Lin J, Kinzler KW, Velculescu V, Vogelstein B. 2009. Design and analysis issues in genome-wide somatic mutation studies of cancer. Genomics 93:17-21.

Pollard LM, Sharma R, Gomez M, Shah S, Delatycki MB, Pianese L, Monticelli A, Keats BJ, Bidichandani SI. 2004. Replication-mediated instability of the GAA triplet repeat mutation in Friedreich ataxia. Nucleic Acids Res 32:5962-5971.

Richter S, Vandezande K, Chen N, Zhang K, Sutherland J, Anderson J, Han L, Panton R, Branco P, Gallie B. 2003. Sensitive and efficient detection of RB1 gene mutations enhances care for families with retinoblastoma. Am J Hum Genet 72:253-269.

Rogozin IB, Pavlov YI, Bebenek K, Matsuda T, Kunkel TA. 2001. Somatic mutation hotspots correlate with DNA polymerase eta error spectrum. Nat Immunol 2:530-536.

Rubin AF, Green P. 2009. Mutation patterns in cancer genomes. Proc Natl Acad Sci USA 106: 21766-21770.

Sharma R, Bhatti S, Gomez M, Clark RM, Murray C, Ashizawa T, Bidichandani SI. 2002. The GAA triplet-repeat sequence in Friedreich ataxia shows a high level of somatic instability in vivo, with a significant predilection for large contractions. Hum Mol Genet 11:21752187.

Sherr CJ. 2004. Principles of tumor suppression. Cell 116:235-246.

Schmutte C, Jones PA. 1998. Involvement of DNA methylation in human carcinogenesis. Biol Chem 379:377-388.

Shanks ME, May CA, Dubrova YE, Balaresque P, Rosser ZH, Adams SM, Jobling MA. 2008. Complex germline and somatic mutation processes at a haploid human minisatellite shown by single-molecule analysis. Mutat. Res. 648:46-53.

Simpson AJ. 2009. Sequence-based advances in the definition of cancer-associated gene mutations. Curr Opin Oncol 21:47-52.

Sjöblom T, Jones S, Wood LD, Parsons DW, Lin J, Barber TD, Mandelker D, Leary RJ, Ptak J, Silliman N, Szabo S, Buckhaults P, Farrell C, Meeh P, Markowitz SD, Willis J, Dawson 
D, Willson JK, Gazdar AF, Hartigan J, Wu L, Liu C, Parmigiani G, Park BH, Bachman KE, Papadopoulos N, Vogelstein B, Kinzler KW, Velculescu VE. 2006. The consensus coding sequences of human breast and colorectal cancers. Science 314:268-274.

Stead JD, Jeffreys AJ. 2000. Allele diversity and germline mutation at the insulin minisatellite. Hum Mol Genet 9:713-723.

Stenson PD, Mort M, Ball EV, Howells K, Phillips AD, Thomas NS, Cooper DN. 2009. The Human Gene Mutation Database: 2008 update. Genome Med. 1:13.

Stratton MR, Campbell PJ, Futreal PA. 2009. The cancer genome. Nature 458:719-724.

Talavera D, Taylor MS, Thornton JM. 2010. The (non)malignancy of cancer amino acidic substitutions. Proteins 78:518-529.

Tappino B, Chuzhanova NA, Regis S, Dardis A, Corsolini F, Stroppiano M, Tonoli E, Beccari T, Rosano C, Mucha J, Blanco M, Szlago M, Di Rocco M, Cooper DN, Filocamo M. 2009. Molecular characterization of 22 novel UDP-N-acetylglucosamine-1-phosphate transferase alpha- and beta-subunit (GNPTAB) gene mutations causing mucolipidosis types IIalpha/beta and IIIalpha/beta in 46 patients. Hum Mutat 30:E956-973.

Tartaglia M, Martinelli S, Stella L, Bocchinfuso G, Flex E, Cordeddu V, Zampino G, van der Burgt I, Palleschi A, Petrucci TC, Sorcini M, Schoch C, Foà R, Emanuel PD, Gelb BD. 2006. Diversity and functional consequences of germline and somatic PTPN11 mutations in human disease. Am J Hum Genet 78:279-290.

Tavtigian SV, Greenblatt MS, Lesueur F, Byrnes GB; IARC Unclassified Genetic Variants Working Group. 2008. In silico analysis of missense substitutions using sequencealignment based methods. Hum Mutat 29:1327-1336.

Tavtigian SV, Oefner PJ, Babikyan D, Hartmann A, Healey S, Le Calvez-Kelm F, Lesueur F, Byrnes GB, Chuang SC, Forey N, Feuchtinger C, Gioia L, Hall J, Hashibe M, Herte B, McKay-Chopin S, Thomas A, Vallée MP, Voegele C, Webb PM, Whiteman DC; 
Australian Cancer Study; Breast Cancer Family Registries (BCFR); Kathleen Cuningham Foundation Consortium for Research into Familial Aspects of Breast Cancer (kConFab), Sangrajrang S, Hopper JL, Southey MC, Andrulis IL, John EM, Chenevix-Trench G. 2009. Am J Hum Genet 85:427-446.

Thomas L, Kluwe L, Chuzhanova N, Mautner V, Upadhyaya M. 2010. Analysis of NF1 somatic mutations in cutaneous neurofibromas from patients with high tumor burden. Neurogenetics 11:391-400.

Thusberg J, Vihinen M. 2009. Pathogenic or not? And if so, then how? Studying the effects of missense mutations using bioinformatics methods. Hum Mutat 30:703-714.

Tornaletti S, Pfeifer GP. 1995. Complete and tissue-independent methylation of CpG sites in the p53 gene: implications for mutations in human cancers. Oncogene 10:1493-1499.

Upadhyaya M, Han S, Consoli C, Majounie E, Horan M, Thomas NS, Potts C, Griffiths S, Ruggieri M, von Deimling A, Cooper DN. 2004. Characterization of the somatic mutational spectrum of the neurofibromatosis type $1(N F 1)$ gene in neurofibromatosis patients with benign and malignant tumors. Hum Mutat 23:134-136.

Upadhyaya M, Kluwe L, Spurlock G, Monem B, Majounie E, Mantripragada K, Ruggieri M, Chuzhanova N, Evans DG, Ferner R, Thomas N, Guha A, Mautner V. 2008. Germline and somatic NFl gene mutation spectrum in NFl-associated malignant peripheral nerve sheath tumors (MPNSTs). Hum Mutat 29:74-82.

Vogelstein B, Kinzler KW. 2004. Cancer genes and the pathways they control. Nat Med 10:789799.

Walker DR, Bond JP, Tarone RE, Harris CC, Makalowski W, Boguski MS. Greenblatt MS. 1999. Evolutionary conservation and somatic mutation hotspot maps of p53: correlation with p53 protein structural and functional features. Oncogene 18:211-218. 
Witten IH, Frank E. 2005. Data mining: practical machine learning tools and techniques, 2nd ed. Morgan Kaufmann, San Francisco, pp. 365-483. 
Table 1. Summary of mutational spectra in the 17 tumour suppressor genes studied

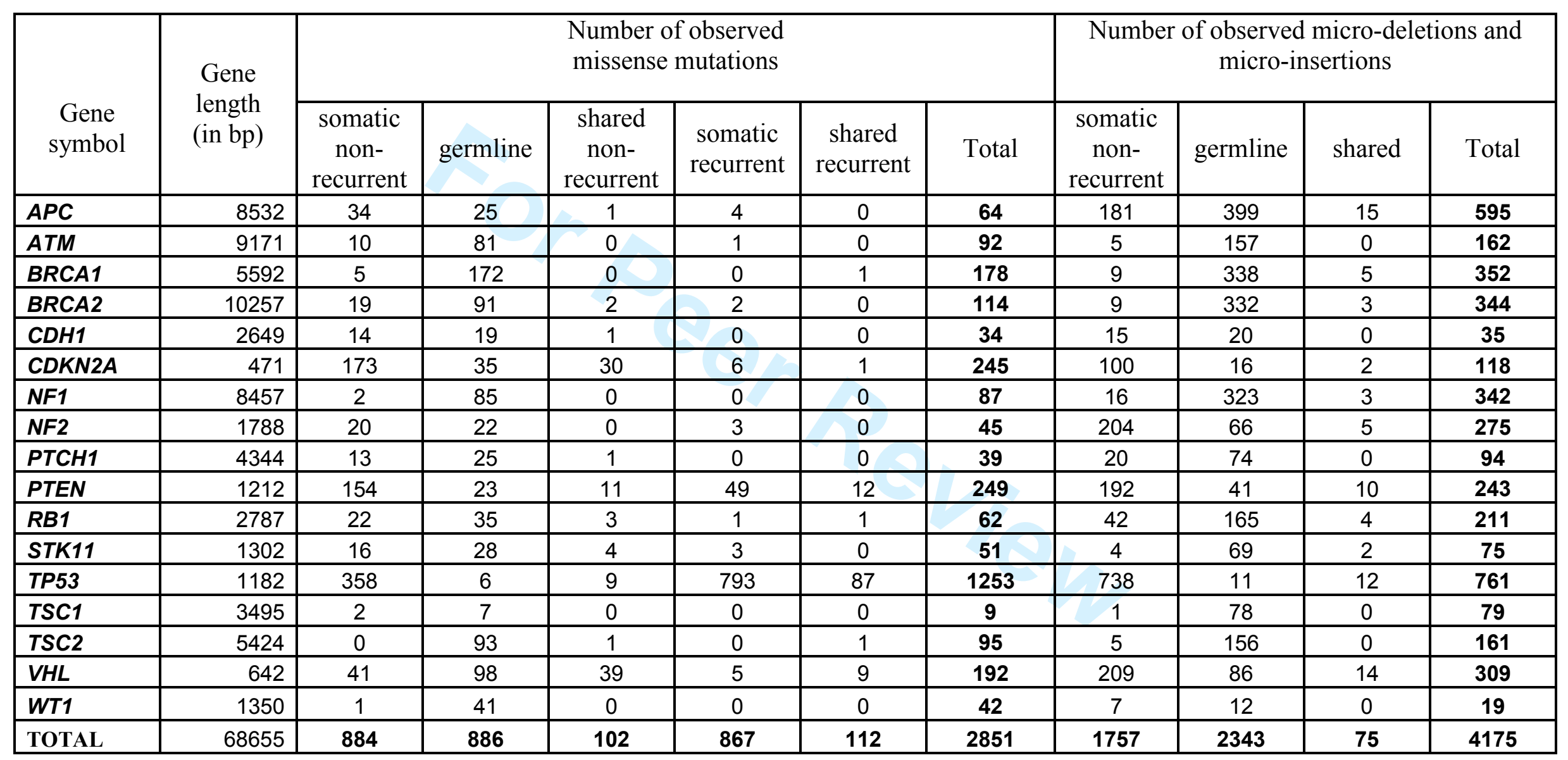


Table 2. Missense mutations found in $\mathrm{CpG}$ and $\mathrm{CpHpG}$ oligonucleotides for the 17 tumour suppressor genes under study.

\begin{tabular}{|c|c|c|c|c|c|c|c|c|c|c|c|c|c|}
\hline \multirow[b]{2}{*}{$\begin{array}{l}\text { Gene } \\
\text { symbol }\end{array}$} & \multicolumn{2}{|c|}{$\begin{array}{c}\text { Number of } \\
\text { possible missense } \\
\text { mutations }\end{array}$} & \multicolumn{6}{|c|}{$\begin{array}{l}\text { Number of observed } \\
\text { CpG-located mutations }\end{array}$} & \multicolumn{5}{|c|}{$\begin{array}{c}\text { Number of observed } \\
\text { CpHpG-located mutations }\end{array}$} \\
\hline & $\begin{array}{l}\text { in } \\
\text { CpG }\end{array}$ & $\begin{array}{l}\text { in } \\
\text { CpHpG }\end{array}$ & $\begin{array}{c}\text { somatic } \\
\text { non- } \\
\text { recurrent }\end{array}$ & germline & $\begin{array}{c}\text { shared } \\
\text { non- } \\
\text { recurrent }\end{array}$ & $\begin{array}{l}\text { somatic } \\
\text { recurrent }\end{array}$ & $\begin{array}{l}\text { shared } \\
\text { recurrent }\end{array}$ & total & $\begin{array}{c}\text { somatic } \\
\text { non- } \\
\text { recurrent }\end{array}$ & germline & $\begin{array}{c}\text { shared } \\
\text { non- } \\
\text { recurrent }\end{array}$ & $\begin{array}{l}\text { somatic } \\
\text { recurrent }\end{array}$ & $\begin{array}{l}\text { shared } \\
\text { recurrent }\end{array}$ \\
\hline$A P C$ & 177 & 300 & 1 & 6 & 0 & 0 & 0 & 7 & 0 & 1 & 0 & 0 & 0 \\
\hline$A T M$ & 157 & 232 & 0 & 12 & 0 & 1 & 0 & 13 & 0 & 3 & 0 & 0 & 0 \\
\hline BRCA1 & 70 & 192 & 0 & 12 & 0 & 0 & 0 & 12 & 0 & 6 & 0 & 0 & 0 \\
\hline BRCA2 & 116 & 310 & 3 & 15 & 2 & 0 & 0 & 20 & 0 & 2 & 0 & 0 & 0 \\
\hline CDH1 & 135 & 116 & 1 & 5 & 0 & 0 & 0 & 6 & 0 & 0 & 0 & 0 & 0 \\
\hline CDKN2A & 50 & 16 & 35 & 3 & 10 & 0 & 0 & 48 & 9 & 0 & 0 & 0 & 0 \\
\hline$N F 1$ & 226 & 275 & 0 & 6 & 0 & 0 & 0 & 6 & 0 & 1 & 3 & 0 & 0 \\
\hline$N F 2$ & 89 & 59 & 1 & 4 & 0 & 1 & 0 & 6 & 0 & 0 & 0 & 0 & 0 \\
\hline РТCH1 & 345 & 213 & 2 & 4 & 0 & 0 & 0 & 6 & 0 & 0 & 0 & 0 & 0 \\
\hline PTEN & 14 & 33 & 1 & 1 & 0 & 5 & 4 & 11 & 2 & 0 & 0 & 0 & 0 \\
\hline$R B 1$ & 80 & 81 & 4 & 3 & 2 & 0 & 0 & 9 & 1 & 1 & 1 & 1 & 0 \\
\hline STK11 & 137 & 60 & 4 & 3 & 2 & 2 & 0 & 11 & 0 & 0 & 0 & 0 & 0 \\
\hline$T P 53$ & 15 & 22 & 8 & 0 & 0 & 35 & 28 & 71 & 10 & 0 & 0 & 23 & 8 \\
\hline$T S C 1$ & 147 & 139 & 0 & 1 & 0 & 0 & 0 & 1 & 0 & 0 & 0 & 0 & 0 \\
\hline$T S C 2$ & 454 & 238 & 0 & 19 & 1 & 0 & 1 & 21 & 0 & 7 & 1 & 0 & 1 \\
\hline$V H L$ & 78 & 24 & 7 & 2 & 4 & 0 & 5 & 18 & 0 & 2 & 4 & 0 & 2 \\
\hline$W T 1$ & 143 & 70 & 0 & 9 & 0 & 0 & 0 & 9 & 0 & 4 & 0 & 0 & 0 \\
\hline TOTAL & 2433 & 2380 & 67 & 105 & 21 & 44 & 38 & 275 & 22 & 27 & 9 & 24 & 11 \\
\hline
\end{tabular}


Table 3. Summary of mutations occurring in runs of identical nucleotides $\geq 4$ bp in the 17 tumour suppressor genes.

\begin{tabular}{|c|c|c|c|c|c|c|c|c|c|c|c|}
\hline \multirow[b]{2}{*}{$\begin{array}{l}\text { Gene } \\
\text { symbol }\end{array}$} & \multirow{2}{*}{$\begin{array}{c}\text { Proportion } \\
\text { of gene } \\
\text { length } \\
\text { covered } \\
\text { by runs } \\
(\%)\end{array}$} & \multicolumn{6}{|c|}{ Number of missense mutations found in runs } & \multicolumn{4}{|c|}{$\begin{array}{l}\text { Number of micro-deletions and micro- } \\
\text { insertions found in runs }\end{array}$} \\
\hline & & $\begin{array}{l}\text { somatic } \\
\text { non- } \\
\text { recurrent }\end{array}$ & germline & $\begin{array}{c}\text { shared } \\
\text { non- } \\
\text { recurrent }\end{array}$ & $\begin{array}{l}\text { somatic } \\
\text { recurrent }\end{array}$ & $\begin{array}{l}\text { shared } \\
\text { recurrent }\end{array}$ & Total & $\begin{array}{l}\text { somatic } \\
\text { non- } \\
\text { recurrent }\end{array}$ & germline & shared & Total \\
\hline$A P C$ & 13 & 5 & 3 & 0 & 2 & 0 & 10 & 74 & 108 & 6 & 188 \\
\hline$A T M$ & 26 & 2 & 20 & 0 & 0 & 0 & 22 & 3 & 55 & 0 & 58 \\
\hline BRCA1 & 16 & 3 & 37 & 0 & 0 & 0 & 40 & 2 & 120 & 3 & 125 \\
\hline BRCA2 & 19 & 4 & 27 & 0 & 0 & 0 & 31 & 5 & 151 & 2 & 158 \\
\hline$C D H 1$ & 18 & 5 & 7 & 0 & 0 & 0 & 12 & 3 & 11 & 0 & 14 \\
\hline$C D K N 2 A$ & 17 & 42 & 7 & 2 & 0 & 1 & 52 & 30 & 5 & 0 & 35 \\
\hline$N F 1$ & 24 & 1 & 15 & 0 & 0 & 0 & 16 & 5 & 74 & 2 & 81 \\
\hline NF2 & 19 & 3 & 2 & 0 & 0 & 0 & 5 & 40 & 8 & 0 & 48 \\
\hline PTCH1 & 15 & 4 & 7 & 0 & 0 & 0 & 11 & 6 & 24 & 0 & 30 \\
\hline PTEN & 32 & 41 & 8 & 1 & 15 & 1 & 66 & 56 & 12 & 2 & 70 \\
\hline$R B 1$ & 37 & 5 & 9 & 1 & 0 & 0 & 15 & 14 & 54 & 3 & 71 \\
\hline STK11 & 24 & 1 & 7 & 0 & 2 & 0 & 10 & 2 & 23 & 2 & 27 \\
\hline TP53 & 29 & 89 & 2 & 1 & 166 & 13 & 271 & 177 & 3 & 7 & 187 \\
\hline TSC1 & 15 & 1 & 2 & 0 & 0 & 0 & 3 & 0 & 15 & 0 & 15 \\
\hline TSC2 & 17 & 0 & 10 & 0 & 0 & 0 & 10 & 0 & 36 & 0 & 36 \\
\hline$V H L$ & 10 & 2 & 3 & 0 & 0 & 0 & 5 & 15 & 6 & 2 & 23 \\
\hline WT1 & 20 & 0 & 12 & 0 & 0 & 0 & 12 & 2 & 4 & 0 & 6 \\
\hline TOTAL & 20 & 208 & 178 & 5 & 185 & 15 & 591 & 434 & 709 & 29 & 1172 \\
\hline
\end{tabular}


Table 4. Mutational hotspots found in 17 tumour suppressor genes. The number of mutations within the hotspots is shown in parentheses. Shared overlapping hotspot regions for somatic and germline micro-deletions/insertions is shown in bold. Positions are given with respect to the corresponding cDNA sequences.

\begin{tabular}{|c|c|c|c|c|}
\hline \multirow{2}{*}{ Gene symbol } & \multicolumn{2}{|c|}{ Missense mutations } & \multicolumn{2}{|c|}{ Micro-deletions/insertions } \\
\hline & somatic & germline & somatic & germline \\
\hline$A P C$ & & & $\begin{array}{c}3856-3882(9) \\
\mathbf{3 8 9 7 - 3 9 3 3}(15) \\
3977-3989(5) \\
4117-4140(7) \\
4178-4200(9) \\
4231-4271(17) \\
4303-4398(33) \\
4450-4495(27) \\
4662-4669(5)\end{array}$ & $\begin{array}{c}1484-1492(4) \\
1857-1882(11) \\
2306-2313(4) \\
2789-2821(13) \\
\mathbf{3 9 1 9 - 3 9 3 5 ( 7 )}\end{array}$ \\
\hline ATM & 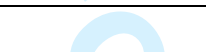 & $8479-8494$ (6) & & \\
\hline$B R C A 1$ & & $\begin{array}{c}181-191(6) \\
5085-5098(8) \\
5201-5222(9) \\
5236-5258(8)\end{array}$ & & \\
\hline BRCA2 & & $8165-8182(4)$ & & $\begin{array}{l}6196-6203(4) \\
6443-6450(8)\end{array}$ \\
\hline$N F 1$ & & $\begin{array}{l}2329-2352(6) \\
2530-2543(5) \\
4255-4274(6) \\
\end{array}$ & & 6788-6798 (5) \\
\hline PTEN & $269-287(18)$ & $367-371(4)$ & & \\
\hline$R B 1$ & & $1960-1970(5)$ & & $202-220(7)$ \\
\hline STK11 & & $526-545(5)$ & & $\begin{array}{l}150-197(11) \\
737-757(6)\end{array}$ \\
\hline TP53 & & $832-848(11)$ & & \\
\hline$T S C 1$ & & +2 & 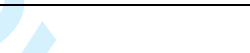 & $2101-2112(5)$ \\
\hline$T S C 2$ & & & 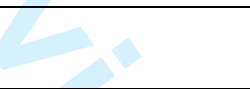 & $\begin{array}{l}2059-2074(5) \\
4247-4268(5)\end{array}$ \\
\hline$W T 1$ & & 1174-1201 (13) & $\sqrt{20}$ & \\
\hline
\end{tabular}



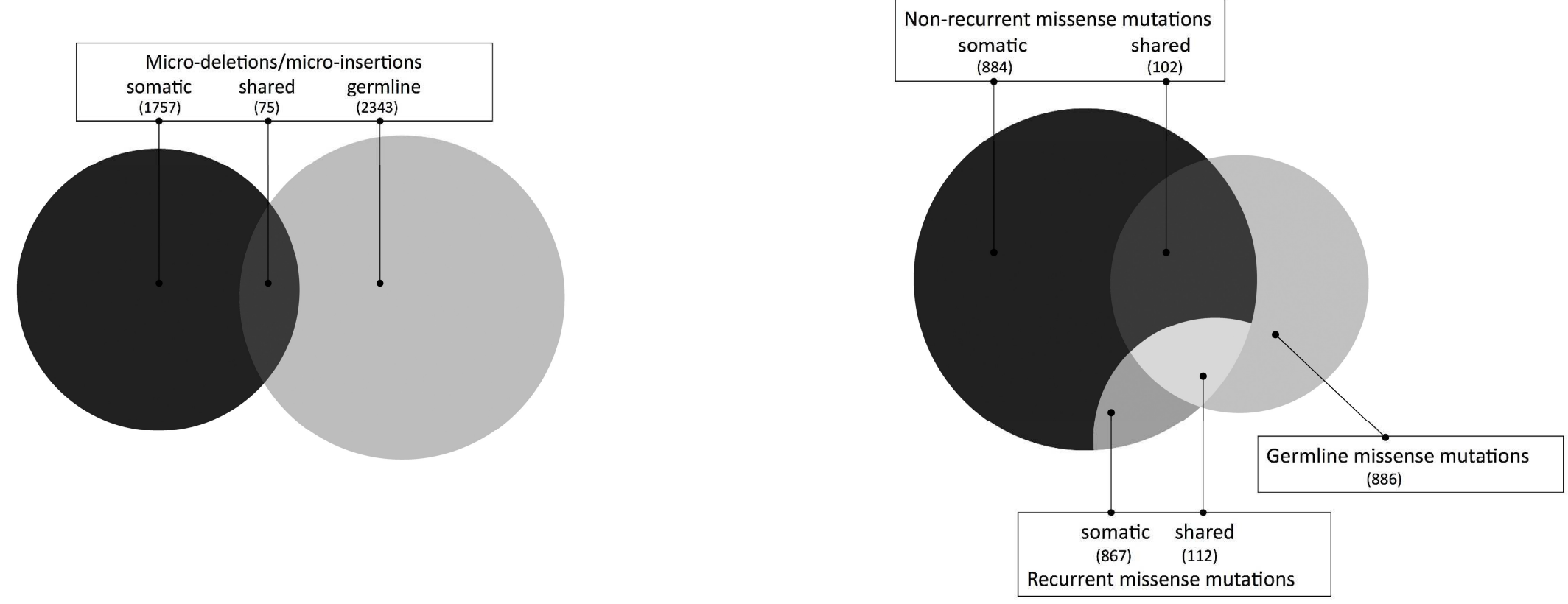

Figure 1. Diagrammatic representation of the number of various types of mutations analysed in the present study. 


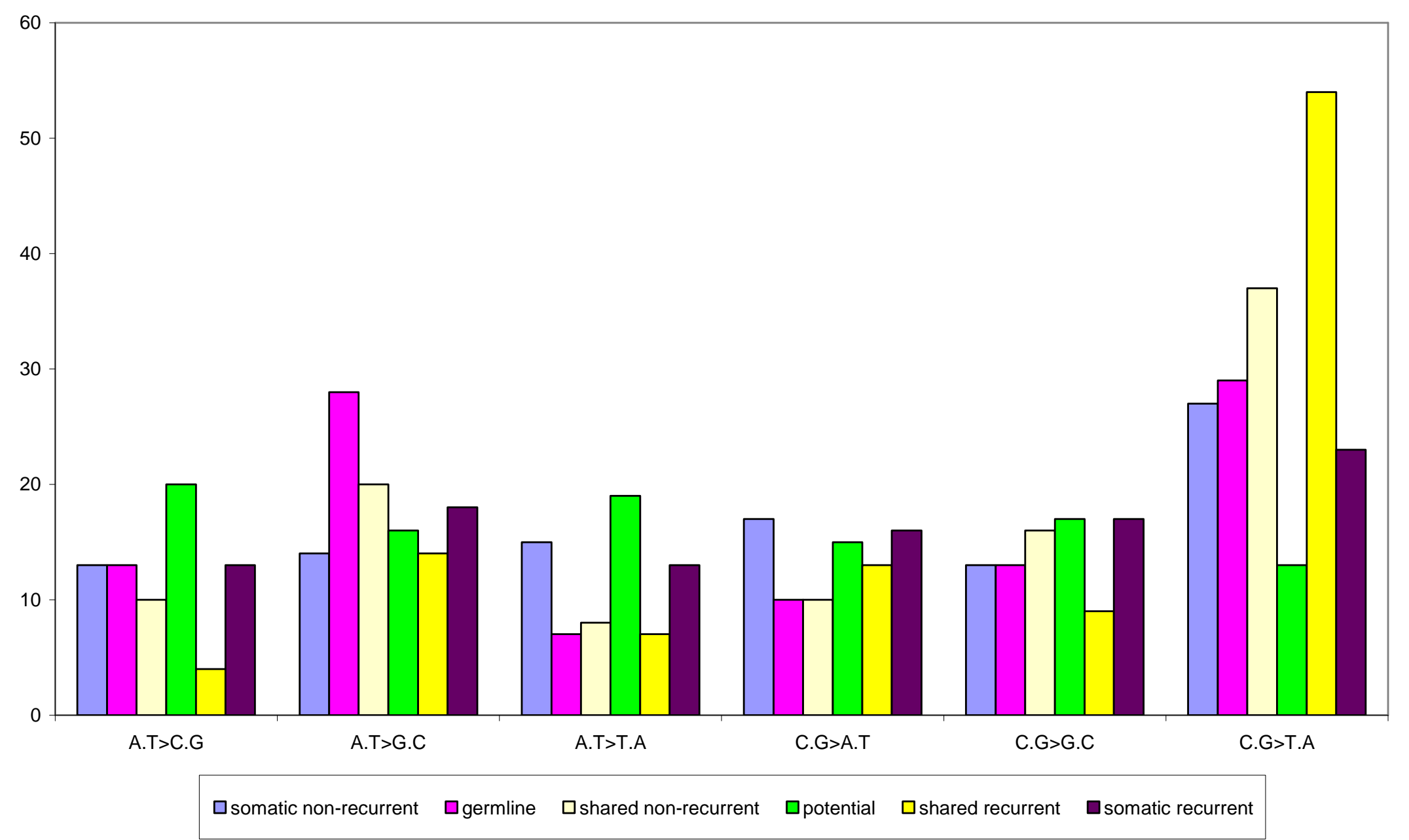

Figure 2. Nucleotide substitution patterns of missense mutations in 17 tumour suppressor genes.

John Wiley \& Sons, Inc. 1 
Supplementary Table 1. Tumour suppressor gene orthologues used to estimate the degree of evolutionary conservation of the various gene coding sequences

\begin{tabular}{|c|c|c|c|}
\hline Gene & Species & $\begin{array}{l}\text { cDNA sequence } \\
\text { identifier }\end{array}$ & $\begin{array}{l}\text { Protein sequence } \\
\text { identifier }\end{array}$ \\
\hline$A P C$ & $\begin{array}{l}\text { Xenopus laevis } \\
\text { Bos taurus } \\
\text { Rattus norvegicus } \\
\text { Mus musculus }\end{array}$ & $\begin{array}{l}\text { U64442.1 } \\
\text { XM_865627.1 } \\
\text { NM_012499.1 } \\
\text { NM_007462.1 }\end{array}$ & $\begin{array}{l}\text { AAB41671.1 } \\
\text { XP_870720.1 } \\
\text { NP_036631.1 } \\
\text { NP_031488.1 }\end{array}$ \\
\hline$A T M$ & $\begin{array}{l}\text { Gallus gallus } \\
\text { Xenopus laevis } \\
\text { Rattus norvegicus } \\
\text { Sus scrofa } \\
\text { Canis familiaris } \\
\text { Mus musculus }\end{array}$ & $\begin{array}{l}\text { XM_417160.1 } \\
\text { AY668954.1 } \\
\text { XM_236275.3 } \\
\text { AY587061 } \\
\text { XM_845871.1 } \\
\text { NM_007499 }\end{array}$ & $\begin{array}{l}\text { XP_417160.1 } \\
\text { AAT72929.1 } \\
\text { XP_236275.3 } \\
\text { AAT01608.1 } \\
\text { XP_850964.1 } \\
\text { NP_031525.1 }\end{array}$ \\
\hline BRCAl & $\begin{array}{l}\text { Gallus gallus } \\
\text { Xenopus laevis } \\
\text { Bos taurus } \\
\text { Rattus norvegicus } \\
\text { Canis familiaris } \\
\text { Mus musculus }\end{array}$ & $\begin{array}{l}\text { NM_204169.1 } \\
\text { AF416868.1 } \\
\text { NM_178573.1 } \\
\text { NM_012514.1 } \\
\text { NM_001013416.1 } \\
\text { NM_009764.2 }\end{array}$ & $\begin{array}{l}\text { NP_989500.1 } \\
A A L 13037.1 \\
N P \_848668.1 \\
\text { NP_036646.1 } \\
\text { NP_001013434.1 } \\
\text { NP_033894.2 }\end{array}$ \\
\hline$B R C A 2$ & $\begin{array}{l}\text { Gallus gallus } \\
\text { Danio rerio } \\
\text { Bos taurus } \\
\text { Rattus norvegicus } \\
\text { Canis familiaris } \\
\text { Mus musculus }\end{array}$ & $\begin{array}{l}\text { NM_204276.1 } \\
X M \_690042.1 \\
X M \_583622.2 \\
\text { NM_031542.1 } \\
\text { NM_001006653.4 } \\
\text { NM_009765.1 }\end{array}$ & $\begin{array}{l}\text { NP_989607.1 } \\
X P \_695134.1 \\
X P \_583622.2 \\
N P \_113730.1 \\
N P \_001006654.2 \\
N P \_033895.1\end{array}$ \\
\hline $\mathrm{CDH} 1$ & $\begin{array}{l}\text { Xenopus laevis } \\
\text { Danio rerio } \\
\text { Bos taurus } \\
\text { Rattus norvegicus } \\
\text { Canis familiaris } \\
\text { Mus musculus }\end{array}$ & $\begin{array}{l}\text { BC068940.1 } \\
\text { NM_131820.1 } \\
\text { NM_001002763.1 } \\
\text { NM_031334.1 } \\
\text { XM_536807.2 } \\
\text { NM_009864.1 }\end{array}$ & $\begin{array}{l}\text { AAH68940.1 } \\
\text { NP_571895.1 } \\
\text { NP_001002763.1 } \\
\text { NP_112624.1 } \\
X P \_536807.2 \\
\text { NP_033994.1 }\end{array}$ \\
\hline$C D K N 2 A$ & $\begin{array}{l}\text { Gallus gallus } \\
\text { Takifugu rubripes } \\
\text { Bos taurus } \\
\text { Rattus norvegicus } \\
\text { Canis familiaris } \\
\text { Mus musculus }\end{array}$ & $\begin{array}{l}\text { NM_204433.1 } \\
\text { AJ250231.1 } \\
X M \_868375.1 \\
\text { NM_031550.1 } \\
X M \_538685.2 \\
A F 044336.1\end{array}$ & $\begin{array}{l}N P \_989764.1 \\
C A C 12808.1 \\
X P \_873468.1 \\
N P \_113738.1 \\
X P \_538685.2 \\
A A C 08963.1\end{array}$ \\
\hline$N F 1$ & $\begin{array}{l}\text { Gallus gallus } \\
\text { Takifugu rubripes } \\
\text { Rattus norvegicus } \\
\text { Canis familiaris } \\
\text { Mus musculus }\end{array}$ & $\begin{array}{l}\text { XM_415914.1 } \\
\text { AF064564.2 } \\
\text { NM_012609.1 } \\
\text { XM_537738.2 } \\
\text { NM_010897.1 }\end{array}$ & $\begin{array}{l}\text { XP_415914.1 } \\
\text { AAD15839.1 } \\
\text { NP_036741.1 } \\
\text { XP_537738.2 } \\
\text { NP_035027.1 }\end{array}$ \\
\hline$N F 2$ & $\begin{array}{l}\text { Gallus gallus } \\
\text { Danio rerio } \\
\text { Bos taurus } \\
\text { Rattus norvegicus } \\
\text { Canis familiaris } \\
\text { Mus musculus }\end{array}$ & $\begin{array}{l}\text { NM_204497.2 } \\
\text { NM_212951.1 } \\
\text { XM_611643.2 } \\
\text { XM_341248.2 } \\
\text { XM_534729.2 } \\
\text { NM_010898.2 }\end{array}$ & $\begin{array}{l}\text { NP_989828.2 } \\
\text { NP_998116.1 } \\
\text { XP_611643.2 } \\
\text { XP_341249.2 } \\
\text { XP_534729.2 } \\
\text { NP_035028.2 }\end{array}$ \\
\hline PTCH1 & $\begin{array}{l}\text { Xenopus laevis } \\
\text { Gallus gallus } \\
\text { Danio rerio } \\
\text { Meriones unguiculatus } \\
\text { Rattus norvegicus } \\
\text { Mus musculus }\end{array}$ & $\begin{array}{l}\text { AF302765.1 } \\
\text { NM_204960.1 } \\
\text { NM_130988.1 } \\
\text { AB188226.1 } \\
\text { NM_053566.1 } \\
\text { NM_008957.1 }\end{array}$ & $\begin{array}{l}\text { AAK15463.1 } \\
\text { NP_990291.1 } \\
\text { NP_571063.1 } \\
\text { BAE78534.1 } \\
\text { NP_446018.1 } \\
\text { NP_032983.1 }\end{array}$ \\
\hline PTEN & Xenopus laevis & AF144732.1 & AAD46165.1 \\
\hline
\end{tabular}




\begin{tabular}{|c|c|c|c|}
\hline & $\begin{array}{l}\text { Gallus gallus } \\
\text { Bos taurus } \\
\text { Canis familiaris } \\
\text { Rattus norvegicus } \\
\text { Mus musculus }\end{array}$ & $\begin{array}{l}\text { XM_421555.1 } \\
\text { XM_613125.2 } \\
\text { NM_001003192.1 } \\
\text { NM_031606.1 } \\
\text { NM_008960.2 }\end{array}$ & $\begin{array}{l}\text { XP_421555.1 } \\
\text { XP_613125.2 } \\
\text { NP_001003192.1 } \\
\text { NP_113794.1 } \\
\text { NP_032986.1 }\end{array}$ \\
\hline$R B 1$ & $\begin{array}{l}\text { Gallus gallus } \\
\text { Rattus norvegicus } \\
\text { Canis familiaris } \\
\text { Mus musculus } \\
\text { Oncorhynchus mykiss } \\
\text { Notophthalmus viridescens }\end{array}$ & $\begin{array}{l}\text { NM_204419.1 } \\
\text { XM_344434.2 } \\
\text { XM_534118.2 } \\
\text { NM_009029.1 } \\
\text { AF102861.1 } \\
\text { Y09226.1 }\end{array}$ & $\begin{array}{l}\text { NP_989750.1 } \\
\text { XP_344435.2 } \\
\text { XP_534118.2 } \\
\text { NP_033055.1 } \\
\text { AAD13390.1 } \\
\text { CAA70428.1 }\end{array}$ \\
\hline STK11 & $\begin{array}{l}\text { Xenopus laevis } \\
\text { Danio rerio } \\
\text { Rattus norvegicus } \\
\text { Raja erinacea } \\
\text { Canis familiaris } \\
\text { Mus musculus }\end{array}$ & $\begin{array}{l}\text { U24435.1 } \\
\text { NM_001017839.1 } \\
\text { XM_234900.2 } \\
\text { AF486831.1 } \\
\text { XM_542206.2 } \\
\text { NM_011492.1 }\end{array}$ & $\begin{array}{l}\text { AAC59904.1 } \\
\text { NP_001017839.1 } \\
\text { XP_234900.2 } \\
\text { AAL92113.1 } \\
\text { XP_542206.2 } \\
\text { NP_035622.1 }\end{array}$ \\
\hline TP53 & $\begin{array}{l}\text { Gallus gallus } \\
\text { Danio rerio } \\
\text { Bos taurus } \\
\text { Rattus norvegicus } \\
\text { Canis familiaris } \\
\text { Mus musculus }\end{array}$ & $\begin{array}{l}\text { NM_205264.1 } \\
\text { NM_131327.1 } \\
\text { NM_174201.2 } \\
\text { NM_030989.1 } \\
\text { NM_001003210.1 } \\
\text { NM_011640.1 }\end{array}$ & $\begin{array}{l}\text { NP_990595.1 } \\
\text { NP_571402.1 } \\
\text { NP_776626.1 } \\
\text { NP_112251.1 } \\
\text { NP_001003210.1 } \\
\text { NP_035770.1 }\end{array}$ \\
\hline$T S C l$ & $\begin{array}{l}\text { Gallus gallus } \\
\text { Danio rerio } \\
\text { Bos taurus } \\
\text { Rattus norvegicus } \\
\text { Canis familiaris } \\
\text { Mus musculus }\end{array}$ & $\begin{array}{l}\text { XM_415449.1 } \\
\text { XM_691747.1 } \\
\text { XM_612846.2 } \\
\text { NM_021854.1 } \\
\text { XM_537808.2 } \\
\text { NM_022887.2 }\end{array}$ & $\begin{array}{l}\text { XP_415449.1 } \\
\text { XP_696839.1 } \\
\text { XP_612846.2 } \\
\text { NP_068626.1 } \\
\text { XP_537808.2 } \\
\text { NP_075025.2 }\end{array}$ \\
\hline TSC2 & $\begin{array}{l}\text { Gallus gallus } \\
\text { Takifugu rubripes } \\
\text { Bos taurus } \\
\text { Rattus norvegicus } \\
\text { Canis familiaris } \\
\text { Mus musculus }\end{array}$ & $\begin{array}{l}\text { XM_414853.1 } \\
\text { AF013614 } \\
\text { XM_581197.2 } \\
\text { NM_012680.2 } \\
\text { XM_537008.2 } \\
\text { NM_011647.2 }\end{array}$ & $\begin{array}{l}\text { XP_414853.1 } \\
\text { AAB86682.1 } \\
\text { XP_581197.2 } \\
\text { NP_036812.2 } \\
\text { XP_537008.2 } \\
\text { NP_035777.2 }\end{array}$ \\
\hline$V H L$ & $\begin{array}{l}\text { Gallus gallus } \\
\text { Danio rerio } \\
\text { Bos taurus } \\
\text { Rattus norvegicus } \\
\text { Canis familiaris } \\
\text { Mus musculus }\end{array}$ & $\begin{array}{l}\text { XM_4144477.1 } \\
\text { XM_681176.1 } \\
\text { XM_613870.2 } \\
\text { NM_052801.1 } \\
\text { NM_001008552.1 } \\
\text { NM_009507.2 }\end{array}$ & $\begin{array}{l}\text { XP_414447.1 } \\
\text { XP_686268.1 } \\
\text { XP_613870.2 } \\
\text { NP_434688.1 } \\
\text { NP_001008552.1 } \\
\text { NP_033533.1 }\end{array}$ \\
\hline$W T 1$ & $\begin{array}{l}\text { Xenopus laevis } \\
\text { Gallus gallus } \\
\text { Rattus norvegicus } \\
\text { Canis familiaris } \\
\text { Sus scrofa } \\
\text { Mus musculus }\end{array}$ & $\begin{array}{l}\text { U42011.1 } \\
\text { NM_205216.1 } \\
\text { NM_031534.1 } \\
\text { XM_846479.1 } \\
\text { NM_001001264.1 } \\
\text { NM_144783.1 }\end{array}$ & $\begin{array}{l}\text { AAB53152.1 } \\
\text { NP_990547.1 } \\
\text { NP_113722.1 } \\
\text { XP_851572.1 } \\
\text { NP_001001264.1 } \\
\text { NP_659032.1 }\end{array}$ \\
\hline
\end{tabular}


SupplementaryTable 2. Differences in distribution of parameters for somatic, germline, shared, somatic recurrent and shared recurrent missense mutations. Observed median and/or mean values are shown in brackets. DAVID: I prefer 'with respect' In my view according means that Hess and KR did the study

\begin{tabular}{|c|c|}
\hline Parameter & $\begin{array}{l}\text { Observed trend } \\
(\mathbf{p}<0.05)\end{array}$ \\
\hline $\begin{array}{l}\text { Median non-disease } \\
\text { associated mutability rate } \\
\text { according to Hess et al. } \\
{[1994]}\end{array}$ & 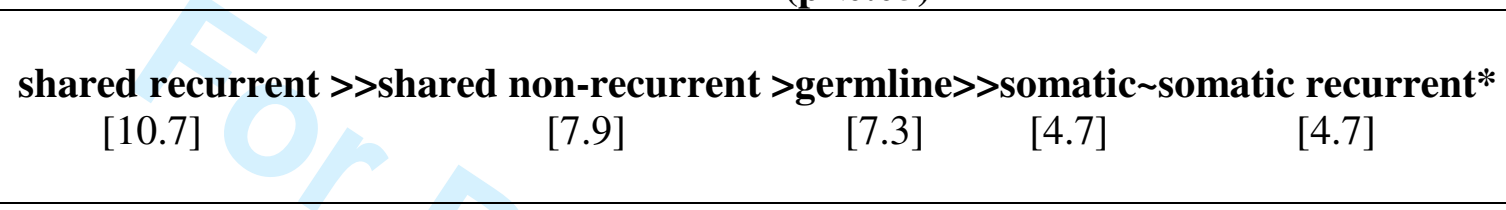 \\
\hline $\begin{array}{l}\text { Median disease-associated } \\
\text { mutability rate according to } \\
\text { Krawczak et al. [1998] }\end{array}$ & $\begin{array}{ccccc}\text { shared recurrent }>\text { shared non-recurrent } & >\text { germline } & \text { > } & \text { somatic } ~ & \text { somatic recurrent } \\
{[1.42]} & {[1.01]} & {[0.85]} & {[0.53]} & {[0.53]}\end{array}$ \\
\hline $\begin{array}{l}\text { Mean/median degree of } \\
\text { evolutionary conservation }\end{array}$ & $\begin{array}{c}\text { shared recurrent }<\text { shared }<<\text { somatic } \\
{[0.072 / 0] \quad[0.138 / 0][0.265 / 0.24]} \\
\text { somatic } \gg \text { germline } \\
{[0.265 / 0.24][0.18 / 0]}\end{array}$ \\
\hline Mean Grantham score & $\begin{array}{c}\text { germline >somatic recurrent } \sim \text { somatic non-recurrent } \\
{[93] \quad[85]} \\
\text { shared recurrent } \sim \text { shared non-recurrent } \\
{[100]}\end{array}$ \\
\hline $\begin{array}{l}\text { Proportion of CpG-located } \\
\text { mutations }\end{array}$ & $\begin{array}{ccccc}\text { shared recurrent } \sim \text { shared }>\text { > germline }>>\text { somatic } & \sim \text { somatic recurrent } \\
{[0.34]} & {[0.21]} & {[0.12]} & {[0.08]} & {[0.05]}\end{array}$ \\
\hline $\begin{array}{l}\text { Proportion of } \mathrm{CpHpG-} \\
\text { located mutations }\end{array}$ & $\begin{array}{ccc}\text { shared recurrent } \sim \text { shared } \gg \text { > somatic recurrent } \\
{[0.098]} & {[0.082]} & {[0.028]} \\
\end{array}$ \\
\hline $\begin{array}{l}\text { Proportion of mutations } \\
\text { located within or in the } \\
\text { vicinity of direct repeats }\end{array}$ & $\begin{array}{ccc}\text { somatic }>>\text { germline } & >>\text { recurrent somatic } \\
{[0.07]} & {[0.04]} & {[0.02]}\end{array}$ \\
\hline
\end{tabular}




\begin{tabular}{|l|cc|}
\hline Proportion of mutations & somatic $>>$ shared & somatic $>>$ shared recurrent \\
located within (or in the & {$[0.24] \quad[0.05]$} & {$[0.24] \quad[0.16]$} \\
vicinity of) runs of identical & germline $>>$ shared & somatic recurrent $>>$ shared \\
nucleotides & {$[0.20] \quad[0.05]$} & {$[0.21] \quad[0.05]$} \\
\hline
\end{tabular}

*Inequality shared $>$ germline $>$ somatic implies that a significant difference $(\mathrm{p}<0.05)$ in the corresponding parameter was observed between each pair of mutational spectra, i.e. shared vs germline, shared vs somatic and germline vs somatic. Symbol ' ' denotes the absence of any significant difference between any two mutational spectra with respect to a given parameter. Symbols ' $>>$ ' or ' $<<$ ' indicate experiment-wise statistical significance of the observed inequality whereas symbols ' $<$ ' or ' $>$ ' indicate gene-wise statistical significance. 
Supplementary Table 3. Various parameters of gene-wise somatic and germline missense mutational spectra vs. potential mutational spectra exhibiting either gene-wise $(\mathrm{p}<0.05)$ or experiment-wise differences $(\mathrm{p}<0.05$; shaded in light grey) with respect to the parameters measured.

\begin{tabular}{|c|c|c|c|c|c|c|c|c|c|c|c|c|}
\hline & \multicolumn{2}{|c|}{$\begin{array}{c}\text { Non-disease } \\
\text { associated mutation } \\
\text { rate }\end{array}$} & \multicolumn{2}{|c|}{$\begin{array}{l}\text { Disease-associated } \\
\text { mutation rate }\end{array}$} & \multicolumn{2}{|c|}{$\begin{array}{c}\text { Evolutionary } \\
\text { conservation rate }\end{array}$} & \multicolumn{2}{|c|}{ Grantham score } & \multicolumn{2}{|c|}{$\begin{array}{l}\text { CpG-located } \\
\text { missense } \\
\text { mutations }\end{array}$} & \multicolumn{2}{|c|}{$\begin{array}{c}\text { CpHpG- } \\
\text { located } \\
\text { missense } \\
\text { mutations }\end{array}$} \\
\hline & $\begin{array}{c}\text { Gene } \\
\text { symbol }\end{array}$ & Median & $\begin{array}{c}\text { Gene } \\
\text { symbol }\end{array}$ & Median & $\begin{array}{c}\text { Gene } \\
\text { symbol }\end{array}$ & Median & $\begin{array}{c}\text { Gene } \\
\text { symbol }\end{array}$ & Median & $\begin{array}{c}\text { Gene } \\
\text { symbol }\end{array}$ & $\%$ & $\begin{array}{c}\text { Gene } \\
\text { symbol }\end{array}$ & $\%$ \\
\hline \multirow{8}{*}{ 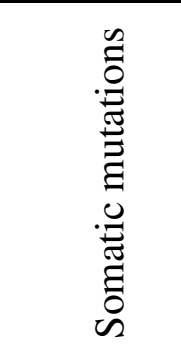 } & & & STK11 & 1.66 & & & & & STK11 & 25 & & \\
\hline & & & PTCH1 & 1.06 & & & & & & & & \\
\hline & $A P C$ & 8.4 & $C D K N 2 A$ & 1.01 & $C D K N 2 A$ & 0.38 & & & $C D K N 2 A$ & 20 & $C D K N 2 A$ & 5.2 \\
\hline & $C D K N 2 A$ & 7.9 & $A P C$ & 0.83 & & & & & & & & \\
\hline & PTEN & 5.6 & PTEN & 0.53 & & & & & & & & \\
\hline & TP53 & 4.6 & TP53 & 0.5 & TP53 & 0.17 & & & $R B 1$ & 18 & $T P 53$ & 2.8 \\
\hline & & & & & VHL & 0.14 & & & BRCA2 & 16 & & \\
\hline & & & & & & & & & PTCH1 & 15 & & \\
\hline \multirow{3}{*}{$\begin{array}{l}\text { for all } 17 \\
\text { genes } \\
\text { combined }\end{array}$} & somatic & 4.7 & somatic & 0.53 & somatic & 0 & somatic & 78 & somatic & 8 & somatic & 2.5 \\
\hline & control & 4.1 & control & 0.4 & control & 0.2 & control & 74 & control & 2 & control & 2 \\
\hline & germline & 7.2 & germline & 0.85 & germline & 0 & germline & 94 & germline & 12 & germline & 3 \\
\hline \multirow{11}{*}{ 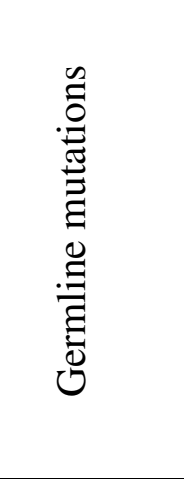 } & & & & & & & & & & & & \\
\hline & $T S C 2$ & 7.2 & & & $T S C 2$ & 0 & & 2 & BRCA1 & 7 & BRCAl & 3.6 \\
\hline & $N F 1$ & 7.3 & & & & & $N F 1$ & 98 & & & & \\
\hline & $R B 1$ & 7.6 & & & & & & & $N F 1$ & 7 & & \\
\hline & $A T M$ & 7.9 & $A T M$ & 0.79 & $A T M$ & 0 & $A T M$ & 98 & $A T M$ & 15 & $A T M$ & 3.8 \\
\hline & BRCAI & 7.9 & BRCAI & 0.81 & $V H L$ & 0 & $V H L$ & 99 & BRCAI & 16 & & \\
\hline & BRCA2 & 8.7 & BRCA2 & 0.81 & & & & & NF1 & 18 & & \\
\hline & & & PTEN & 0.92 & & & & & & & $T S C 2$ & 8.1 \\
\hline & & & $R B 1$ & 0.99 & & & & & & & $W T 1$ & 10.8 \\
\hline & & & $N F 1$ & 1.03 & & & & & & & & \\
\hline & & & $T S C 2$ & 1.03 & & & & & & & & \\
\hline
\end{tabular}




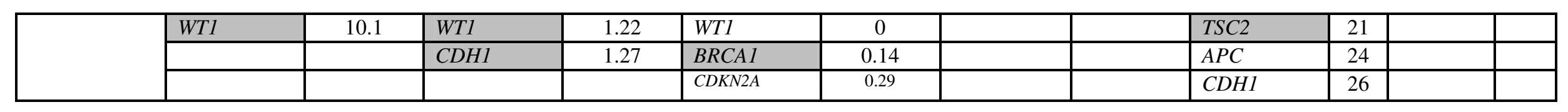


Supplementary Table 4. Summary of mutations occurring in direct repeats of length $\geq 8 \mathrm{bp}$ in the 17 tumour suppressor genes.

\begin{tabular}{|c|c|c|c|c|c|c|c|c|c|c|c|}
\hline \multirow[b]{2}{*}{$\begin{array}{c}\text { Gene } \\
\text { symbol }\end{array}$} & \multirow{2}{*}{$\begin{array}{c}\text { Proportion } \\
\text { of gene } \\
\text { length } \\
\text { covered } \\
\text { by repeats } \\
(\%)\end{array}$} & \multicolumn{6}{|c|}{ Number of missense mutations found in repeats } & \multicolumn{4}{|c|}{$\begin{array}{l}\text { Number of micro-deletions and micro- } \\
\text { insertions found in repeats }\end{array}$} \\
\hline & & $\begin{array}{l}\text { somatic } \\
\text { non- } \\
\text { recurrent }\end{array}$ & germline & $\begin{array}{c}\text { shared } \\
\text { non- } \\
\text { recurrent }\end{array}$ & $\begin{array}{l}\text { somatic } \\
\text { recurrent }\end{array}$ & $\begin{array}{l}\text { shared } \\
\text { recurrent }\end{array}$ & Total & $\begin{array}{l}\text { somatic } \\
\text { non- } \\
\text { recurrent }\end{array}$ & germline & shared & Total \\
\hline$A P C$ & 4 & 3 & 0 & 0 & 0 & 0 & 3 & 17 & 21 & 1 & 17 \\
\hline$A T M$ & 7 & 2 & 0 & 0 & 0 & 0 & 2 & 0 & 11 & 0 & 0 \\
\hline BRCA1 & 5 & 0 & 9 & 0 & 0 & 0 & 9 & 1 & 8 & 0 & 1 \\
\hline BRCA2 & 2 & 0 & 0 & 0 & 0 & 0 & 0 & 1 & 12 & 0 & 1 \\
\hline$C D H 1$ & 3 & 0 & 0 & 0 & 0 & 0 & 0 & 0 & 1 & 0 & 0 \\
\hline CDKN2A & 17 & 25 & 8 & 3 & 0 & 0 & 36 & 28 & 2 & 0 & 28 \\
\hline NF1 & 7 & 0 & 2 & 0 & 0 & 0 & 2 & 0 & 15 & 0 & 0 \\
\hline NF2 & 3 & 0 & 0 & 0 & 0 & 0 & 0 & 1 & 1 & 0 & 1 \\
\hline PTCH1 & 3 & 0 & 0 & 0 & 0 & 0 & 0 & 0 & 0 & 0 & 0 \\
\hline PTEN & 17 & 7 & 0 & 0 & 4 & 2 & 13 & 20 & 5 & 1 & 20 \\
\hline$R B 1$ & 12 & 0 & 1 & 0 & 0 & 0 & 1 & 2 & 12 & 0 & 2 \\
\hline STK11 & 10 & 0 & 3 & 1 & 0 & 0 & 4 & 0 & 6 & 0 & 0 \\
\hline TP53 & 14 & 24 & 1 & 0 & 13 & 2 & 40 & 21 & 0 & 0 & 21 \\
\hline TSC1 & 5 & 0 & 1 & 0 & 0 & 0 & 1 & 0 & 4 & 0 & 0 \\
\hline TSC2 & 5 & 0 & 10 & 1 & 0 & 0 & 11 & 0 & 6 & 0 & 0 \\
\hline$V H L$ & 6 & 0 & 1 & 0 & 0 & 0 & 1 & 0 & 1 & 0 & 0 \\
\hline WT1 & 7 & 1 & 0 & 0 & 0 & 0 & 1 & 0 & 0 & 0 & 0 \\
\hline TOTAL & 6 & 62 & 36 & 5 & 17 & 4 & 124 & 91 & 105 & 2 & 91 \\
\hline
\end{tabular}


Supplementary Table 5. Summary of mutations occurring in inverted repeats of length $\geq 8$ bp in the 17 tumour suppressor genes.

\begin{tabular}{|c|c|c|c|c|c|c|c|c|c|c|c|}
\hline \multirow[b]{2}{*}{$\begin{array}{l}\text { Gene } \\
\text { symbol }\end{array}$} & \multirow{2}{*}{$\begin{array}{c}\text { Proportion } \\
\text { of gene } \\
\text { length } \\
\text { covered } \\
\text { by repeats } \\
(\%) \\
\end{array}$} & \multicolumn{6}{|c|}{ Number of missense mutations found in repeats } & \multicolumn{4}{|c|}{$\begin{array}{l}\text { Number of micro-deletions and micro- } \\
\text { insertions found in repeats }\end{array}$} \\
\hline & & $\begin{array}{l}\text { somatic } \\
\text { non- } \\
\text { recurrent }\end{array}$ & germline & $\begin{array}{c}\text { shared } \\
\text { non- } \\
\text { recurrent }\end{array}$ & $\begin{array}{l}\text { somatic } \\
\text { recurrent }\end{array}$ & $\begin{array}{l}\text { shared } \\
\text { recurrent }\end{array}$ & Total & $\begin{array}{l}\text { somatic } \\
\text { non- } \\
\text { recurrent }\end{array}$ & germline & shared & Total \\
\hline$A P C$ & 6 & 5 & 4 & 1 & 1 & 0 & 5 & 21 & 27 & 2 & 50 \\
\hline ATM & 13 & 1 & 14 & 0 & 0 & 0 & 1 & 1 & 16 & 0 & 17 \\
\hline BRCA1 & 6 & 0 & 15 & 0 & 0 & 0 & 0 & 0 & 22 & 1 & 23 \\
\hline BRCA2 & 7 & 3 & 1 & 0 & 0 & 0 & 3 & 1 & 27 & 0 & 28 \\
\hline CDH1 & 5 & 0 & 1 & 0 & 0 & 0 & 0 & 1 & 0 & 0 & 1 \\
\hline CDKN2A & 8 & 30 & 5 & 6 & 2 & 1 & 30 & 13 & 2 & 1 & 16 \\
\hline NF1 & 11 & 0 & 3 & 0 & 0 & 0 & 0 & 1 & 24 & 0 & 25 \\
\hline NF2 & 10 & 1 & 3 & 0 & 0 & 0 & 1 & 11 & 6 & 0 & 17 \\
\hline PTCH1 & 5 & 1 & 0 & 0 & 0 & 0 & 1 & 0 & 2 & 0 & 2 \\
\hline PTEN & 6 & 10 & 1 & 1 & 4 & 1 & 10 & 9 & 2 & 0 & 11 \\
\hline$R B 1$ & 16 & 4 & 5 & 1 & 0 & 0 & 4 & 7 & 28 & 0 & 35 \\
\hline STK11 & 13 & 1 & 5 & 0 & 1 & 0 & 1 & 1 & 9 & 0 & 10 \\
\hline TP53 & 5 & 13 & 0 & 0 & 51 & 9 & 13 & 53 & 2 & 0 & 55 \\
\hline TSC1 & 5 & 0 & 1 & 0 & 0 & 0 & 0 & 0 & 7 & 0 & 7 \\
\hline TSC2 & 9 & 0 & 6 & 0 & 0 & 0 & 0 & 1 & 13 & 0 & 14 \\
\hline$V H L$ & 12 & 9 & 8 & 1 & 1 & 0 & 9 & 36 & 15 & 2 & 53 \\
\hline WT1 & 7 & 0 & 2 & 0 & 0 & 0 & 0 & 0 & 0 & 0 & 0 \\
\hline TOTAL & 9 & 78 & 74 & 10 & 60 & 11 & 78 & 156 & 202 & 6 & 364 \\
\hline
\end{tabular}

John Wiley \& Sons, Inc. 8 
Supplementary Table 6. Summary of mutations occurring within symmetric repeats of length $\geq 8 \mathrm{bp}$ in the 17 tumour suppressor genes.

\begin{tabular}{|c|c|c|c|c|c|c|c|c|c|c|c|}
\hline \multirow[b]{2}{*}{$\begin{array}{c}\text { Gene } \\
\text { symbol }\end{array}$} & \multirow{2}{*}{$\begin{array}{c}\text { Proportion } \\
\text { of gene } \\
\text { length } \\
\text { covered } \\
\text { by repeats } \\
(\%)\end{array}$} & \multicolumn{6}{|c|}{ Number of missense mutations found in repeats } & \multicolumn{4}{|c|}{$\begin{array}{l}\text { Number of micro-deletions and micro- } \\
\text { insertions found in repeats }\end{array}$} \\
\hline & & $\begin{array}{l}\text { somatic } \\
\text { non- } \\
\text { recurrent }\end{array}$ & germline & $\begin{array}{c}\text { shared } \\
\text { non- } \\
\text { recurrent }\end{array}$ & $\begin{array}{l}\text { somatic } \\
\text { recurrent }\end{array}$ & $\begin{array}{l}\text { shared } \\
\text { recurrent }\end{array}$ & Total & $\begin{array}{l}\text { somatic } \\
\text { non- } \\
\text { recurrent }\end{array}$ & germline & shared & Total \\
\hline$A P C$ & 16 & 5 & 2 & 0 & 2 & 0 & 9 & 58 & 87 & 6 & 151 \\
\hline ATM & 32 & 2 & 11 & 0 & 0 & 0 & 13 & 2 & 43 & 0 & 45 \\
\hline BRCA1 & 20 & 1 & 30 & 0 & 0 & 0 & 31 & 0 & 82 & 2 & 84 \\
\hline BRCA2 & 18 & 6 & 18 & 0 & 0 & 0 & 24 & 2 & 79 & 3 & 84 \\
\hline$C D H 1$ & 24 & 4 & 0 & 0 & 0 & 0 & 4 & 5 & 8 & 0 & 13 \\
\hline CDKN2A & 24 & 49 & 13 & 5 & 2 & 0 & 69 & 35 & 7 & 1 & 43 \\
\hline NF1 & 31 & 1 & 20 & 0 & 0 & 0 & 21 & 2 & 85 & 2 & 89 \\
\hline NF2 & 24 & 6 & 3 & 0 & 1 & 0 & 10 & 49 & 12 & 3 & 64 \\
\hline PTCH1 & 23 & 5 & 8 & 1 & 0 & 0 & 14 & 5 & 23 & 0 & 28 \\
\hline PTEN & 44 & 27 & 3 & 1 & 9 & 0 & 40 & 42 & 13 & 1 & 56 \\
\hline$R B 1$ & 48 & 3 & 10 & 1 & 0 & 0 & 14 & 4 & 41 & 1 & 46 \\
\hline STK11 & 33 & 3 & 6 & 0 & 2 & 0 & 11 & 1 & 20 & 1 & 22 \\
\hline TP53 & 30 & 60 & 2 & 1 & 132 & 23 & 218 & 147 & 1 & 0 & 148 \\
\hline TSC1 & 23 & 0 & 3 & 0 & 0 & 0 & 3 & 0 & 27 & 0 & 27 \\
\hline TSC2 & 23 & 0 & 13 & 0 & 0 & 0 & 13 & 1 & 29 & 0 & 30 \\
\hline VHL & 17 & 3 & 9 & 2 & 0 & 2 & 16 & 25 & 7 & 2 & 34 \\
\hline$W T 1$ & 26 & 0 & 6 & 0 & 0 & 0 & 6 & 3 & 4 & 0 & 7 \\
\hline TOTAL & 25 & 175 & 157 & 11 & 148 & 25 & 516 & 381 & 568 & 22 & 971 \\
\hline
\end{tabular}


Suplementary Table 7. Occurrence of missense mutations in repeats/runs of identical nucleotides and/or $\mathrm{CpG} / \mathrm{CpHpG}$ oligonucleotides

\begin{tabular}{|c|c|c|c|c|c|}
\hline \multirow[b]{2}{*}{$\begin{array}{l}\text { Type of } \\
\text { Repeats }\end{array}$} & \multirow[b]{2}{*}{$\begin{array}{c}\text { Type of } \\
\text { mutational } \\
\text { spectrum }\end{array}$} & \multicolumn{3}{|c|}{ Number of mutations } & \multirow[b]{2}{*}{$\begin{array}{c}\text { Remaining } \\
\text { number of } \\
\text { mutations }\end{array}$} \\
\hline & & $\begin{array}{l}\text { exclusively in } \\
\text { repeats/runs }\end{array}$ & $\begin{array}{l}\text { exclusively in } \\
\mathrm{CpG} / \mathrm{CpHpG}\end{array}$ & $\begin{array}{c}\text { in both } \\
\text { repeats/runs } \\
\text { and } \\
\text { CpG/CpHpG }\end{array}$ & \\
\hline \multirow{6}{*}{ Runs } & $\begin{array}{l}\text { somatic } \\
\text { non- } \\
\text { recurrent }\end{array}$ & 184 & 58 & 24 & 618 \\
\hline & germline & 151 & 100 & 27 & 608 \\
\hline & $\begin{array}{l}\text { somatic } \\
\text { recurrent }\end{array}$ & 167 & 46 & 18 & 636 \\
\hline & $\begin{array}{l}\text { shared non- } \\
\text { recurrent }\end{array}$ & 5 & 28 & 0 & 69 \\
\hline & $\begin{array}{l}\text { shared } \\
\text { recurrent }\end{array}$ & 10 & 38 & 5 & 59 \\
\hline & potential & 32861 & 3902 & 765 & 111495 \\
\hline \multirow{6}{*}{ Direct } & $\begin{array}{l}\text { somatic } \\
\text { non- } \\
\text { recurrent }\end{array}$ & 52 & 72 & 10 & 750 \\
\hline & germline & 31 & 122 & 5 & 728 \\
\hline & $\begin{array}{l}\text { somatic } \\
\text { recurrent }\end{array}$ & 14 & 61 & 3 & 789 \\
\hline & $\begin{array}{l}\text { shared non- } \\
\text { recurrent }\end{array}$ & 3 & 26 & 2 & 71 \\
\hline & $\begin{array}{l}\text { shared } \\
\text { recurrent }\end{array}$ & 2 & 41 & 2 & 67 \\
\hline & potential & 5252 & 4431 & 236 & 139104 \\
\hline
\end{tabular}

John Wiley \& Sons, Inc. 10 


\begin{tabular}{|c|c|c|c|c|c|}
\hline \multirow[t]{6}{*}{ Inverted } & $\begin{array}{l}\text { somatic } \\
\text { non- } \\
\text { recurrent }\end{array}$ & 65 & 69 & 13 & 737 \\
\hline & germline & 64 & 117 & 10 & 695 \\
\hline & $\begin{array}{l}\text { somatic } \\
\text { recurrent }\end{array}$ & 55 & 59 & 5 & 748 \\
\hline & $\begin{array}{l}\text { shared non- } \\
\text { recurrent }\end{array}$ & 8 & 26 & 2 & 66 \\
\hline & $\begin{array}{l}\text { shared } \\
\text { recurrent }\end{array}$ & 7 & 39 & 4 & 62 \\
\hline & potential & 10790 & 4314 & 353 & 133566 \\
\hline \multirow[t]{6}{*}{ Symmetric } & $\begin{array}{l}\text { somatic } \\
\text { non- } \\
\text { recurrent }\end{array}$ & 155 & 62 & 20 & 647 \\
\hline & germline & 140 & 110 & 17 & 619 \\
\hline & $\begin{array}{l}\text { somatic } \\
\text { recurrent }\end{array}$ & 137 & 53 & 11 & 666 \\
\hline & $\begin{array}{l}\text { shared non- } \\
\text { recurrent }\end{array}$ & 7 & 24 & 4 & 67 \\
\hline & $\begin{array}{l}\text { shared } \\
\text { recurrent }\end{array}$ & 16 & 34 & 9 & 53 \\
\hline & potential & 28646 & 3752 & 915 & 115710 \\
\hline
\end{tabular}


Supplementary Table 8. Truncating vs. non-truncating lesions

\begin{tabular}{|c|c|c|c|c|c|c|c|c|c|c|}
\hline Gene & & Missense & Nonsense & $\begin{array}{c}\text { Micro- } \\
\text { deletions }\end{array}$ & $\begin{array}{c}\text { Micro- } \\
\text { insertions }\end{array}$ & $\begin{array}{c}\text { Micro- } \\
\text { indels }\end{array}$ & $\begin{array}{c}\text { Non-truncating } \\
\text { lesions }\end{array}$ & $\begin{array}{c}\text { Truncating } \\
\text { lesions }\end{array}$ & $\begin{array}{l}\text { Ratio of non-truncating } \\
\text { to truncating lesions }\end{array}$ & $\begin{array}{c}\text { Ratio of } \\
\text { truncating } \\
\text { somatic to } \\
\text { truncating } \\
\text { germline } \\
\text { lesions }\end{array}$ \\
\hline \multirow{2}{*}{$A P C$} & Somatic & 39 & 79 & 152 & 44 & 3 & 39 & 278 & 0.14 & \multirow{2}{*}{0.46} \\
\hline & Germline & 23 & 180 & 299 & 115 & 12 & 23 & 606 & 0.04 & \\
\hline \multirow{2}{*}{$A T M$} & Somatic & 11 & 7 & 4 & 1 & 0 & 11 & 12 & 0.92 & \multirow{2}{*}{0.05} \\
\hline & Germline & 76 & 75 & 122 & 35 & 14 & 76 & 246 & 0.31 & \\
\hline \multirow{2}{*}{$B R C A 1$} & Somatic & 6 & 9 & 9 & 5 & 0 & 6 & 23 & 0.26 & \multirow{2}{*}{0.05} \\
\hline & Germline & 170 & 121 & 259 & 85 & 12 & 170 & 477 & 0.36 & \\
\hline \multirow{2}{*}{ BRCA2 } & Somatic & 21 & 1 & 8 & +8 & 0 & 21 & 13 & 1.62 & \multirow{2}{*}{0.03} \\
\hline & Germline & 86 & 76 & 247 & 90 & 11 & 86 & 424 & 0.20 & \\
\hline \multirow{2}{*}{ CDH1 } & Somatic & 15 & 7 & 13 & 2 & 0 & 15 & 22 & 0.68 & \multirow{2}{*}{0.69} \\
\hline & Germline & 19 & 11 & 12 & 8 & 1 & 19 & 32 & 0.59 & \\
\hline \multirow{2}{*}{$C D K N 2 A$} & Somatic & 198 & 18 & 77 & 25 & 8 & 198 & 128 & 1.55 & \multirow{2}{*}{4.74} \\
\hline & Germline & 62 & 7 & 11 & 7 & 2 & 62 & 27 & 2.30 & \\
\hline \multirow{2}{*}{$N F 1$} & Somatic & 2 & 11 & 16 & 3 & 0 & 2 & 30 & 0.07 & \multirow{2}{*}{0.07} \\
\hline & Germline & 83 & 115 & 221 & 105 & 8 & 83 & 449 & 0.18 & \\
\hline \multirow{2}{*}{$N F 2$} & Somatic & 23 & 42 & 182 & 28 & 6 & 23 & 258 & 0.09 & \multirow{2}{*}{2.22} \\
\hline & Germline & 20 & 43 & 55 & 16 & 2 & 20 & 116 & 0.17 & \\
\hline \multirow{2}{*}{ РТCH1 } & Somatic & 14 & 9 & 14 & 6 & 1 & 14 & 30 & 0.47 & \multirow{2}{*}{0.28} \\
\hline & Germline & 24 & 27 & 42 & 32 & 8 & 24 & 109 & 0.22 & \\
\hline \multirow{2}{*}{ PTEN } & Somatic & 226 & 56 & 152 & 51 & 4 & 226 & 263 & 0.86 & \multirow{2}{*}{3.21} \\
\hline & Germline & 45 & 28 & 29 & 22 & 3 & 45 & 82 & 0.55 & \\
\hline$R B 1$ & Somatic & 25 & 27 & 34 & 12 & 3 & 25 & 76 & 0.33 & 0.30 \\
\hline
\end{tabular}




\begin{tabular}{|c|c|c|c|c|c|c|c|c|c|c|}
\hline & Germline & 37 & 76 & 117 & 53 & 11 & 37 & 257 & 0.14 & \multirow{3}{*}{0.17} \\
\hline \multirow{2}{*}{ STK11 } & Somatic & 20 & 10 & 5 & 1 & 1 & 20 & 17 & 1.18 & \\
\hline & Germline & 30 & 27 & 47 & 24 & 3 & 30 & 101 & 0.30 & \\
\hline \multirow{2}{*}{ TP53 } & Somatic & 1229 & 96 & 512 & 238 & 0 & 1229 & 846 & 1.45 & \multirow{2}{*}{24.89} \\
\hline & Germline & 94 & 10 & 16 & 5 & 3 & 94 & 34 & 2.76 & \\
\hline \multirow{2}{*}{$T S C 1$} & Somatic & 2 & 1 & 1 & 0 & 0 & 2 & 2 & 1.00 & \multirow{2}{*}{0.02} \\
\hline & Germline & 7 & 37 & 53 & 25 & 4 & 7 & 119 & 0.06 & \\
\hline \multirow{2}{*}{$T S C 2$} & Somatic & 2 & 1 & 3 & 2 & 1 & 2 & 7 & 0.29 & \multirow{2}{*}{0.03} \\
\hline & Germline & 89 & 74 & 110 & 46 & 3 & 89 & 233 & 0.38 & \\
\hline \multirow{2}{*}{$V H L$} & Somatic & 88 & 15 & 180 & 44 & 1 & 88 & 240 & 0.37 & \multirow{2}{*}{1.82} \\
\hline & Germline & 143 & 27 & 63 & 37 & 5 & 143 & 132 & 1.08 & \\
\hline \multirow{2}{*}{ WT1 } & Somatic & 1 & 3 & 4 & 3 & 0 & 1 & 10 & 0.10 & \multirow{2}{*}{0.37} \\
\hline & Germline & 40 & 14 & 8 & 4 & 1 & 40 & 27 & 1.48 & \\
\hline \multirow{2}{*}{ Total } & Somatic & 1922 & 392 & 1366 & 469 & 28 & 1922 & 2255 & 0.85 & \multirow{2}{*}{0.65} \\
\hline & Germline & 1048 & 948 & 1711 & 709 & 103 & 1048 & 3471 & 0.30 & \\
\hline
\end{tabular}


Supplementary Figure 1. Naive Bayes Tree Classifier. Number in parenthesis shows the probability of a mutations being somatic non-recurrent, germline, shared non-recurrent, somatic recurrent and shared recurrent respectively.

Attributes:

$$
\begin{aligned}
& \text { Mut_Type } \\
& \text { Hess_value } \\
& \text { Krawczak_value } \\
& \text { Evol } \\
& \text { Grantham_score } \\
& \text { CpG/CHG } \\
& \text { Repeats }
\end{aligned}
$$

Test mode: $\quad 10$-fold cross-validation

NBTree

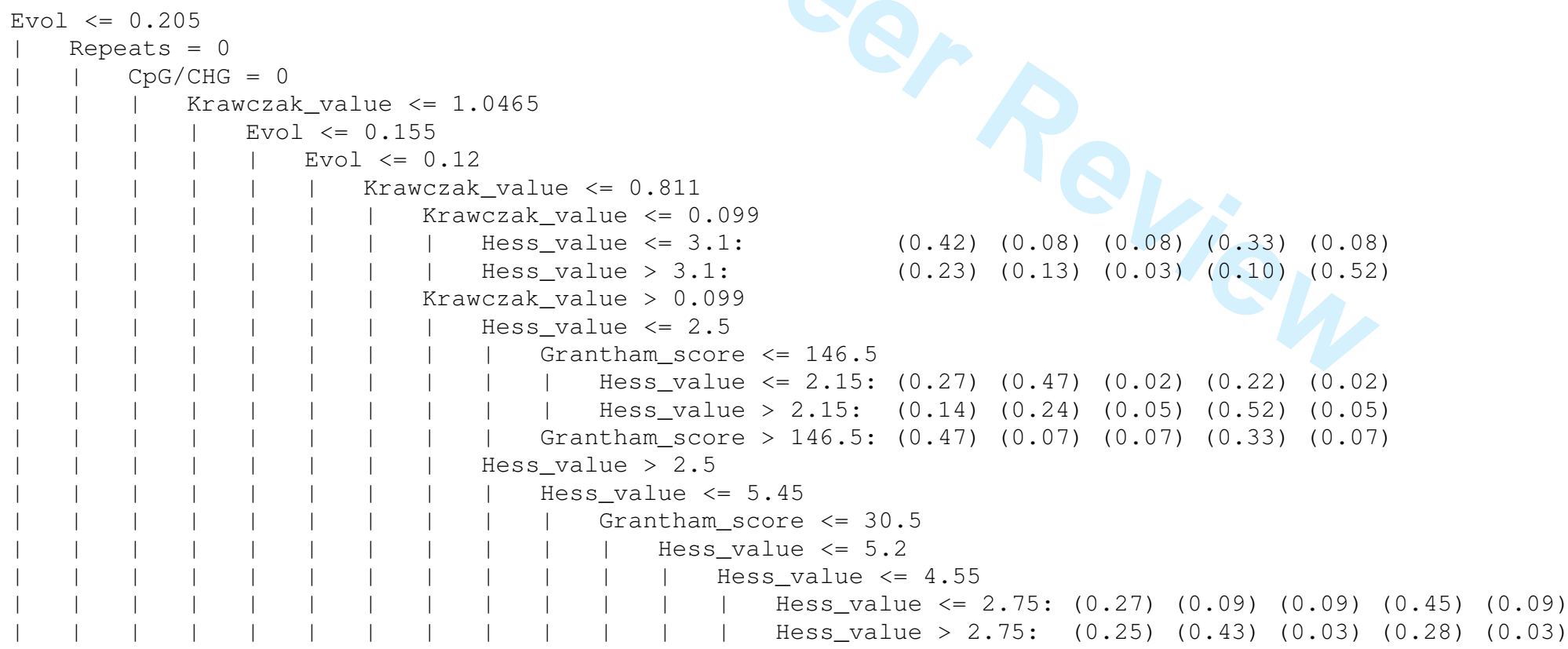

John Wiley \& Sons, Inc. ${ }^{14}$ 


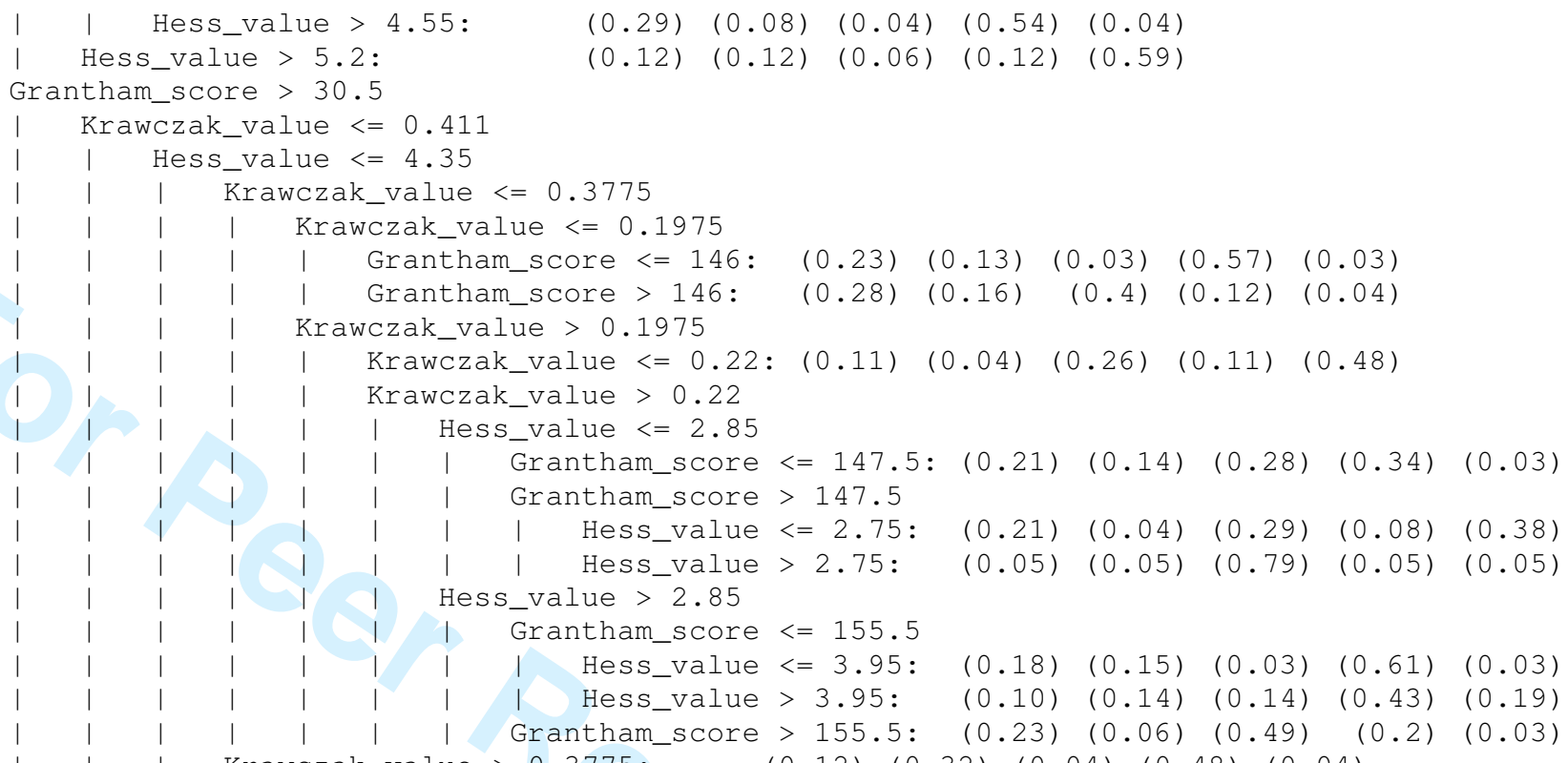

John Wiley \& Sons, Inc. 15 


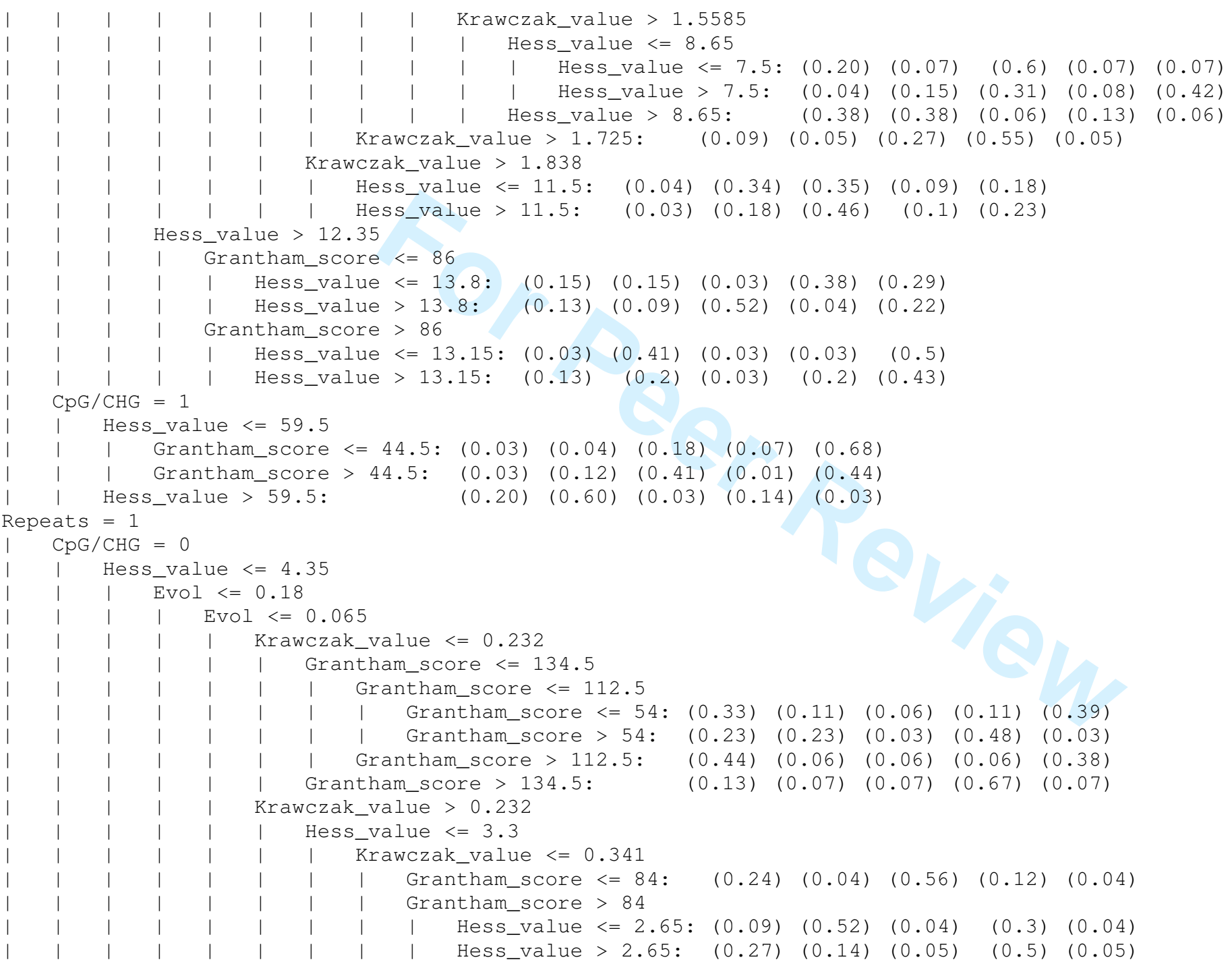




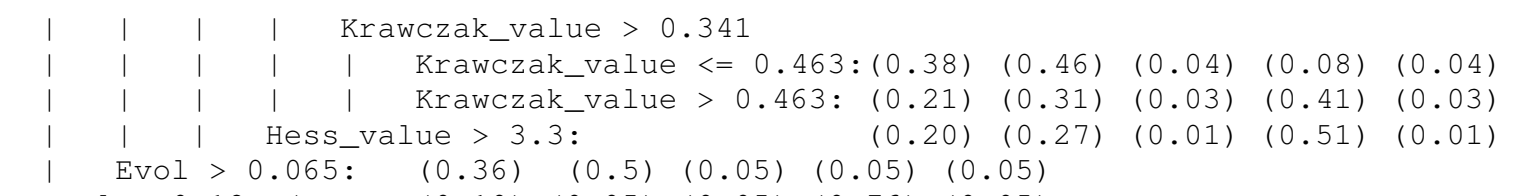




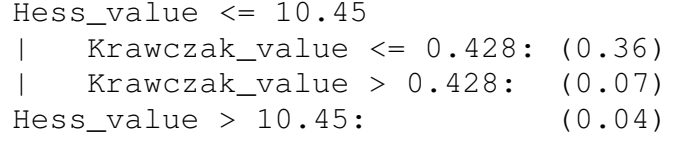




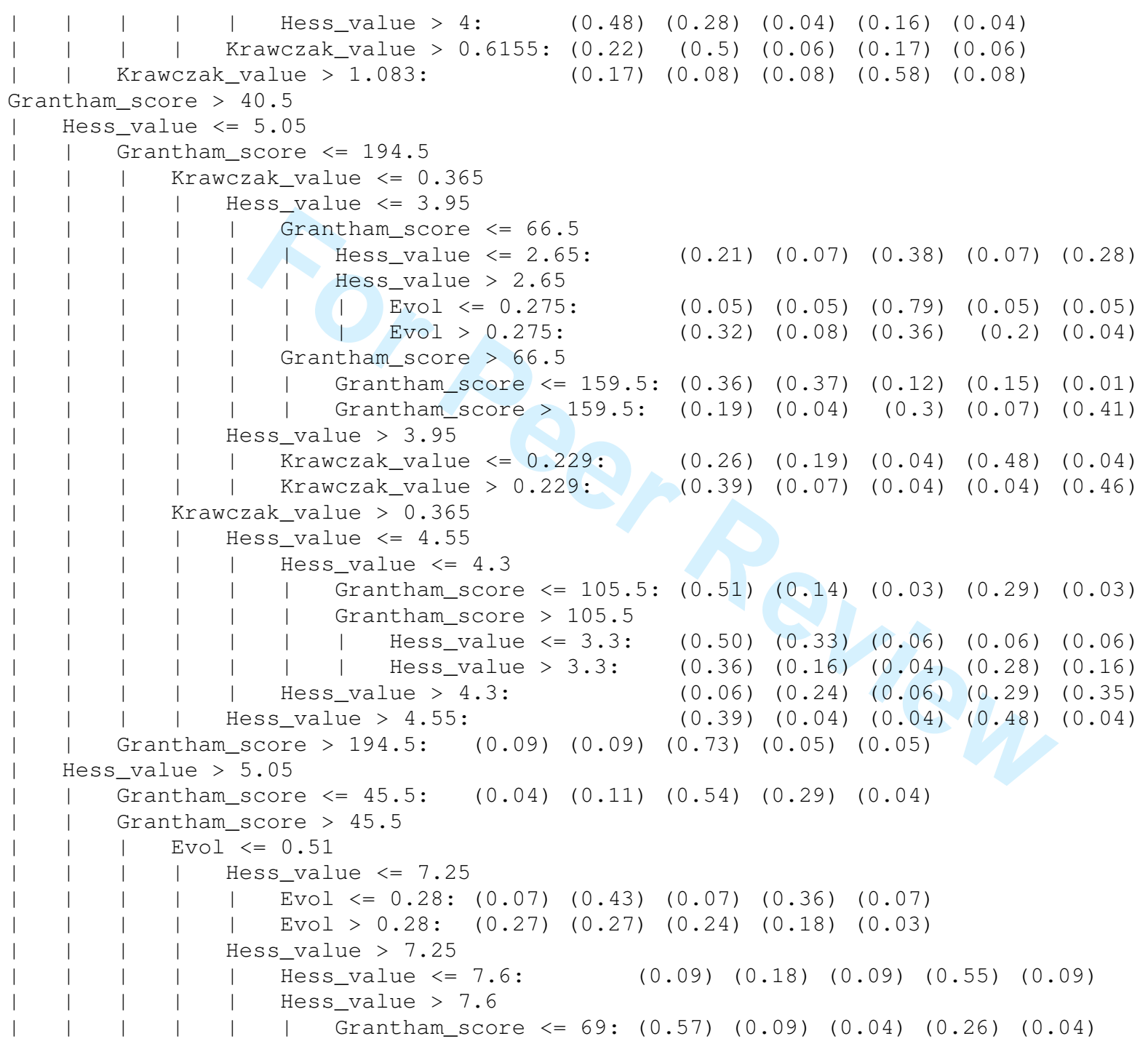




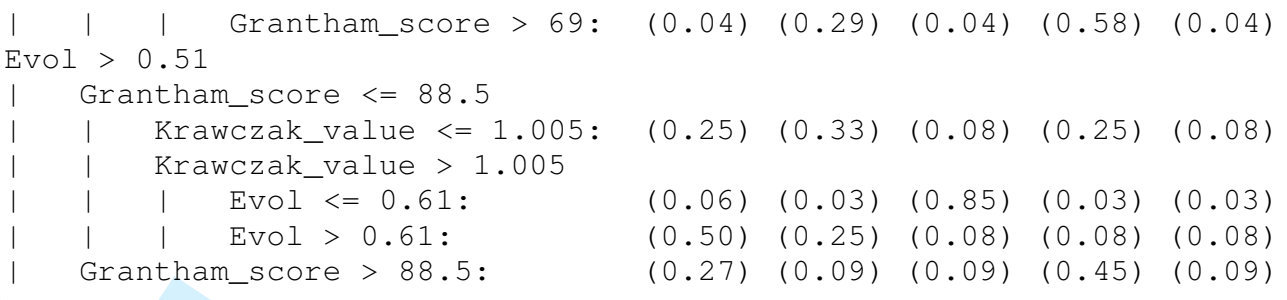




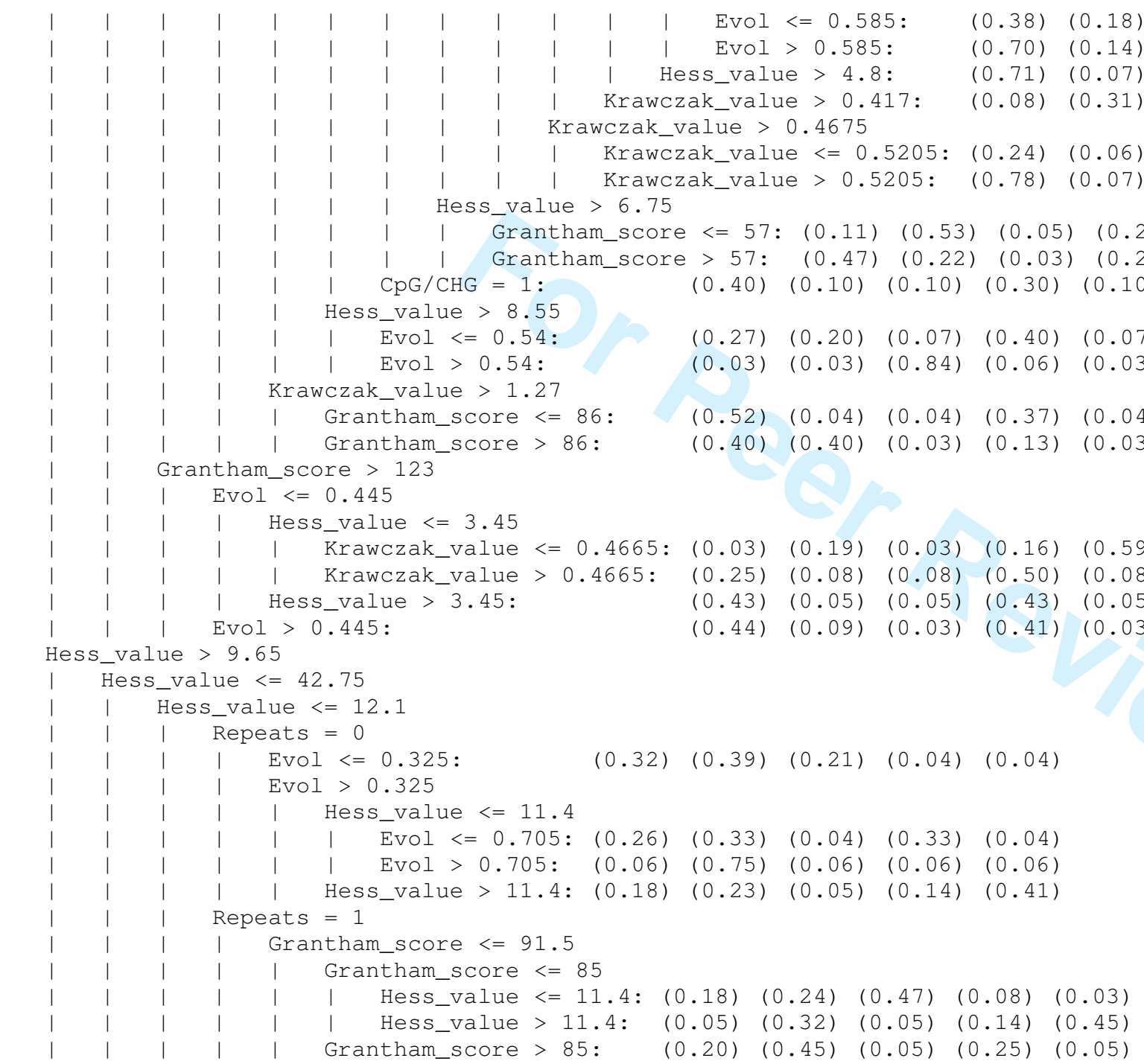




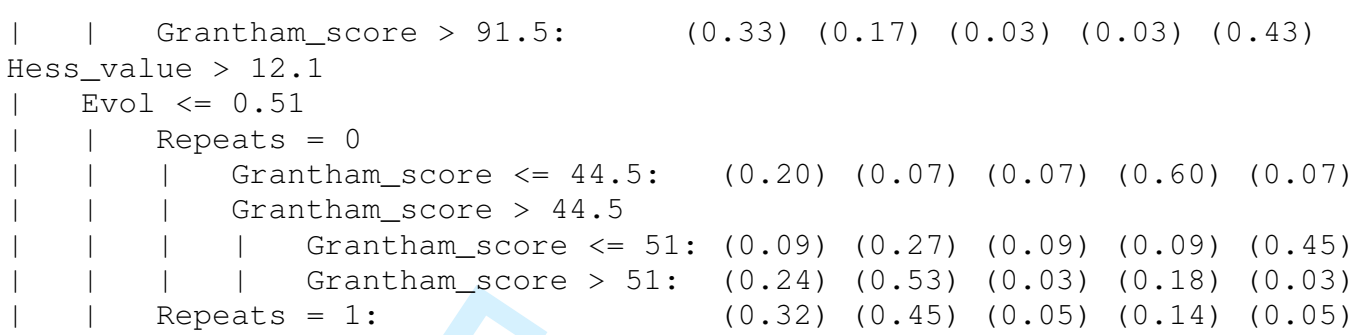

2797
1633

0.5392

0.1878

0.3177

$58.6858 \%$ 


\section{Page 71 of 141}

\section{Human Mutation}

Root relative squared error

$79.4156 \%$

Total Number of Instances

4430

$===$ Detailed Accuracy By Class ===

\begin{tabular}{|c|c|c|c|c|c|c|}
\hline Weighted & Avg. & & $\begin{array}{l}\text { Rate } \\
0.505 \\
0.426 \\
0.894 \\
0.475 \\
0.858 \\
0.631\end{array}$ & & $\begin{array}{r}\text { P Rate } \\
0.106 \\
0.082 \\
0.091 \\
0.109 \\
0.073 \\
0.092\end{array}$ & $\begin{array}{r}\text { recis } \\
0.5 \\
0.5 \\
0.7 \\
0.5 \\
0.7\end{array}$ \\
\hline \multicolumn{7}{|c|}{$===$ Confusion Matrix $===$} \\
\hline a $\quad b$ & $\mathrm{C}$ & d & e & $<--$ & classified & \\
\hline $447 \quad 125$ & 63 & 207 & 441 & a & $=1$ & \\
\hline $170 \quad 377$ & 89 & 153 & 971 & $\mathrm{~b}$ & $=2$ & \\
\hline 129 & 792 & 9 & 641 & $\mathrm{c}$ & $=3$ & \\
\hline $181 \quad 144$ & 85 & 421 & 551 & d & $=4$ & \\
\hline $12 \quad 11$ & 84 & 19 & 7601 & e & $=5$ & \\
\hline
\end{tabular}

John Wiley \& Sons, Inc. 24 


\title{
Comparative Analysis of Germline and Somatic Micro-lesion Mutational Spectra in 17 Human Tumour Suppressor Genes
}

\author{
Dobril Ivanov ${ }^{1,2}$, Stephen E. Hamby ${ }^{3}$, Peter D. Stenson ${ }^{1}$, Andrew D. Phillips ${ }^{1}$, \\ Hildegard Kehrer-Sawatzki ${ }^{4}$, David N. Cooper ${ }^{1}$ and Nadia Chuzhanova ${ }^{3}$ \\ ${ }^{1}$ Institute of Medical Genetics, School of Medicine, Cardiff University, Cardiff, CF14 4XN, UK \\ ${ }^{2}$ MRC Centre for Neuropsychiatric Genetics and Genomics, Department of Psychological Medicine \\ and Neurology, Biostatistics and Bioinformatics Unit, School of Medicine, Cardiff University, \\ Cardiff, CF14 4XN, UK \\ ${ }^{3}$ School of Science and Technology, Nottingham Trent University, Nottingham, NG11 \\ $8 \mathrm{NS}, \mathrm{UK}$ \\ ${ }^{4}$ Institute of Human Genetics, University of Ulm, Albert-Einstein-Allee 11, 89081 Ulm, \\ Germany
}

\begin{abstract}
*All correspondence to: Prof. Nadia Chuzhanova, School of Science and Technology
Nottingham Trent University, Clifton Lane, Nottingham NG11 8NS, UK

Tel: +44 (0) $01158488304 \quad$ E-mail: nadia.chuzhanova@ntu.ac.uk
\end{abstract}




\begin{abstract}
Mutations associated with tumorigenesis may either arise somatically or can be inherited through

the germline. We performed a comparison of somatic, germline, shared (found in both soma and germline) and somatic recurrent mutational spectra for 17 human tumour suppressor genes which included missense single base-pair substitutions and micro-deletions/micro-insertions. Somatic and germline mutational spectra were similar in relation to C.G $>$ T.A transitions but differed with respect to the frequency of A.T>G.C, A.T>T.A and C.G $>$ A.T substitutions. Shared missense mutations were characterised by higher mutability rates, greater physicochemical differences between wild-type and mutant residues, and a tendency to occur in evolutionarily conserved residues and within $\mathrm{CpG} / \mathrm{CpHpG}$ oligonucleotides. Mononucleotide runs ( $\geq 4 \mathrm{bp}$ ) were identified as hotspots for shared micro-deletions/micro-insertions. Both germline and somatic microdeletions/micro-insertions were found to be significantly overrepresented within the 'indelhotspot' motif, GTAAGT. Using a naïve Bayes' classifier trained to discriminate between five missense mutation groups, $63 \%$ of mutations in our dataset were on average correctly recognized. Applying this classifier to an independent dataset of probable driver mutations, we concluded that $\sim 50 \%$ of these somatic missense mutations possess features consistent with their being either shared or recurrent, suggesting that a disproportionate number of such lesions are likely to be drivers of tumorigenesis.
\end{abstract}

Deleted: In this study

Key Words: germline and somatic mutational spectra; tumour suppressor genes; recurrent mutation; mutation hotspot; non-B DNA; driver mutations 


\section{Introduction}

A major distinction to be made between somatic and germline mutations is that the former occur during mitotic cell cycles whereas the latter are generally meiotic in origin. In addition, whilst somatic cancer-causing gene lesions come to clinical attention by conferring a growth advantage upon the affected cells or tissue, germ-line gene mutations causing inherited disease normally come to attention by conferring a disadvantage upon the individual, usually through haploinsufficiency. Finally, whereas inherited disease usually implies only one or two pathological mutations at a specific locus, cancer is often characterized by multiple somatic mutations distributed genome-wide. Those somatic mutations which confer a growth advantage on the cells in which they occur, which are positively selected for in the emerging tumour mass and which have therefore been causally implicated in tumorigenesis, are termed 'driver' mutations [Stratton et al., 2009]. By contrast, those mutations which do not confer any growth advantage and have not been subject to selection during tumorigenesis, are termed 'passenger' mutations [Stratton et al., 2009]. Such passenger mutations may arise at high frequency as a consequence either of increased genomic instability or simply due to the considerable number of cell divisions required to convert a single transformed cell into a clinically detectable tumour [Lengauer et al., 1998; Boland and Ricciardiello, 1999; Simpson 2008; Parmigiani et al. 2009; Stratton et al., 2009].

Despite these basic differences, the mutational spectra (and hence the underlying mutational mechanisms) associated with single base-pair substitutions [Krawczak et al., 1995; Schmutte and Jones, 1998; Cole et al., 2008; Lobo et al., 2009], micro-deletions and micro-insertions [Jego et al., 1993; Greenblatt et al. 1996] and gross gene rearrangements [Oldenburg et al., 2000; Kolomietz et al., 2002] in specific genes often appear to exhibit marked similarities between the germline and the soma. Further, certain triplet repeats associated with a number of inherited human conditions are known to be unstable in both the germline and somatic tissues, a finding 
which serves to explain not only the phenomenon of genetic anticipation characteristic of these disorders but also their inherent inter-individual clinical variability [Giovannone et al., 1997; Leeflang et al., 1999; Martorell et al., 2000; Sharma et al., 2002; Pollard et al., 2004]. However, by contrast, highly variable human minisatellites can display markedly different degrees of instability between the soma and the germline [Buard et al., 2000; Stead and Jeffreys, 2000; Shanks et al., 2008]. These studies notwithstanding, few attempts have so far been made to compare the nature, location and relative frequency of germline and somatic mutations.

Human cancer genes usually harbour either somatic or germline mutations [Goode et al., 2002; Futreal et al., 2004; Vogelstein and Kinzler, 2004]. There is, however, one category of cancer gene, broadly termed tumour suppressors, that by virtue of their being mutated in both the germline and the soma, provides us with an ideal model system to compare somatic vs. germline mutational spectra [Futreal et al., 2004]. Tumour suppressor genes, defined as "genes that sustain loss-of-function mutations in the development of cancer" [Haber and Harlow, 1997], are involved in the regulation of a diverse array of different cellular functions including cell cycle checkpoint control, detection and repair of DNA damage, protein ubiquitination and degradation, mitogenic signalling, cell specification, differentiation and migration, and tumour angiogenesis [Sherr, 2004]. They encode proteins with a regulatory role in cell cycle progression (e.g. Rb), DNA-binding transcription factors (e.g. p53) and inhibitors of cyclin-dependent kinases required for cell cycle progression (e.g. p16). In inherited cancer syndromes, the mutational inactivation of both tumour suppressor alleles is required to change the phenotype of the cell. This 'two hit hypothesis' provides the basis for our mechanistic understanding of tumour suppressor gene mutagenesis: a first (inherited) mutation in one tumour suppressor allele is followed by the somatic loss of the remaining wild-type allele via a number of different mutational mechanisms [Knudson, 2001]. Whereas the inherited lesion is usually fairly subtle, the second (somatic) hit may also involve the deletional loss of the entire gene or even a substantial portion of the 
chromosome involved. Alternatively, both 'hits' may constitute somatic mutations: whatever the actual mechanism, the end result is the same - the loss or inactivation of both gene copies. Some interplay may however occur between the soma and the germline in that the location of the germline mutation can in some instances influence the nature, frequency and location of the subsequent somatic mutation [Lamlum et al., 1999; Groves et al., 2002; Latchford et al., 2007; Dallosso et al., 2009; Dworkin et al., 2010].

Tumour suppressor genes are often somatically inactivated by mutational mechanisms that are almost exclusively confined to the soma and which are found only infrequently in the germline (e.g. gross mutations characterized by loss of heterozygosity, epi-mutations such as methylationmediated promoter inactivation, and micro-lesions within highly repetitive sequence elements that are consequent to microsatellite instability). However, a typical spectrum of somatic mutations associated with tumorigenesis may also include gross rearrangements, copy number variation, and various types of micro-lesion (e.g. micro-deletions, micro-insertions and indels) including single base-pair substitutions [Loeb and Harris, 2008; Stratton et al., 2009]. Although the somatic micro-lesions are often quite similar to their germline counterparts, few studies of tumour suppressor genes have so far attempted to compare and contrast germline and somatic mutational spectra with respect to these relatively subtle types of mutation. However, several such studies have indicated that germline and somatic micro-lesions can display remarkable similarities in terms of mutation type, location and relative frequency of occurrence, and hence by inference the putative underlying mechanisms of mutagenesis [Marshall et al., 1997; Ali et al., 1999; Gallou et al., 1999; Richter et al., 2003; Upadhyaya et al., 2004; Glazko et al., 2004; Tartaglia et al., 2006; Baser et al., 2006; Upadhyaya et al., 2008].

We attempt here a first formal comparison between germline and somatic micro-lesion mutational spectra for a total of 17 different human tumour suppressor genes [APC (MIM\# 611731), ATM (MIM\# 607585), BRCA1 (MIM\# 113705), BRCA2 (MIM\# 600185), CDH1 
1

2

3

4

5

6

7

8

9

10

11

12

13

14

(MIM\# 192090), CDKN2A (MIM\# 600160), NF1 (MIM\# 162200), NF2 (MIM\# 607379), PTCH1 (MIM\# 601309), PTEN (MIM\# 601728), RB1 (MIM\# 180200), STK11 (MIM\# 602216), TP53 (MIM\# 191170), TSC1 (MIM\# 605284), TSC2 (MIM\# 191092), VHL (MIM\# 608537) and WT1 (MIM\# 607102)].

\section{Materials and Methods}

Sources of germline and somatic mutation data

Data on germline and somatic micro-lesions (viz. missense mutations, micro-deletions and micro-insertions involving $\leq 20 \mathrm{bp}$ ) were collated for 17 different human tumour suppressor genes. Germline mutation data were obtained from the Human Gene Mutation Database [HGMD; http://www.hgmd.org; Stenson et al., 2009]. HGMD lists mutations for which there is direct evidence for a pathological effect but includes only one example of every lesion. Apart from this, no specific filters were applied to the available data. Somatic mutation data were compiled from a number of different sources including online somatic mutational databases viz. Catalogue of Somatic Mutations in Cancer (http://www.sanger.ac.uk/genetics/CGP/cosmic; RB1 and PTEN), the Breast Cancer Information Core (http://research.nhgri.nih.gov/bic; BRCA1), the RB1 Gene Mutation Database (http://www.verandi.de/joomla; RB1), the International NF2 Mutation Database (http://www.hgmd.cf.ac.uk/nf2; NF2), the CDKN2A Database (https://biodesktop.uvm.edu/perl/p16; CDKN2A) and the IARC TP53 Mutation Database (http://www-p53.iarc.fr; TP53), the VHL Mutations Database (http://www.umd.be/VHL/), and data privately communicated by Eamonn Maher $(V H L)$ and Gareth Evans (NF2). Additional somatic mutation data [for APC, ATM, BRCA1, BRCA2, CDH1, NF1, PTCH1, STK11, TSC1, TSC2 and WT1] were obtained by searching PubMed.

To be regarded as bona fide somatic mutations, and therefore suitable for inclusion in this analysis, reported lesions had to have been shown not only to be present in a tumour tissue but 
also to be absent from a non-tumour tissue (usually blood) from the same patient. Hence, mutational data derived from 'sporadic' patients were not included unless a non-tumour tissue had also been examined in order to exclude the possibility that the lesions detected were constitutional in origin. Depending upon the number of independent occurrences, $f$, of a given somatic or shared mutation described in the literature, these mutation types were further subdivided into two categories: recurrent mutations $(f>1)$ and non-recurrent mutations $(f=1)$. At the time this study was initiated (October 2006), the number of available germline and somatic missense mutations for each of the 17 studied tumour suppressor genes were as listed in Table 1.

The analysis reported here focussed exclusively on missense mutations and micro-deletions/ micro-insertions. Nonsense mutations in tumour suppressor genes have already been addressed in the context of a general meta-analysis of this type of lesion [Mort et al., 2008]. Indels (complex lesions representing combined micro-deletion/micro-insertions) were excluded fro the analysis owing to their paucity.

\section{Control datasets of potential mutations}

For every tumour suppressor gene examined, all possible single base-pair substitutions in the gene coding sequence that (i) could potentially have given rise to a missense mutation and (ii) were not already included in either of the corresponding observed somatic and/or germline mutational spectra, were generated. These 'potential missense mutations' were used as a control dataset.

For each tumour suppressor gene, a matching control dataset of 'potential micro-deletions' was also generated by randomly selecting a first breakpoint and then choosing the length of the simulated micro-deletion (and hence the position of the second breakpoint) by reference to the probability distribution calculated for micro-deletions (from $1 \mathrm{bp}$ to $20 \mathrm{bp}$ ) observed in the corresponding dataset of mutations. A matching dataset of micro-insertions was generated in 
similar fashion, with the sites of insertion being randomly selected. Since some of the microdeletion/micro-insertion breakpoints occurred within an intron, extended cDNA sequences comprising exons and additional flanking intronic sequence were used to generate corresponding control datasets.

\section{Grantham scores}

The 'Grantham score' or 'Grantham difference' [Grantham, 1974] measures the chemical difference between wild-type and mutated amino acid residues in terms of their side chain composition (i.e. the weight ratio of non-carbon components in end-groups or rings to carbons in side chains), polarity (i.e. basic, acidic or nonpolar depending upon side chain charge) and molecular volume.

On average, the physicochemical differences manifested by orthologous amino acid substitutions that have accumulated over evolutionary time will tend to be relatively small. By contrast, disease-causing substitutions are expected to exhibit higher Grantham scores, indicative of more dramatic physicochemical differences between the wild-type and mutated amino acid residues [Krawczak et al., 1998]. The values tabulated by Grantham [1974] were used in this study to calculate a median Grantham score for each set of missense mutations for each tumour suppressor gene.

\section{Degree of evolutionary conservation}

Amino acid residues that are highly conserved in orthologous proteins frequently represent sites of structural or functional importance. Hence, such highly conserved amino acid residues/protein regions often constitute hotspots for observed pathological mutations as a consequence of phenotype selection (rather than intrinsic mutability). To assess the degree of evolutionary conservation of those codons affected by somatic/germline mutations, orthologous tumour 
suppressor cDNA and protein sequences from different vertebrate species were retrieved from NCBI's Entrez Gene database (http://www.ncbi.nlm.nih.gov/sites/entrez?db=gene). The species used as a source of these cDNA and protein sequences are listed in Supp. Table 1 for each tumour suppressor gene/protein. ClustalX (http://www.clustal.org/) was used to align the protein sequences. A program was written to replace all amino acids in the protein alignments by cDNAderived codons, thereby avoiding the introduction of gaps within codons.

The evolutionary constraints acting upon the 17 human tumour suppressor genes at the codon level were inferred by calculating the $\frac{K a}{K a+K s}$ ratio for each codon where $K s$ and $K a$ are respectively the relative numbers of synonymous and nonsynonymous substitutions between codons in two aligned sequences [Walker et al., 1999]. If two aligned codons required more than one substitution to be transformed into each other, then the minimum number of substitutions was assumed, and the most parsimonious path was determined using a PAM100 matrix and the Nei \& Gojobori [1986] pathway method. Gaps inserted into the non-human vertebrate orthologous cDNA sequences during alignment were treated as being equivalent to a nonsynonymous substitution. Codons that were not present in the human cDNA sequence were not considered. A value representing the median level of evolutionary conservation across all codons was then derived for each mutational spectrum; the higher values correspond to less conserved genes whereas the lower values refer to more highly conserved ones.

\section{Relative mutability rates}

To assess the likelihood of observing a certain nucleotide change in a given position and in a specific context, two tabulated measures of the nearest neighbour-dependent mutation rate were employed. The first was derived from 20,200 single base-pair substitutions inferred from alignments of paired human gene/pseudogene sequences [Hess et al., 1994]. This was termed the non-disease-associated mutability rate and, since it approximates to the neutral mutation 
1

2

3

4

5

6

7

8

9

10

11

12

13

14

frequency, it should reflect the intrinsic mutability of the underlying DNA sequence. One would expect the non-disease-associated mutation rates associated with pathological mutations to be low implying that these specific substitutions are much less likely to occur as neutral substitutions.

The nearest neighbour-dependent mutation rates derived from germline single base-pair substitutions [using data from the Human Gene Mutation Database (HGMD); Stenson et al., 2009] by Krawczak et al. [1998] were used as an approximation of the disease-associated mutability rate. This mutation rate is a function of selection for loss of biological function as well as the underlying intrinsic mutability of the DNA sequence. This mutability rate varies between 0.032 for the $\mathrm{C}(\mathrm{A}>\mathrm{T}) \mathrm{G}$ mutation and 13.023 for the $\mathrm{C}(\mathrm{G}>\mathrm{A}) \mathrm{G}$ mutation [Krawczak et al., 1998].

\section{Repetitive sequence elements}

A variety of repetitive sequence elements have been reported in association with human gene mutations causing both inherited disease and cancer. Direct and inverted repeats and symmetric elements [see Chuzhanova et al. 2003 for definitions] of length $\geq 8 \mathrm{bp}$, and less than $21 \mathrm{bp}$ apart, capable of forming non-B DNA structures, were therefore sought within the extended cDNA sequences (comprising exons and up to \pm 85 bp of flanking sequence) using purposely designed software. In addition, DNA sequences were screened for the presence of mononucleotide runs of $\geq 4 \mathrm{bp}$.

\section{Mutation descriptors}

Each missense mutation was ascribed various descriptors indicating (a) the type of mutation [i.e. shared mutation (i.e. found to occur both somatically and in the germline); exclusively somatic; exclusively germline; shared recurrent mutation (i.e. found to occur not only in the germline but 
also somatically on more than one occasion; somatic recurrent mutation (recorded in the soma more than once, but not in the germline); potential mutation (as defined above)] and (b) its location [i.e. $\mathrm{C} \rightarrow \mathrm{T}$ and $\mathrm{G} \rightarrow \mathrm{A}$ within a $\mathrm{CpG}$ dinucleotide or within a $\mathrm{CpHpG}$ trinucleotide (where $\mathrm{H}=\mathrm{A}, \mathrm{C}$ or $\mathrm{T}$ ) or in a repeat sequence (as described above)]. Mutations that have been reported as being exclusively somatic or exclusively germline will henceforth be referred to simply as 'somatic' and 'germline', respectively. The shared mutations, comprising the overlap between the somatic and germline mutations, may be visualized in the form of a Venn diagram (Figure 1). All somatic missense (including shared) mutations were further described as being either recurrent or non-recurrent (in the soma, see above; Figure 1). No such division was made for the relatively small number of recurrent micro-deletions and micro-insertions available; both recurrent and non-recurrent somatic mutations were therefore included in either the somatic or the shared datasets and labelled accordingly (Figure 1).

All micro-lesions (viz. missense mutations, micro-deletions and micro-insertions) in each gene were also labelled with respect to their occurrence within a region spanning a repetitive element or mononucleotide run including $\pm 5 \mathrm{bp}$ of flanking sequence. If a missense mutation (or at least one micro-deletion/micro-insertion breakpoint) was found to occur within this extended region, the micro-lesion was labelled as being found in association with the corresponding type of repeat.

Assessing the statistical significance of the results generated

To assess the similarity (or dissimilarity) of the germline and somatic mutational spectra with respect to (i) the frequency with which the missense mutations were located within $\mathrm{CpG} / \mathrm{non}$ $\mathrm{CpG}$ dinucleotides or $\mathrm{CpHpG} / \mathrm{non}-\mathrm{CpHpG}$ trinucleotides and (ii) the frequency with which the micro-deletions/micro-insertions were found within/outwith repeats, the various non-overlapping mutation datasets (bearing specific descriptors) were compared by means of the $\chi^{2}$ test. Since the 
1

2

3

4

5

6

7

8

9

10

11

12

13

14

15

16

17

18

19

20

21

22

23

24

25

26

27

28

29

30

31

32

33

34

35

36

normality assumption did not hold for the datasets studied, the Wilcoxon rank-sum test was used to compare and contrast missense mutational spectra with respect to the Grantham score, degree of evolutionary conservation, and both the non-disease- and disease-associated mutability rates.

The permutation-based method [Olshen and Jain, 2002] was used to estimate the significance of our findings and to allow for multiple testing wherever appropriate. For each comparison, the null hypothesis [viz. no overall difference between two groups of mutations (e.g. somatic and potential) with respect to the specific property in question (e.g. occurrence in $\mathrm{CpG}$ or non- $\mathrm{CpG}$ nucleotides)], was tested for, either in the context of each gene or all genes combined. $\chi^{2}$ or ranksum statistics were calculated for the observed germline and somatic mutations as well as for 10,000 control sets of mutations created from the original sets by random permutation of the assigned mutational descriptors (e.g. randomly chosen mutations labelled as 'somatic' were relabelled as 'germline'; randomly chosen mutations labelled as 'shared' were re-labelled as 'somatic', etc.). The test statistic ( $\chi^{2}$ or rank-sum) for the original datasets that exceeded the 95 th percentile of $\chi^{2}$ maxima for 10,000 control sets was deemed to be statistically significant; the corresponding p-value was termed the 'gene-wise' p-value. To allow for multiple testing in those cases where specific mutations in all genes were combined, a Bonferroni correction was applied; the corresponding $\mathrm{p}$-value was termed the 'experiment-wise' $\mathrm{p}$-value.

Power calculations for the $\chi^{2}$ tests were performed using the Pwr.Chisq.test package, part of the R Statistical Language (http://cran.r-project.org/). A data based simulation method [Walters 2004] was used to perform power calculations for the Wilcoxon rank-sum tests. Only results showing $\geq 80 \%$ power to detect experiment- or gene-wise significance were reported.

Naïve Bayes classifier

A decision tree classifier known as a Naïve Bayes tree [NBTree; Kohavi, 1996], implemented in the Weka machine learning package [Witten and Frank, 2005], was trained to discriminate 
between somatic, germline, shared, recurrent somatic and recurrent shared missense mutations.

Each mutation was described by a total of six features including the degree of evolutionary

conservation, the non-disease-associated and disease-associated relative mutability rates,

Grantham score, and occurrence in $\mathrm{CpG} / \mathrm{CpHpG}$, non-CpG/non-CpHpG doublets/triplets or in repeats/mononucleotide runs. Ten-fold cross-validation was used to assess the accuracy of classification. The mutation datasets were balanced using random oversampling [Kotsiantis et al., 2006] by replicating random instances from the minority classes until all classes were represented by the same number of instances as the majority class.

\section{Results and Discussion}

The availability of both germline and somatic mutational spectra from tumour suppressor genes provides us with an ideal opportunity to study the nature of mutation of the same gene sequences in both the germline and the soma. The analysis reported here explores for the first time the similarities and differences exhibited by the germline, somatic (and shared) micro-lesion mutational spectra in 17 human tumour suppressor genes. The study presented here focussed upon missense mutations and micro-deletions as well as micro-insertions. Nonsense mutations in tumour suppressor genes have already been addressed elsewhere in the context of a general meta-analysis of this type of lesion [Mort et al., 2008].

\section{Characteristics of germline and somatic missense mutations with respect to mutation type}

Taken together, the combined mutational spectra for all 17 tumour suppressor genes containe $C D K N 2 A, N F 2, P T E N$ and $T P 53)$, twice as many somatic $(61 \%)$ as germline $(31 \%)$ mutations. Further details are provided in th predominance of somatic over germline mutations was noted, with the TP53 gene Supplementary Text online, having the highest proportion of somatic mutations $(92 \%)$. For the majority of genes, however (namely ATM, BRCAI, BRCA2, CDH1, NF1, PTCH1, RBI, STK11, TSC1, TSC2, VHL and WT1), the analysed dataset included more germline than somatic mutations, with $>97 \%$ of all mutations in the BRCA1,NF1, TSC2 and $W T l$ genes being germline in origin. 
Shared mutations are of particular interest because identical mutational mechanisms operating in the germline and the soma may be inferred for such lesions. The expected number of shared mutations for each gene was calculated as $p_{\text {somatic }} \times p_{\text {germline }} \times($ total number of mutations $)$, where $p$ denotes the relative frequencies of somatic and germline mutations. Although the proportion of shared mutations varies markedly between genes (from $0 \%$ to $25 \%$ of the total), only two genes (TP53 and VHL) were found to have a higher than expected number of shared mutations as calculated above.

\section{Patterns of germline and somatic missense mutations by mutation type}

Missense mutations were characterised by a predominance of transitions over transversions (Figure 2). The transition:transversion ratio was at its highest for shared recurrent mutations (3.5) and shared non-recurrent mutations (2.7). By contrast, the transition:transversion ratio for the control group (i.e. potential mutations) was 0.85 . Significant differences in the transition:transversion ratio were observed between all mutation types $(\mathrm{p}<0.05)$ with the exception of germline vs. shared mutations (Figure 2).

Not surprisingly, a strong positive correlation was noted between somatic and shared mutational spectra (Pearson's correlation $r=0.986, p=2.91 \times 10^{-4}$ ) with respect to the frequencies of six mutational changes viz. A.T>C.G, A.T>G.C, A.T>T.A, C.G>A.T, C.G>G.C and C.G>T.A. Weaker negative correlations were found between somatic mutations and the control dataset of mutations $(\mathrm{r}=-0.887, \mathrm{p}=0.019)$ and between the shared and control $(\mathrm{r}=-0.837$, $\mathrm{p}=0.038$ ) mutational spectra, indicative of the non-randomness of somatic mutation.

C.G>T.A transitions constituted the most frequent type of mutation in shared (46\%), germline (29\%) and somatic (25\%) mutational spectra, significantly higher proportions than noted in the spectrum of mutations within our control dataset $(13 \%, \mathrm{p}<0.001)$ (Figure 2). Intriguingly, the number of A.T $>$ G.C mutations was significantly higher (28\%) in the germline as compared to 
the somatic (16\%), shared (17\%) and control (16\%) mutational spectra (Figure 2). A.T>C.G mutations were significantly under-represented in the shared mutational spectrum $(7 \%, \mathrm{p}<0.001)$ as compared to the other spectra whereas A.T $>$ T.A mutations were under-represented (7\%, $\mathrm{p}<0.001)$ in both the germline and shared mutational spectra compared to both somatic and potential mutations (Figure 2). Finally, C.G >A.T mutations were significantly underrepresented in the germline mutational spectrum $(10 \%)$ as compared to the somatic $\left(16 \%, \mathrm{p}=1.2 \times 10^{-5}\right)$ and potential $\left(15 \%, \mathrm{p}=2.6 \times 10^{-5}\right)$ spectra. Thus, the main similarity between the somatic and germline missense mutational spectra was in relation to C.G $>$ T.A transitions whereas the main differences between these spectra involved the A.T>G.C, A.T>T.A and C.G>A.T mutations. In passing, it should be noted that the patterns of somatic nucleotide substitution exhibited by the 17 tumour suppressor genes studied here were markedly different from the genome-wide patterns of somatic nucleotide substitution observed in various cancer genome sequencing studies [Sjöblom Deleted: previously et al., 2006; Greenman et al., 2007; Kan et al., 2010]; these mutation datasets are likely to differ quite dramatically with respect to their relative proportions of 'passenger' mutations.

\section{$C p G$ - and $C p H p G$-located missense mutations}

The CpG dinucleotide is a well known mutational hotspot in the human genome as a consequence of the spontaneous (and endogenous) deamination of 5-methylcytosine. In addition, Lister et al. [2009] reported abundant DNA methylation in $\mathrm{CpHpG}$ trinucleotides in the human genome, where $\mathrm{H}$ is either $\mathrm{A}, \mathrm{C}$ or $\mathrm{T}$, raising the possibility that $\mathrm{CpHpG}$ might also be a generalized mutation hotspot [Cooper et al., 2010].

The proportion of missense mutations that were either $\mathrm{C}>\mathrm{T}$ or $\mathrm{G}>\mathrm{A}$ within $\mathrm{CpG}$ or $\mathrm{CpHpG}$ oligonucleotides in the 17 tumour suppressor genes was found to vary between $0 \%$ and $100 \%$ (Table 2). This wide range in values may be attributed to the small size of some of the gene mutation datasets under study. Importantly, the $\mathrm{CpG}$ and $\mathrm{CpHpG}$ oligonucleotides were found to 
be disproportionately likely to harbour shared mutations; thus, $34 \%$ of shared recurrent mutations and $21 \%$ of shared non-recurrent mutations were $\mathrm{C}>\mathrm{T}$ and $\mathrm{G}>\mathrm{A}$ mutations in $\mathrm{CpG}$ dinucleotides with an additional $10 \%$ and $9 \%$ of mutations, respectively, occurring within $\mathrm{CpHpG}$ trinucleotides. Since driver mutations tend to occur disproportionately frequently within CpG dinucleotides [Talavera et al., 2010], we postulate that missense mutations identified as being shared are highly likely to be driver mutations.

Significant differences were noted between the relative frequencies of $\mathrm{CpG}$ - and $\mathrm{CpHpG}$ located mutations for somatic, germline, shared, somatic recurrent and shared recurrent missense mutations (Supp. Table 2).

We have previously shown that $18.2 \%$ and $9.9 \%$ of all missense/nonsense mutations recorded in the HGMD are $\mathrm{C}>\mathrm{T}$ and $\mathrm{G}>\mathrm{A}$ transitions in $\mathrm{CpG}$ and $\mathrm{CpHpG}$ oligonucleotides respectively [Cooper et al., 2010]. In the present study, we observed that the mutational spectra of shared and shared recurrent missense mutations in tumour suppressor genes were both found to be significantly enriched in CpG-located mutations ( $\chi^{2}$-test; p-values, 0.028 and $1.1 \times 10^{-9}$ respectively). This implies that the $\mathrm{CpG}$ dinucleotide is a generalized mutation hotspot in both the soma and the germline as a consequence of the endogenous mutational mechanism of methylation-mediated deamination of 5-methylcytosine. By contrast, the number of CpG-located mutations was significantly underrepresented $\left(\chi^{2}\right.$-test; $p$-values $\left.<5 \times 10^{-14}\right)$ in the other mutational spectra (i.e. non-recurrent somatic, somatic recurrent and germline mutations) by comparison with HGMD data. To perform these comparisons, missense mutations (Table 2) and nonsense mutations [previously reported in Mort et al., 2008; see Table 6 therein] in all 17 tumour suppressor genes were combined. The proportion of shared recurrent missense mutations in tumour suppressor genes that were $\mathrm{CpHpG-located} \mathrm{was} \mathrm{found} \mathrm{to} \mathrm{be} \mathrm{significantly} \mathrm{higher}$ $(\mathrm{p}=0.023)$ than for mutations recorded in the HGMD whereas $\mathrm{CpHpG-located} \mathrm{somatic} \mathrm{and}$ recurrent somatic mutations were significantly under-represented $\left(\mathrm{p}<4 \times 10^{-10}\right)$. Significant 
enrichment in $\mathrm{CpHpG}$-located mutations was observed for germline mutations as compared to somatic mutations $\left(\mathrm{p}<3 \times 10^{-10}\right)$ consistent with the reported decrease in $\mathrm{CpHpG}$ methylation in differentiated cells [Lister et al., 2009]. In summary, germline and shared missense mutations were found to be significantly enriched at $\mathrm{CpG}$ and $\mathrm{CpHpG}$ oligonucleotides.

The numbers of somatic and shared $\mathrm{C}>\mathrm{T}$ and $\mathrm{G}>\mathrm{A}$ transitions recorded within $\mathrm{CpG}$ dinucleotides for each gene (Table 2) did not correlate with the numbers of $\mathrm{CpG}$ dinucleotides found in these genes $(r<-0.5, \mathrm{p}>0.127)$ and hence do not simply reflect intragenic $\mathrm{CpG}$ frequency. A weak positive correlation between CpG-located mutations and the number of genic $\mathrm{CpG}$ dinucleotides was however noted for germline mutations $(\mathrm{r}=0.489, \mathrm{p}=0.046)$ indicating that $\mathrm{CpG}$ methylation is not entirely unrelated to the number of $\mathrm{CpG}$ dinucleotides, at least with respect to the germline; the relationship is however clearly more complex in the soma, possibly due to inter-tissue differences in gene methylation patterns [Tornaletti and Pfeifer, 1995] or transcription-coupled repair [Rubin and Green, 2009].

No correlation was found between the numbers of somatic, germline and shared mutations recorded within $\mathrm{CpHpG}$ trinucleotides and the corresponding numbers of $\mathrm{CpHpG}$ trinucleotides for these genes ( $r=-0.316,0.373,-0.414$; p-values $0.281,0.216$ and 0.098 , respectively) indicating that mutation within $\mathrm{CpHpG}$ trinucleotides is likely to be very much a gene-specific phenomenon (presumably dependent on both the extent and the degree of spatial localization of $\mathrm{CpHpG}$ methylation in the germline and/or soma).

Finally, the number of $\mathrm{CpG}$ dinucleotides in the various tumour suppressor genes studied (Table 2) was not found to correlate with gene length $(r=0.3$, p-value $=0.241)$. By contrast, we found a significant correlation $\left(r=0.885, \mathrm{p}\right.$-value $\left.=2.35 \times 10^{-6}\right)$ between tumour suppressor gene length and the number of $\mathrm{CpHpG}$ trinucleotides (excluding those with mutations), indicating that the tumour suppressor genes under study possess a similar density of $\mathrm{CpHpG}$ trinucleotides per 
1

2

3

4

5

6

7

8

9

10

11

12

13

14

unit length. We surmise that the factors that govern the establishment of the methylation pattern of $\mathrm{CpHpG}$ trinucleotides are likely to be quite complex.

\section{Evolutionary conservation of tumour suppressor genes in relation to the sites of somatic and} germline missense mutations

For all 17 tumour suppressor genes, the degree of evolutionary conservation, as measured by $\mathrm{Ka} / \mathrm{Ks}$, was less than unity, indicating that these genes (and proteins) have been highly conserved evolutionarily as a consequence of the action of purifying selection. Indeed, the degree of evolutionary conservation displayed by most of the studied genes was markedly lower than the average ( 0.18) noted in a comparison of 1880 human, rat and mouse gene orthologues [Makalowski and Boguski, 1998]. However, three genes (CDKN2A, BRCA1 and BRCA2) were found to exhibit a higher rate of evolutionary conservation than the average between human and rodents.

The evolutionary conservation of each mutated codon was inferred by calculating the $\frac{K a}{K a+K s}$ ratio; for each gene/spectrum, the mean value was then calculated across all mutations in the corresponding gene/spectrum. Shared recurrent missense mutations were found to occur disproportionately in highly conserved amino acid residues (mean degree of evolutionary conservation, 0.072$)$ followed by shared non-recurrent mutations (0.138), somatic recurrent (0.169), germline (0.175), non-recurrent somatic (0.265), and control dataset mutations $(0.255)$. The observed differences in the degree of evolutionary conservation for the different mutational spectra are shown in Supp. Table 2. These quite specific findings are consistent with the previously reported general tendency for cancer-associated mutations to occur frequently at evolutionarily conserved sites [Greenblatt et al., 2003; Tavtigian et al., 2009; Talavera et al., 2010]. 
Somatic non-recurrent mutations were found to occur in codons characterized by the highest mean value of $\frac{K a}{K a+K s}$ ratios as compared not only to the shared recurrent and shared nonrecurrent mutations (see above) but also to the mutations within the control dataset. This is consistent with the interpretation that a high proportion of non-recurrent somatic mutations, and most notably those which are located in less evolutionarily conserved regions (characterised by higher values of the degree of evolutionary conservation), are likely to be 'passenger' mutations.

\section{Missense mutations in relation to the disease-and non-disease-associated substitution rates}

Employing alignments of paired human gene/pseudogene sequences, Hess et al. [1994] derived relative (non-disease-associated) nearest-neighbour-dependent mutability rates using the lowest frequency substitution type, $\mathrm{C}(\mathrm{T}>\mathrm{G}) \mathrm{A} / \mathrm{T}(\mathrm{A}>\mathrm{C}) \mathrm{G}$, as a baseline. These mutability rates were found to vary over a 52-fold range, with unity being assigned to the lowest frequency substitution type. This non-disease-associated mutability rate approximates to the neutral mutation frequency and hence reflects the intrinsic mutability of the underlying DNA sequence. Depending upon the observed nearest-neighbour context, we retrieved the corresponding nondisease-associated mutability rate (from the data of Hess et al. 1994) for each mutation (either observed or from the control dataset) and calculated the median value for each mutational spectrum. These median values are indicative of the relative mutability of each tumour suppressor gene. Further details are provided in the Supplementary Text online,

When data from all 17 genes were combined, shared recurrent mutations were found to be characterised by intrinsically low non-disease-associated mutability (median=11), followed b even lower median mutability values for shared non-recurrent mutations (7.9), germline Deleted: The median values were found to vary between 4 (NF2) and 8.9 (STK11) for somatic mutations, 4.1 (TP53) and $10.1(W T I)$ for germline mutations, and $7.2(R B I)$ and $11(P T E N)$ for shared mutations (values given only for genes with more than three mutations in the corresponding category; see Supp. Table 3 , indicating that many of the median values are quite low and hence the corresponding mutations are unlikely to be neutral.II mutations (7.2), somatic recurrent and non-recurrent (4.7) and control dataset mutations (4.1). Such low median mutability values across all groups indicates that at least half of the mutations within observed triplets are unlikely to be neutral in the sense defined by Hess et al. [1994] and 
hence are not simply explicable in terms of intrinsic DNA mutability. The low median mutability values for the control dataset of mutations within tumour suppressor genes reflect the high level of evolutionary conservation manifested by tumour suppressor gene coding sequences across different species, implying that any mutation within a triplet characterized by a low non-diseaseassociated mutation rate is very likely to have pathological consequences and would thus be subject to purifying selection.

In contrast to the non-disease-associated mutability rate (which is purely a reflection of the intrinsic DNA mutability), the disease-associated mutability rate reflects (in addition to the intrinsic DNA mutability) the increased likelihood of coming to clinical attention conferred by the loss of biological function. The $\mathrm{C}(\mathrm{G}>\mathrm{T}) \mathrm{T}$ mutation is one of the most frequent types of mutation associated with the loss of biological function [disease-associated mutability rate 10.255; Krawczak et al., 1998] but occurs much less frequently among neutral mutations [nondisease-associated mutability rate 4.4; Hess et al., 1994].

For each tumour suppressor gene and each mutational spectrum, the disease-associated median mutability values were calculated using mutability rates derived from Krawczak et al. [1998]. The disease-associated median value was found to be 0.85 for the germline mutations. Further details are provided in the Supplementary Text online. We found that shared recurrent and shared non-recurrent mutational spectra were characterized by higher median values of the disease-associated mutability rates (1.42 and 1.01 respectively) whereas somatic non-recurrer

Deleted: The highest and lowest disease-associated median values for the mutation rates were noted for somatic mutations in the STK11 gene (1.7; Supp. Table 3 ) and for germline mutations in the TP53 (0.42) gene (values given only for genes with more than three mutations in the corresponding category). somatic recurrent and control dataset mutations exhibited lower median mutability rates $(0.5,0.5$ and 0.4 respectively) as compared to germline mutations (0.85). The finding that the shared mutations (which, by definition, occur in both the germline and the soma) are characterized by higher disease-associated mutability rates is not surprising since mutations that occur with the highest probability are among those most likely to be shared. 
We postulated that those mutations which occur both in the germline and the soma, and which are characterised by higher disease-associated mutability rates are disproportionately likely to be drivers of tumour development. Consistent with this postulate, somatic recurrent and nonrecurrent mutational spectra are characterized by lower median disease-associated mutability rates as compared to the germline spectrum. However, given that higher disease-associated mutability rates are a characteristic feature of driver mutations, a certain proportion of the somatic mutations, namely those characterised by higher disease-associated mutability rates, may correspond to functionally significant driver mutations.

In assessing the significance of our results, it was appropriate to consider the possibility that somatic mutations might display quite different nearest-neighbour-dependent disease-associated mutability rates from germline mutations. However, since a good correlation was observed between the mutability rates derived from inherited disease data [Krawczak et al., 1998] and the neighbour-dependent mutability rates calculated for the somatic mutations of the 17 tumoursuppressor genes studied here (Pearson's correlation $\mathrm{r}=0.703, \mathrm{p}=6.6 \times 10^{-30}$ ), this caveat appears not to be an issue.

\section{Distribution of Grantham scores with respect to tumour suppressor gene mutations}

Shared recurrent mutations were found to exhibit the largest median chemical difference value (Grantham scores) between the wild-type and mutated amino acid residues (100) followed by shared non-recurrent mutations and germline mutations (both 93), somatic recurrent (85), somatic non-recurrent (80) and potential mutations (78). Since there was an obvious trend for shared recurrent and non-recurrent mutations to cause the most dramatic chemical changes of the affected codon, we may infer that these types of lesion are also more likely to be driver mutations. However, bearing in mind that the range of theoretically possible values varies between 5 (Leu $\leftrightarrow$ Ile) and 215 (Cys $\leftrightarrow$ Trp), less elevated median values may simply indicate 
that a proportion of the mutations in each mutational spectrum are likely to be chemically less dramatic (Grantham scores $<100)$.

\section{Missense mutations occurring within repeats and runs of identical nucleotides}

A number of studies have noted that single base-pair substitutions associated with inherited disease occur disproportionately either within, or in close proximity to, repetitive sequences [Jego et al., 1993; Greenblatt et al., 1996; Tappino et al., 2009; Thomas et al., 2010; Leclercq et al., 2010]. Hence, we wished to assess whether either germline or somatic mutations occurred disproportionately either within, or in the vicinity (see Mutation descriptors) of, direct, inverted and symmetric repeats or mononucleotide runs in the 17 tumour suppressor genes under study (Table 3, Supplementary Tables 4-6).

On average, direct repeats of length $\geq 8$ bp were found to cover $5.6 \%$ of the cDNA lengths of the 17 tumour suppressor genes. Further details are provided in the Supplementary Text ońlin $\begin{aligned} & \text { Deleted: the coverage varying } \\ & \text { between } 2.5 \% \text { (BRCA2) and } 17 \% \text { (PTEN) } \\ & \text { of the respective gene sequences. The } \\ & \text { On averasponding proportion of the cDNA } \\ & \text { lengths for inverted repeats } \geq 8 \text { bp was } \\ & 85 \% \text { with }\end{aligned}$

Deleted: the coverage varying between $2.5 \%$ (BRCA2) and $17 \%(P T E N)$ of the respective gene sequences. The corresponding proportion of the cDNA $24 \%$ of non-recurrent somatic and $20 \%$ of germline missense mutations were found in $8.5 \%$, with proportions varying between $P T C H I(4.5 \%)$ and $R B I(15.7 \%)$ while mononucleotide runs; these proportions were significantly higher than noted for shared nonsymmetric elements $\geq 8$ bp were found to encompass $25 \%$ of the cDNA lengths (varying between $15.5 \%$ for $A P C$ and recurrent misense mutations $\left(4.9 \%, \mathrm{p} \leq 1.6 \times 10^{4}\right)$. A geate poporion of non recurrent missense mutations $\left(4.9 \%, \mathrm{p} \leq 1.6 \times 10^{-4}\right)$. A greater proportion of non-recurrent somant Deted: , varying between $9.5 \%(V H L)$ missense mutations was found in direct repeats (7\%) as compared to recurrent somatic missense mutations $\left(2 \%, \mathrm{p}=8.8 \times 10^{-7}\right)$, germline missense $(4 \%, \mathrm{p}=0.028)$ and potential missense mutations $\left(3.7 \%, \mathrm{p}=8.1 \times 10^{-7}\right)$. This result may reflect the disproportionate number of $\mathrm{CpG} / \mathrm{CpHpG}$ mutations among shared and recurrent somatic missense mutations. Further, for all mutational spectra examined (with the exception of the shared mutations), missense mutations were preferentially found in association with inverted and symmetric repeats as compared to the control dataset of mutations $(\mathrm{p}<0.05)$. However, no statistically significant differences were found between mutational spectra. Further details are provided in the Supplementary Text online. 
Towards a classification of somatic and germline missense mutations

Deleted: No correlation was observed between the number of mutations located within repeats and the fractional length of the cDNA covered by repeats, indicating that not every repeat sequence is

mutation-prone. However, a strong correlation between the fractional length

All observed mutations within each mutational spectrum were re-categorized (Supp. Table 7) of the cDNA covered by repeats and with respect to the location of mutations within $\mathrm{CpG} / \mathrm{CpHpG}$ oligonucleotides, within differe $\begin{gathered}\text { sensity per unit length was approximately } \\ \text { the same for all tumour suppressor genes }\end{gathered}$ types of repeat/mononucleotide runs, within both $\mathrm{CpG} / \mathrm{CpHpG}$ oligonucleotides and repeats. $4 \times 2$ the same for all tumour suppressor genes
studied. If contingency tables were then used to measure the strength of the pairwise associations between the various mutational distributions presented in Supp. Table 7, the significance of the associations being assessed by means of a Chi-square test. Significant $(\mathrm{p}<0.002)$ pairwise differences were noted between somatic and germline, somatic and shared, and between germline and shared mutational spectra $(\mathrm{p}<0.002)$ with respect to the features listed above and each of four types of repeat, indicating that these features have great discriminant potential.

All somatic, germline, shared non-recurrent, recurrent somatic and shared recurrent missense mutations (each described by a combination of different features (i.e. degree of evolutionary conservation, non-disease- and disease-associated mutability rates, Grantham score, $\mathrm{CpG} / \mathrm{CpHpG}$ location, occurrence within repeat/mononucleotide run) were then used to train a Naïve Bayes Tree classifier. On average, $63.1 \%$ of somatic, germline, shared, recurrent somatic and shared recurrent mutations were correctly classified [the area under the Receiver Operating Characteristic (ROC) curve being 0.869 , indicating a reasonably good classification] with $71 \%$ and $75 \%$ respectively of shared and shared recurrent mutations being correctly recognized implying that the mutation groupings differ with respect to the different features in a consistent fashion. One would expect $20 \%$ of mutations to be assigned to each of the five groups by chance alone. Indeed, the average percentage did not exceed $20 \%$ when randomly selected datasets matching the number of somatic, germline, shared, recurrent somatic and shared mutations were drawn from the set of potential mutations; the average was taken over 10 matching datasets. The complete Naïve Bayes Tree classifier is depicted in Supp. Figure 1. 
1

2

3

4

5

6

7

8

9

10

11

12

13

14

An additional non-overlapping dataset of 568 missense somatic mutations, identified in the 17 tumour suppressor genes under study, were extracted from a collection of 2,488 mutations identified as being probable driver mutations [Carter et al., 2009]. Features such as the degree of evolutionary conservation, Grantham score, mutability rates, $\mathrm{CpG} / \mathrm{CpHpG}$ location, occurrence within repeats/mononucleotide runs were again determined for each of these mutations. Employing our classifier, $7 \%$ and $10 \%$ respectively of these 568 mutations were found to possess features consistent with their being shared recurrent and shared non-recurrent mutations. In addition, $32 \%$ of these probable driver mutations were found to bear features characteristic of recurrent somatic mutations (i.e. mutations documented in different tumours). A further $25 \%$ of the probable (somatic) driver mutations were classified as possessing features characteristic of germline mutations and hence could conceivably be treated as shared mutations missing from the original training dataset. The remaining $25 \%$ of mutations were classified as non-recurrent somatic mutations. Using this classifier, which is based on a very modest number (6) of predictive features, to analyse an independent dataset of probable driver mutations, we were able to predict that $\sim 50 \%$ of these somatic missense mutations exhibited features specific to either shared or recurrent mutations, indicating that a disproportionate number of such lesions are likely to be drivers of tumorigenesis. This percentage is certainly lower (79\%) than that obtained by Carter et al., [2009] through the application of a Random Forest Classifier based on 500 trees and $>50$ predictive features (using an 'out-of-the-bag' error estimate similar to the cross-validation procedure) to the set of putative 2,488 driver mutations. However, based on the results of this study, we may conclude that, in general, the mutational spectrum of driver mutations is likely to contain a disproportionate number of somatic mutations that have germline counterparts $(\sim 17 \%)$ whilst an additional $32 \%$ of the driver mutations are likely to occur recurrently in the soma. 
Occurrence of micro-deletions and micro-insertions within repeats and runs of identical nucleotides

The mutational spectrum of micro-deletions, combined for all 17 tumour suppressor genes, comprised $55 \%$ germline, $43 \%$ somatic and $2 \%$ shared mutations. The mutational spectrum micro-insertions was similar to that of micro-deletions and comprised $60 \%$ germline, $38 \%$ somatic and $2 \%$ shared mutations. Approximately $77 \%$ somatic, $87 \%$ germline and $91 \%$ shar micro-deletions and micro-insertions were $\leq 4$ bp in length. Strong $(r=\sim 1)$ correlations were noted between the distributions of micro-deletions and micro-insertions with respect to the le of the deleted/inserted fragments, both gene-wise and for all genes combined $\left(r>0.9, \mathrm{p}<10^{-8}\right)$ for all mutational spectra.

Recent studies have revealed that simple repetitive DNA sequences are not only capable of adopting non-B DNA conformations and are highly mutagenic [Bacolla et al., 2004; Bacolla and Wells, 2004; Chuzhanova et al., 2009]. Indeed, both direct repeats and mononucleotide runs have long been known to be mutation hotspots in the TP53 gene [Jego et al., 1993; Greenblatt et al., 1996]. The number of micro-lesions occurring in the vicinity (see Mutation descriptors) of direct, symmetric and inverted repeats (capable respectively of slipped, triplex and cruciform non-B structure formation), or within mononucleotide runs (which often mediate microdeletions/micro-insertions) were therefore determined. The number of mutations found in the vicinity of all three types of repeat, and within mononucleotide runs, are given in Tables 3 and Supp. Tables 4-6.

The highest proportion of mutations in mononucleotide runs was found for the shared (39\%), germline (30\%) and somatic (25\%) mutational spectra. Significant differences were observed between shared and germline $(\mathrm{p}=0.0002)$, somatic and shared $(\mathrm{p}=0.045)$, and between all mutational spectra and potential mutations $(\mathrm{p}<0.0001)$ with respect to their occurrence within mononucleotide runs, confirming that these simple repeats constitute an important hotspot for 
micro-deletions and micro-insertions in both the soma and the germline. The preponderance of such mutations in mononucleotide runs is unsurprising in the context of the shared mutations since all mutations that occur with high frequency within mutation hotspots are more likely to be shared between the germline and the soma (as previously noted for $\mathrm{CpG}$ and $\mathrm{CpHpG}$ mutations). No other types of repeat were disproportionately associated (after correction for multiple testing) with micro-deletions and micro-insertions.

\section{$\underline{\text { Regional hotspots in somatic and germline mutational spectra }}$}

For the purposes of the following analysis, a regional mutation hotspot was defined as a stretch of DNA of length $\leq 20 \mathrm{bp}$ where four or more independent mutational events have been reported and a significant degree $(\mathrm{p} \leq 0.05)$ of clustering of these mutations was evident for a given stretch of DNA. In this definition of a regional hotspot, each recurrent mutation was considered only once. The order statistics, r-scans, as described by Karlin and Macken [1991] and applied in Bacolla et al. [2006], were used to detect significant clustering of mutations by comparison with a Poisson distribution of mutations along the gene sequence. Overlapping hotspot regions were considered as a single regional hotspot.

The only regional mutational hotspot for somatic missense mutations was observed in the PTEN gene and comprised 18 mutations in the region between nucleotide positions 269 and 286. Several germline regional mutational hotspots were however detected for missense mutational spectra in the ATM, BRCA1, BRCA2, NF1, PTEN, RB1, STK11, TP53 and WT1 genes (Table 4). Several somatic regional mutational hotspots were found for micro-deletions/micro-insertions in the APC gene, the largest of which contained 33 mutations (positions 4303-4398) and forms part of a previously reported mutation cluster region [Miyoshi et al., 1992]. Regional hotspots identified in different mutational spectra were however unique to that spectrum. The only overlap noted between regional mutational hotspots identified in germline and somatic micro- 
deletion/micro-insertion mutational spectra was observed for the $A P C$ gene (the overlapping region comprising nucleotide positions 3919-3933). This micro-deletion/micro-insertion hotspot also includes codon 1309 (cDNA positions 3925-3927) found to be frequently mutated in Greek and French patients with familial adenomatous polyposis [Fostira et al. 2010; Lagarde et al. 2010].

Inspection of regional hotspot sequences revealed that they are rich in repetitive elements, runs of identical nucleotides and $\mathrm{CpG} / \mathrm{CpHpG}$ oligonucleotides, offering immediate explanations for the elevated mutability.

\section{Germline and somatic mutations located within specific hotspot motifs}

The cDNA sequences of 17 tumour suppressor genes were screened for the presence of nine specific motifs (and their complements) previously reported as being hotspots for mutation. These motifs included the putative somatic (cancer) mutation hotspot, WKVNRRRNVWK [the 'THEMIS motif'; Makridakis et al., 2009], the RGYW motif that correlates with the DNA polymerase eta error spectrum [Rogozin et al., 2001] and several so-called 'super hotspot' motifs originally found in germline micro-insertions and micro-deletions [Ball et al., 2005] and indels [Chuzhanova et al., 2003]. For the purposes of this analysis, the shared mutations were added to both the germline and somatic mutational spectra. Both germline and somatic micro-deletions and micro-insertions were found to be significantly overrepresented $(\mathrm{p} \leq 0.002)$ in the 'indel super hotspot' motif GTAAGT and its complement. Somatic micro-deletions and micro-insertions were also significantly overrepresented $(\mathrm{p}=0.009)$ with respect to the micro-deletion/microinsertion super hotspot AAATCT and its complement. The number of germline (but not somatic) micro-deletions/micro-insertions in the THEMIS motif were significantly overrepresented $(\mathrm{p}=0.003)$ as compared to the controls. No significant difference was however observed in the number of missense mutations occurring in any motifs analysed. 


\section{Conclusions}

Several conclusions may be drawn from the results reported here. Firstly, it would appear that those missense mutations that are found both in the soma and the germline ('shared mutations') are disproportionately more likely to exert an effect on tumour development and/or progrés Deleted: profound 10 11 (i.e. more likely to be driver mutations) than exclusively somatic non-recurrent missense mutations (at least for the TP53 and CDKN2A genes whose mutations contributed the bulk of the documented shared mutations in our tumour suppressor gene mutation dataset). Shared mutations also occur preferentially in $\mathrm{CpG} / \mathrm{CpHpG}$ oligonucleotides and are characterised by higher mutability rates (both non-disease- and disease-associated). Further, we found that shared mutations tend to occur in those codons that have been more highly conserved evolutionarily, and are associated with more dramatic chemical differences between the substituted (wild-type) and substituting amino acids. Taken together, it would thus appear that shared mutations are influenced to a greater extent by the local nucleotide sequence context than either germline or somatic non-recurrent missense mutations. Since this implies that shared mutations (the mutation category most likely to harbour driver mutations) have a tendency to arise through the action of similar endogenous mutational mechanisms, we may infer that endogenous mechanisms of mutagenesis exert a disproportionate effect on tumorigenesis.

In an analysis of an unrelated dataset, we demonstrated that $17 \%$ of somatic missense mutations previously identified as being probable drivers [Carter et al., 2009] were found to possess the same features as shared (both recurrent and non-recurrent) mutations. A further $32 \%$ of these probable driver mutations shared the features expected of recurrent somatic mutations. Thus, we may conclude that $\sim 50 \%$ of these somatic missense mutations possess features consistent with their being either shared or recurrent, suggesting that a disproportionate number of such lesions are likely to be drivers of tumorigenesis. 


\section{Acknowledgements}

We are most grateful to Eamonn Maher (Birmingham, UK), Gareth Evans (Manchester, UK) and the late Michael Baser for their provision of somatic mutation data. We are also very grateful to Larry Brody (NIH, Bethesda, MD, USA), Shiu-Ru Lin (Kaohsiung Medical University, Taiwan) and Tone Lovig (University of Oslo, Norway) for providing us with further information on 
1

2

3

4

5

6

8

9

10

11

12

13

14

15

16

17

18

19

20

21

22

23

24

25

26

27

28

29

30

31

32

33

34

35

36

37

38

39

40

41

42

43

44

45

46

47

48

49

50

51

52

53

54

55

56

57

58

59

60

specific somatic mutations and Rachel Karchin (Johns Hopkins University, Baltimore, USA) for making available her dataset of probable driver mutations. 


\section{References}

Ali IU, Schriml LM, Dean M. 1999. Mutational spectra of PTEN/MMAC1 gene: a tumor suppressor with lipid phosphatase activity. J Natl Cancer Inst 91:1922-1932.

Bacolla A, Jaworski A, Larson JE, Jakupciak JP, Chuzhanova NA, Abeysinghe SS, O'Connell CD, Cooper DN, Wells RD. 2004. Breakpoints of gross deletions coincide with non-B DNA conformations. Proc Natl Acad Sci USA 101:14162-14167.

Bacolla A, Wells RD. 2004. Non-B DNA conformations, genomic rearrangements, and human disease. J Biol Chem 279:47411-47414.

Bacolla A, Collins JR, Gold B, Chuzhanova N, Yi M, Stephens RM, Stefanov S, Olsh A, Jakupciak JP, Dean M, Lempicki RA, Cooper DN, Wells RD. 2006. Long homopurine•homopyrimidine sequences are characteristic of genes expressed in brain and the pseudoautosomal region. Nucleic Acids Res 34: 2663-2675.

Ball EV, Stenson PD, Krawczak M, Cooper DN, Chuzhanova NA. 2005. Micro-deletions and micro-insertions causing human genetic disease: common mechanisms of mutagenesis and the role of local DNA sequence complexity. Human Mutat 26:205-213.

Baser ME, Contributors to the International NF2 Mutation Database. Hum. Mutat. 27:297-306.

Boland CR, Ricciardiello L. 1999. How many mutations does it take to make a tumor? Proc Natl Acad Sci USA 96:14675-14677.

Buard J, Collick A, Brown J, Jeffreys AJ. 2000. Somatic versus germline mutation processes at minisatellite CEB1 (D2S90) in humans and transgenic mice. Genomics 65:95-103.

Carter H, Chen S, Isik L, Tyekucheva S, Velculescu VE, Kinzler KW, Vogelstein B, Karchin R. 2009. Cancer-specific high-throughput annotation of somatic mutations: computational prediction of driver missense mutations. Cancer Res 69:6660-6667. 
Chuzhanova NA, Anassis EJ, Ball E, Krawczak M, Cooper DN. 2003. Meta-analysis of indels causing human genetic disease: mechanisms of mutagenesis and the role of local DNA sequence complexity. Hum Mutat 21:28-44.

Chuzhanova N, Chen JM, Bacolla A, Patrinos GP, Férec C, Wells RD, Cooper DN. 2009. Gene conversion causing human inherited disease: the evidence for involvement of recombination-associated motifs and non-B DNA-forming sequences in DNA breakage. Hum Mutat 30:1189-1198.

Cole DN, Carlson JA, Wilson VL. 2008. Human germline and somatic cells have similar TP53 and Kirsten-RAS gene single base mutation frequencies. Environ. Mol. Mutagen. 2008 49:417-425.

Cooper DN, Mort M, Stenson PD, Ball EV, Chuzhanova NA. 2010. Methylation-mediated deamination of 5-methylcytosine appears to give rise to mutations causing human inherited disease in $\mathrm{CpNpG}$ trinucleotides as well as in $\mathrm{CpG}$ dinucleotides. Hum Genomics 4:406-410.

Couch FJ, Rasmussen LJ, Hofstra R, Monteiro AN, Greenblatt MS, de Wind N; IARC Unclassified Genetic Variants Working Group. 2008. Assessment of functional effects of unclassified genetic variants. Hum Mutat 29:1314-1326.

Dallosso AR, Jones S, Azzopardi D, Moskvina V, Al-Tassan N, Williams GT, Idziaszczyk S, Davies DR, Milewski P, Williams S, Beynon J, Sampson JR, Cheadle JP. 2009. The APC variant p.Glu1317Gln predisposes to colorectal adenomas by a novel mechanism of relaxing the target for tumorigenic somatic APC mutations. Hum Mutat 30:1412-1418.

Dworkin AM, Ridd K, Bautista D, Allain DC, Iwenofu OH, Roy R, Bastian BC, Toland AE. 2010. Germline variation controls the architecture of somatic alterations in tumors. PLoS

\section{Genet 6: e1001136.}


Fostira F, Thodi G, Sandaltzopoulos R, Fountzilas G, Yannoukakos D. 2010. Mutational spectrum of $A P C$ and genotype-phenotype correlations in Greek FAP patients. BMC Cancer 10:389.

Futreal PA, Coin L, Marshall M, Down T, Hubbard T, Wooster R, Rahman N, Stratton MR. 2004. A census of human cancer genes. Nat Rev Cancer 4:177-183.

Gallou C, Joly D, Mejean A, Staroz F, Martin N, Tarlet G, Orfanelli MT, Bouvier R, Droz D, Chretien Y, Maréchal JM, Richard S, Junien C, Béroud C. 1999. Mutations of the VHL gene in sporadic renal cell carcinoma: definition of a risk factor for VHL patients to develop an RCC. Hum Mutat 13:464-475.

Giovannone B, Sabbadini G, Di Maio L, Calabrese O, Castaldo I, Frontali M, Novelleto A, Squitieri F. 1997. Analysis of (CAG)n size heterogeneity in somatic and sperm cell DNA from intermediate and expanded Huntington disease gene carriers. Hum Mutat 10:458464.

Glazko GV, Koonin EV, Rogozin IB. 2004. Mutation hotspots in the p53 gene in tumors of different origin: correlation with evolutionary conservation and signs of positive selection. Biochim Biophys Acta 1679:95-106.

Goode EL, Ulrich CM, Potter JD. 2002. Polymorphisms in DNA repair genes and associations with cancer risk. Cancer Epidemiol Biomarkers Prev 11:1513-1530.

Grantham R. 1974. Amino acid difference formula to help explain protein evolution. Science $185: 862-864$.

Greenblatt MS, Grollman AP, Harris CC. 1996. Deletions and insertions in the p53 tumor suppressor gene in human cancers: confirmation of the DNA polymerase slippage/misalignment model. Cancer Res 56:2130-2136.

Greenblatt MS, Beaudet JG, Gump JR, Godin KS, Trombley L, Koh J, Bond JP. 2003. Detailed computational study of p53 and p16: using evolutionary sequence analysis and disease- 
associated mutations to predict the functional consequences of allelic variants. Oncogene 22:1150-1163.

Greenman C, Stephens P, Smith R, Dalgliesh GL, Hunter C, Bignell G, Davies H, Teague J, Butler A, Stevens C, Edkins S, O'Meara S, Vastrik I, Schmidt EE, Avis T, Barthorpe S, Bhamra G, Buck G, Choudhury B, Clements J, Cole J, Dicks E, Forbes S, Gray K, Halliday K, Harrison R, Hills K, Hinton J, Jenkinson A, Jones D, Menzies A, Mironenko T, Perry J, Raine K, Richardson D, Shepherd R, Small A, Tofts C, Varian J, Webb T, West S, Widaa S, Yates A, Cahill DP, Louis DN, Goldstraw P, Nicholson AG, Brasseur F, Looijenga L, Weber BL, Chiew YE, DeFazio A, Greaves MF, Green AR, Campbell P, Birney E, Easton DF, Chenevix-Trench G, Tan MH, Khoo SK, Teh BT, Yuen ST, Leung SY, Wooster R, Futreal PA, Stratton MR. 2007. Patterns of somatic mutation in human cancer genomes. Nature 446:153-158.

Groves C, Lamlum H, Crabtree M, Williamson J, Taylor C, Bass S, Cuthbert-Heavens D, Hodgson S, Phillips R, Tomlinson I. 2002. Mutation cluster region, association between germline and somatic mutations and genotype-phenotype correlation in upper gastrointestinal familial adenomatous polyposis. Am J Pathol 160:2055-2061.

Haber D, Harlow E. 1997. Tumour-suppressor genes: evolving definitions in the genomic age. Nat Genet 16:320-322.

Hess ST, Blake JD, Blake RD. 1994. Wide variations in neighbor-dependent substitution rates. J Mol Biol 236:1022-1033.

Jego N, Thomas G, Hamelin R. 1993. Short direct repeats flanking deletions, and duplicating insertions in p53 gene in human cancers. Oncogene 8:209-213.

Kan Z, Jaiswal BS, Stinson J, Janakiraman V, Bhatt D, Stern HM, Yue P, Haverty PM, Bourgon R, Zheng J, Moorhead M, Chaudhuri S, Tomsho LP, Peters BA, Pujara K, Cordes S, Davis DP, Carlton VE, Yuan W, Li L, Wang W, Eigenbrot C, Kaminker JS, Eberhard 
DA, Waring P, Schuster SC, Modrusan Z, Zhang Z, Stokoe D, de Sauvage FJ, Faham M, Seshagiri S. 2010. Diverse somatic mutation patterns and pathway alterations in human cancers. Nature 466:869-873.

Karlin S, Macken C. 1991. Some statistical problems in the assessment of inhomogenesis of DNA sequence data. J Am Statist Assoc 86:27-35.

Knudson AG. 2001. Two genetic hits (more or less) to cancer. Nat Rev Cancer 1:157-162.

Kohavi R. 1996. Scaling up the accuracy of naive-Bayes classifiers: a decision-tree hHybrid. Proceedings of the Second International Conference on Knowledge Discovery and Data Mining. AAAI Press, pp 202-207.

Kolomietz E, Meyn MS, Pandita A, Squire JA. 2002. The role of Alu repeat clusters as mediators of recurrent chromosomal aberrations in tumors. Genes Chrom Cancer 35:97-112.

Kondrashov AS, Rogozin IB. 2004. Context of deletions and insertions in human coding sequences. Hum Mutat 23:177-185.

Kotsiantis S, Kanellopoulos D, Pintelas P. 2006. Handling imbalanced datasets: a review. GESTS International Transactions on Computer Science and Engineering 30:25-36.

Krawczak M, Smith-Sorensen B, Schmidtke J, Kakkar VV, Cooper DN, Hovig E. 1995. Somatic spectrum of cancer-associated single basepair substitutions in the TP53 gene is determined mainly by endogenous mechanisms of mutation and by selection. Hum Mutat 5:48-57.

Krawczak M, Ball EV, Cooper DN. 1998. Neighboring-nucleotide effects on the rates of germline single-base-pair substitution in human genes. Am J Hum Genet 63:474-488.

Lagarde A, Rouleau E, Ferrari A, Noguchi T, Qiu J, Briaux A, Bourdon V, Rémy V, Gaildrat P, Adélaïde J, Birnbaum D, Lidereau R, Sobol H, Olschwang S. 2010. Germline $A P C$ mutation spectrum derived from 863 genomic variations identified through a 


\section{5-year medical genetics service to French patients with FAP. J Med Genet} 47:721-722.

Lamlum H, Ilyas M, Rowan A, Clark S, Johnson V, Bell J, Frayling I, Efstathiou J, Pack K, Payne S, Roylance R, Gorman P, Sheer D, Neale K, Phillips R, Talbot I, Bodmer W, Tomlinson I. 1999. The type of somatic mutation at $A P C$ in familial adenomatous polyposis is determined by the site of the germline mutation: a new facet to Knudson's 'two-hit' hypothesis. Nat Med 5:1071-1075.

Latchford A Volikos E, Johnson V, Rogers P, Suraweera N, Tomlinson I, Phillips R, Silver A. 2007. APC mutations in FAP-associated desmoid tumours are non-random but not just right'. Hum Mol Genet 16:78-82.

Leclercq S, Rivals E, Jarne P. 2010. DNA slippage occurs at microsatellite loci without minimal threshold length in human: a comparative genomic approach. Genome Biol Evol 2:325335.

Leeflang EP, Tavare S, Marjoram P, Neal CO, Srinidhi J, MacFarlane H, MacDonald ME, Gusella JF, de Young M, Wexler NS, Arnheim N. 1999. Analysis of germline mutation spectra at the Huntington's disease locus supports a mitotic mutation mechanism. Hum Mol Genet 8:173-183.

Lengauer C, Kinzler KW, Vogelstein B. 1998. Genetic instabilities in human cancers. Nature 396:643-649.

Lister R, Pelizzola M, Dowen RH, Hawkins RD, Hon G, Tonti-Filippini J, Nery JR, Lee L, Ye Z, Ngo QM, Edsall L, Antosiewicz-Bourget J, Stewart R, Ruotti V, Millar AH, Thomson JA, Ren B, Ecker JR. 2009. Human DNA methylomes at base resolution show widespread epigenomic differences. Nature 19:315-322. 
Lobo GP, Waite KA, Planchon SM, Romigh T, Nassif NT, Eng C. 2009. Germline and somatic cancer-associated mutations in the ATP-binding motifs of PTEN influence its subcellular localization and tumor suppressive function. Hum. Mol. Genet. 18:2851-2862.

Loeb LA, Harris CC. 2008. Advances in chemical carcinogenesis: a historical review and prospective. Cancer Res 68: 6863-6872.

Makalowski W, Boguski MS. 1998. Evolutionary parameters of the transcribed mammalian genome: an analysis of 2,820 orthologous rodent and human sequences. Proc Natl Acad Sci USA 95:9407-9412.

Makridakis NM, Caldas Ferraz LF, Reichardt JK. 2009. Genomic analysis of cancer tissue reveals that somatic mutations commonly occur in a specific motif. Hum Mutat 30:39-48.

Marshall B, Isidro G, Carvalhas R, Boavida M. 1997. Germline versus somatic mutations of the APC gene: evidence for mechanistic differences. Hum Mutat 9:286-288.

Martorell L, Monckton DG, Gamez J, Baiget M. 2000. Complex patterns of male germline instability and somatic mosaicism in myotonic dystrophy type 1. Eur J Hum Genet 8: 423-430.

Miyoshi Y, Nagase H, Ando H, Horii A, Ichii S, Nakatsuru S, Aoki T, Miki Y, Mori T, Nakamura Y. 1992. Somatic mutations of the APC gene in colorectal tumors: mutation cluster region in the APC gene. Hum Mol Genet 1:229-33.

Mort M, Ivanov D, Cooper DN, Chuzhanova NA. 2008. A meta-analysis of nonsense mutations causing human genetic disease. Hum Mutat 29:1037-1047.

Nei M, Gojobori T. 1986. Simple methods for estimating the numbers of synonymous and nonsynonymous nucleotide substitutions. Mol Biol Evol 3:418-426.

Oldenburg J, Rost S, El-Maarri O, Leuer M, Olek K, Muller CR, Schwaab R. 2000. De novo factor VIII gene intron 22 inversion in a female carrier presents as a somatic mosaicism. Blood 96: 2905-2906. 
Olshen AB, Jain AN. 2002. Deriving quantitative conclusions from microarray expression data. Bioinformatics 18:961-970.

Parmigiani G, Boca S, Lin J, Kinzler KW, Velculescu V, Vogelstein B. 2009. Design and analysis issues in genome-wide somatic mutation studies of cancer. Genomics 93:17-21.

Pollard LM, Sharma R, Gomez M, Shah S, Delatycki MB, Pianese L, Monticelli A, Keats BJ, Bidichandani SI. 2004. Replication-mediated instability of the GAA triplet repeat mutation in Friedreich ataxia. Nucleic Acids Res 32:5962-5971.

Richter S, Vandezande K, Chen N, Zhang K, Sutherland J, Anderson J, Han L, Panton R, Branco P, Gallie B. 2003. Sensitive and efficient detection of $R B 1$ gene mutations enhances care for families with retinoblastoma. Am J Hum Genet 72:253-269.

Rogozin IB, Pavlov YI, Bebenek K, Matsuda T, Kunkel TA. 2001. Somatic mutation hotspots correlate with DNA polymerase eta error spectrum. Nat Immunol 2:530-536.

Rubin AF, Green P. 2009. Mutation patterns in cancer genomes. Proc Natl Acad Sci USA 106: 21766-21770.

Sharma R, Bhatti S, Gomez M, Clark RM, Murray C, Ashizawa T, Bidichandani SI. 2002. The GAA triplet-repeat sequence in Friedreich ataxia shows a high level of somatic instability in vivo, with a significant predilection for large contractions. Hum Mol Genet 11:21752187.

Sherr CJ. 2004. Principles of tumor suppression. Cell 116:235-246.

Schmutte C, Jones PA. 1998. Involvement of DNA methylation in human carcinogenesis. Biol Chem 379:377-388.

Shanks ME, May CA, Dubrova YE, Balaresque P, Rosser ZH, Adams SM, Jobling MA. 2008. Complex germline and somatic mutation processes at a haploid human minisatellite shown by single-molecule analysis. Mutat Res 648:46-53.

Simpson AJ. 2009. Sequence-based advances in the definition of cancer-associated gene mutations. Curr Opin Oncol 21:47-52. 
Sjöblom T, Jones S, Wood LD, Parsons DW, Lin J, Barber TD, Mandelker D, Leary RJ, Ptak J, Silliman N, Szabo S, Buckhaults P, Farrell C, Meeh P, Markowitz SD, Willis J, Dawson D, Willson JK, Gazdar AF, Hartigan J, Wu L, Liu C, Parmigiani G, Park BH, Bachman KE, Papadopoulos N, Vogelstein B, Kinzler KW, Velculescu VE. 2006. The consensus coding sequences of human breast and colorectal cancers. Science 314:268-274.

Stead JD, Jeffreys AJ. 2000. Allele diversity and germline mutation at the insulin minisatellite. Hum Mol Genet 9:713-723.

Stenson PD, Mort M, Ball EV, Howells K, Phillips AD, Thomas NS, Cooper DN. 2009. The Human Gene Mutation Database: 2008 update. Genome Med. 1:13.

Stratton MR, Campbell PJ, Futreal PA. 2009. The cancer genome. Nature 458:719-724.

Talavera D, Taylor MS, Thornton JM. 2010. The (non)malignancy of cancer amino acidic substitutions. Proteins 78:518-529.

Tappino B, Chuzhanova NA, Regis S, Dardis A, Corsolini F, Stroppiano M, Tonoli E, Beccari T, Rosano C, Mucha J, Blanco M, Szlago M, Di Rocco M, Cooper DN, Filocamo M. 2009. Molecular characterization of 22 novel UDP-N-acetylglucosamine-1-phosphate transferase alpha- and beta-subunit (GNPTAB) gene mutations causing mucolipidosis types IIalpha/beta and IIIalpha/beta in 46 patients. Hum Mutat 30:E956-973.

Tartaglia M, Martinelli S, Stella L, Bocchinfuso G, Flex E, Cordeddu V, Zampino G, van der Burgt I, Palleschi A, Petrucci TC, Sorcini M, Schoch C, Foà R, Emanuel PD, Gelb BD. 2006. Diversity and functional consequences of germline and somatic PTPN11 mutations in human disease. Am J Hum Genet 78:279-290.

Tavtigian SV, Greenblatt MS, Lesueur F, Byrnes GB; IARC Unclassified Genetic Variants Working Group. 2008. In silico analysis of missense substitutions using sequencealignment based methods. Hum Mutat 29:1327-1336. 
Tavtigian SV, Oefner PJ, Babikyan D, Hartmann A, Healey S, Le Calvez-Kelm F, Lesueur F, Byrnes GB, Chuang SC, Forey N, Feuchtinger C, Gioia L, Hall J, Hashibe M, Herte B, McKay-Chopin S, Thomas A, Vallée MP, Voegele C, Webb PM, Whiteman DC; Australian Cancer Study; Breast Cancer Family Registries (BCFR); Kathleen Cuningham Foundation Consortium for Research into Familial Aspects of Breast Cancer (kConFab), Sangrajrang S, Hopper JL, Southey MC, Andrulis IL, John EM, Chenevix-Trench G. 2009. Am J Hum Genet 85:427-446.

Thomas L, Kluwe L, Chuzhanova N, Mautner V, Upadhyaya M. 2010. Analysis of NF1 somatic mutations in cutaneous neurofibromas from patients with high tumor burden. Neurogenetics 11:391-400.

Thusberg J, Vihinen M. 2009. Pathogenic or not? And if so, then how? Studying the effects of missense mutations using bioinformatics methods. Hum Mutat 30:703-714.

Tornaletti S, Pfeifer GP. 1995. Complete and tissue-independent methylation of CpG sites in the p53 gene: implications for mutations in human cancers. Oncogene 10:1493-1499.

Upadhyaya M, Han S, Consoli C, Majounie E, Horan M, Thomas NS, Potts C, Griffiths S, Ruggieri M, von Deimling A, Cooper DN. 2004. Characterization of the somatic mutational spectrum of the neurofibromatosis type $1(N F 1)$ gene in neurofibromatosis patients with benign and malignant tumors. Hum Mutat 23:134-136.

Upadhyaya M, Kluwe L, Spurlock G, Monem B, Majounie E, Mantripragada K, Ruggieri M, Chuzhanova N, Evans DG, Ferner R, Thomas N, Guha A, Mautner V. 2008. Germline and somatic $N F 1$ gene mutation spectrum in $N F 1$-associated malignant peripheral nerve sheath tumors (MPNSTs). Hum Mutat 29:74-82.

Vogelstein B, Kinzler KW. 2004. Cancer genes and the pathways they control. Nat Med 10:789799. 
Walker DR, Bond JP, Tarone RE, Harris CC, Makalowski W, Boguski MS. Greenblatt MS. 1999. Evolutionary conservation and somatic mutation hotspot maps of p53: correlation with $\mathrm{p} 53$ protein structural and functional features. Oncogene 18:211-218.

Walters, S. J. 2004. Sample size and power estimation for studies with health related quality of life outcomes: a comparison of four methods using the SF-36. Health Qual Life Outcomes 2, p. 26.

Witten IH, Frank E. 2005. Data mining: practical machine learning tools and techniques, 2nd ed. Morgan Kaufmann, San Francisco, pp. 365-483. 


\section{Figure Legends}

Figure 1. Diagrammatic representation of the number of various types of mutations analysed in the present study.

Figure 2. Nucleotide substitution patterns of missense mutations in 17 tumour suppressor genes. 


\section{Comparative Analysis of Germline and Somatic Micro-lesion Mutational Spectra in}

\section{Human Tumour Suppressor Genes}

(Supplementary Text)

${ }^{1}$ Institute of Medical Genetics, School of Medicine, Cardiff University, Cardiff, CF14 4XN, UK

${ }^{2}$ MRC Centre for Neuropsychiatric Genetics and Genomics, Department of Psychological Medicine and Neurology, Biostatistics and Bioinformatics Unit, School of Medicine, Cardiff University, Cardiff, CF14 4XN, UK

${ }^{3}$ School of Science and Technology, Nottingham Trent University, Nottingham, NG11 $8 \mathrm{NS}, \mathrm{UK}$

${ }^{4}$ Institute of Human Genetics, University of Ulm, Albert-Einstein-Allee 11, 89081 Ulm, Germany

\footnotetext{
*All correspondence to: Prof. Nadia Chuzhanova, School of Science and Technology

Nottingham Trent University, Clifton Lane, Nottingham NG11 8NS, UK

Tel: +44 (0) $01158488304 \quad$ E-mail: nadia.chuzhanova@ntu.ac.uk
} 
Gene-wise characteristics of germline and somatic missense mutations with respect to mutation type

Taken together, the combined mutational spectra for all 17 tumour suppressor genes contained twice as many somatic $(61 \%)$ as germline (31\%) mutations. For five genes (APC, CDKN2A, NF2, PTEN and TP53), a predominance of somatic over germline mutations was noted, with the TP53 gene having the highest proportion of somatic mutations (92\%). For the majority of genes, however (namely ATM, BRCA1, BRCA2, CDH1, NF1, PTCH1, RB1, STK11, TSC1, TSC2, VHL and WT1), the analysed dataset included more germline than somatic mutations, with $>97 \%$ of all mutations in the BRCA1, NF1, TSC2 and WT1 genes being germline in origin.

Gene-wise characteristics of missense mutations in relation to the disease-and non-diseaseassociated substitution rates

The median values were found to vary between 4 (NF2) and 8.9 (STK11) for somatic mutations, 4.1 (TP53) and 10.1 (WT1) for germline mutations, and $7.2($ RB1) and 11 (PTEN) for shared mutations (values given only for genes with more than three mutations in the corresponding category; see Supp. Table 3, indicating that many of the median values are quite low and hence the corresponding mutations are unlikely to be neutral.

The highest and lowest disease-associated median values for the mutation rates were noted for somatic mutations in the STK11 gene (1.7; Supp. Table 3) and for germline mutations in the TP53 (0.42) gene (values given only for genes with more than three mutations in the corresponding category).

Gene-wise occurrence of missense mutations within repeats and runs of identical nucleotides 
On average, the coverage of the respective gene sequences by direct repeats of length $\geq 8 \mathrm{bp}$ was found to vary between $2.5 \%$ (BRCA2) and $17 \%$ (PTEN). The corresponding proportion of the cDNA lengths for inverted repeats $\geq 8$ bp was found to vary between $4.5 \%$ (PTCH1) and $R B 1$ $15.7 \%$ (RBI ) while symmetric elements $\geq 8$ bp were found to vary between $15.5 \%$ for $A P C$ and $44 \%$ for PTEN genes.

On average, mononucleotide runs $\geq 4$ bp spanned $19.9 \%$ of the cDNA lengths, varying between $9.5 \%(V H L)$ and $29 \%(T P 53)$.

No correlation was observed between the number of mutations located within repeats and the fractional length of the cDNA covered by repeats, indicating that not every repeat sequence is mutation-prone. However, a strong correlation between the fractional length of the cDNA covered by repeats and cDNA length of genes $\left(r>0.87\right.$ and $\left.p<10^{-6}\right)$ served to demonstrate that repeat density per unit length was approximately the same for all tumour suppressor genes studied.

\section{Truncating vs non-truncating mutations in the germline and soma}

Somatic mutational spectra from the BRCA2, CDKN2A, STK11, TP53 and TSC1 genes were characterized by the predominance of non-truncating (i.e. missense) lesions over truncating lesions (i.e. nonsense mutations, frameshift micro-deletions, micro-insertions and indels) when nonsense mutations [reported in Mort et al. (2008)] and micro-indels (excluded from previous analyses) were also considered (Supp. Table 8). A similar predominance of non-truncating over truncating lesions was observed for the germline mutational spectra of the CDKN2A,TP53,VHL and WT1 genes. In general, the ratio of non-truncating to truncating lesions was found to be significantly higher in the soma $(0.85)$ than in the germline $(0.30 ; \mathrm{p}$-value $<2.20 \mathrm{E}-16)$. All other mutational spectra were characterized by the predominance of truncating mutations. 


\section{References}

Mort M, Ivanov D, Cooper DN, Chuzhanova NA. 2008. A meta-analysis of nonsense mutations causing human genetic disease. Hum Mutat 29:1037-1047. 
Supplementary Figure 1. Naive Bayes Tree Classifier. Number in parenthesis shows the probability of a mutations being somatic non-recurrent, germline, shared non-recurrent, somatic recurrent and shared recurrent respectively.

Attributes:

$$
\begin{aligned}
& \text { Mut_Type } \\
& \text { Hess_value } \\
& \text { Krawczak_value } \\
& \text { Evol } \\
& \text { Grantham_score } \\
& \text { CpG/CHG } \\
& \text { Repeats }
\end{aligned}
$$




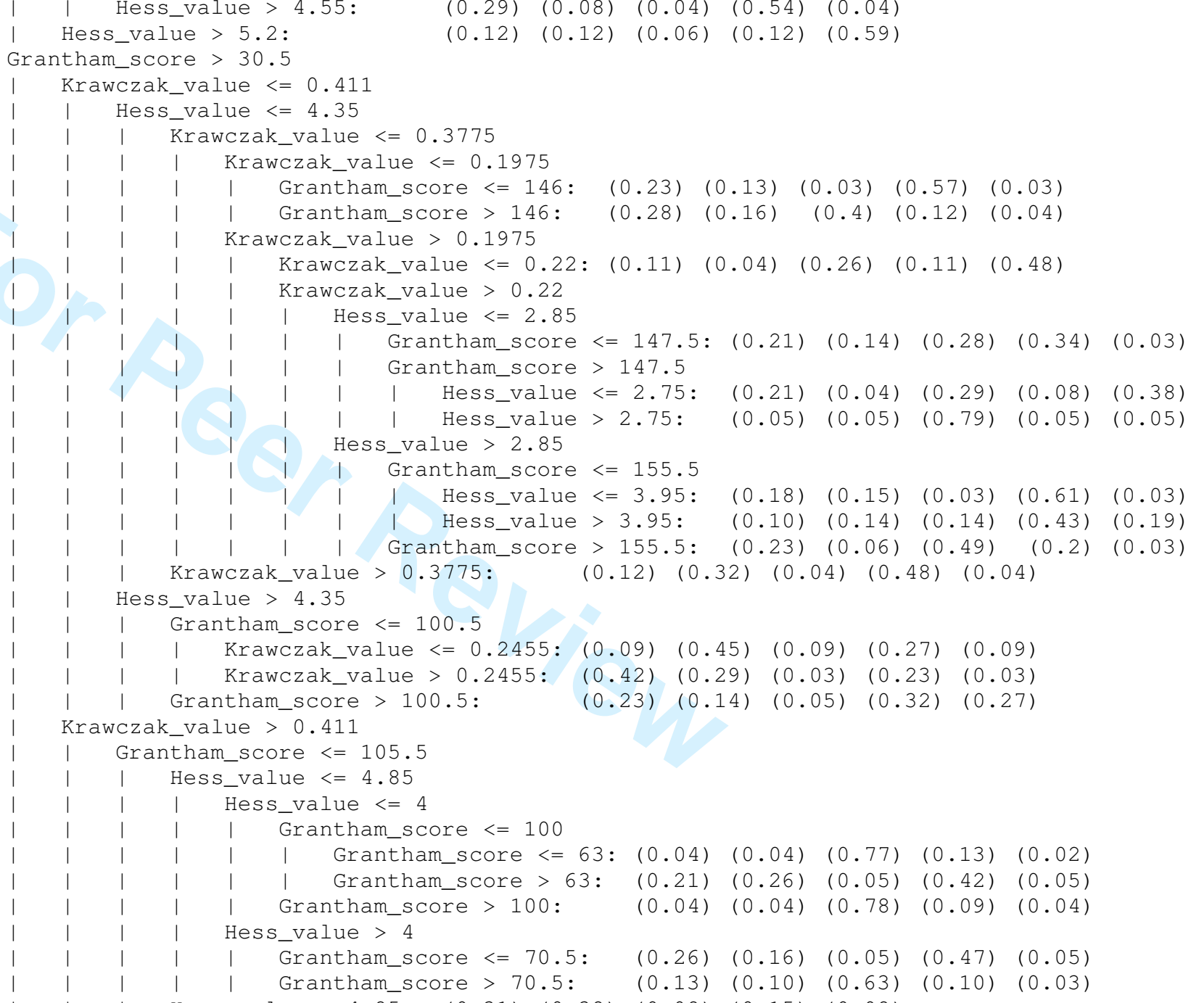

John Wiley \& Sons, Inc. 6 


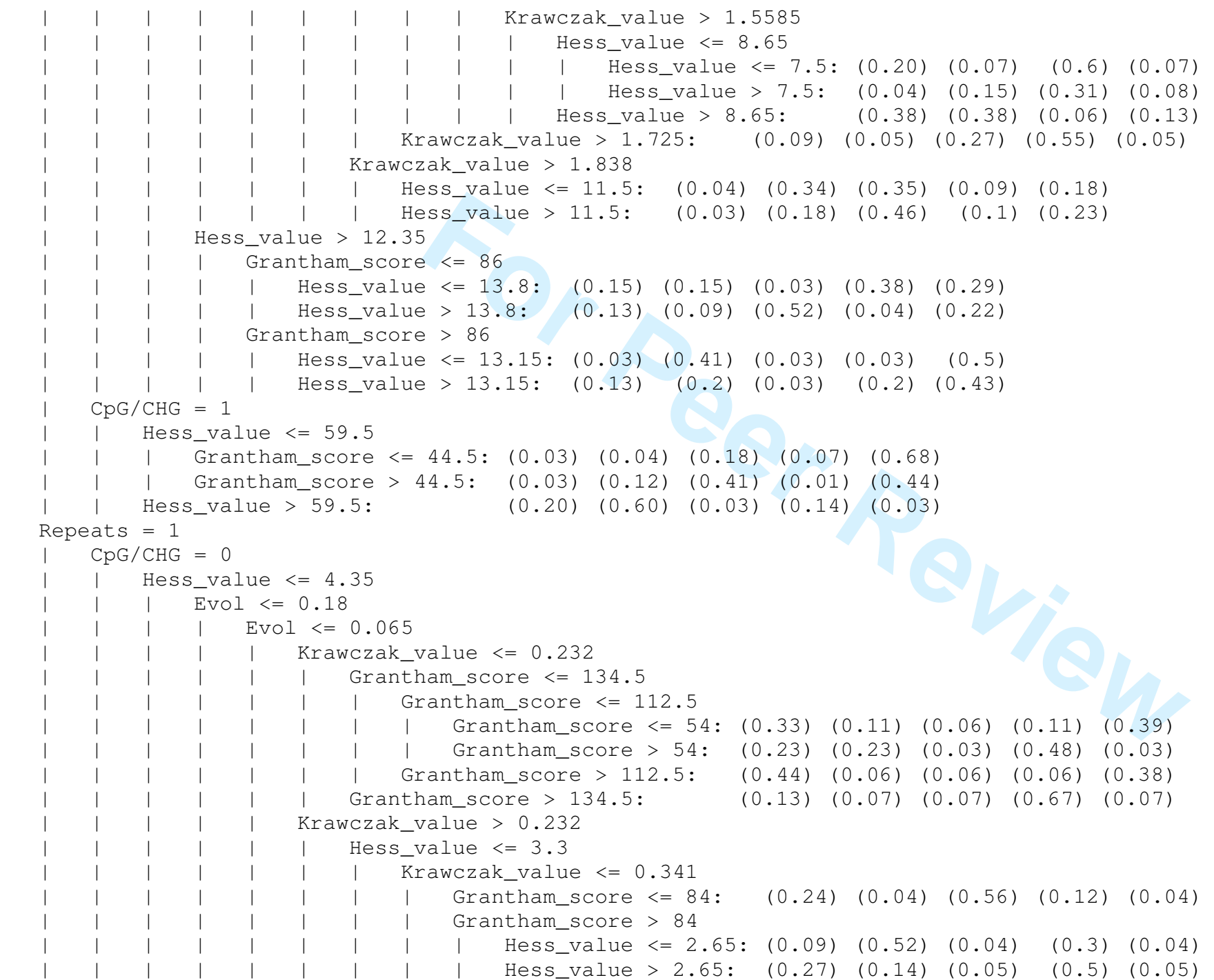




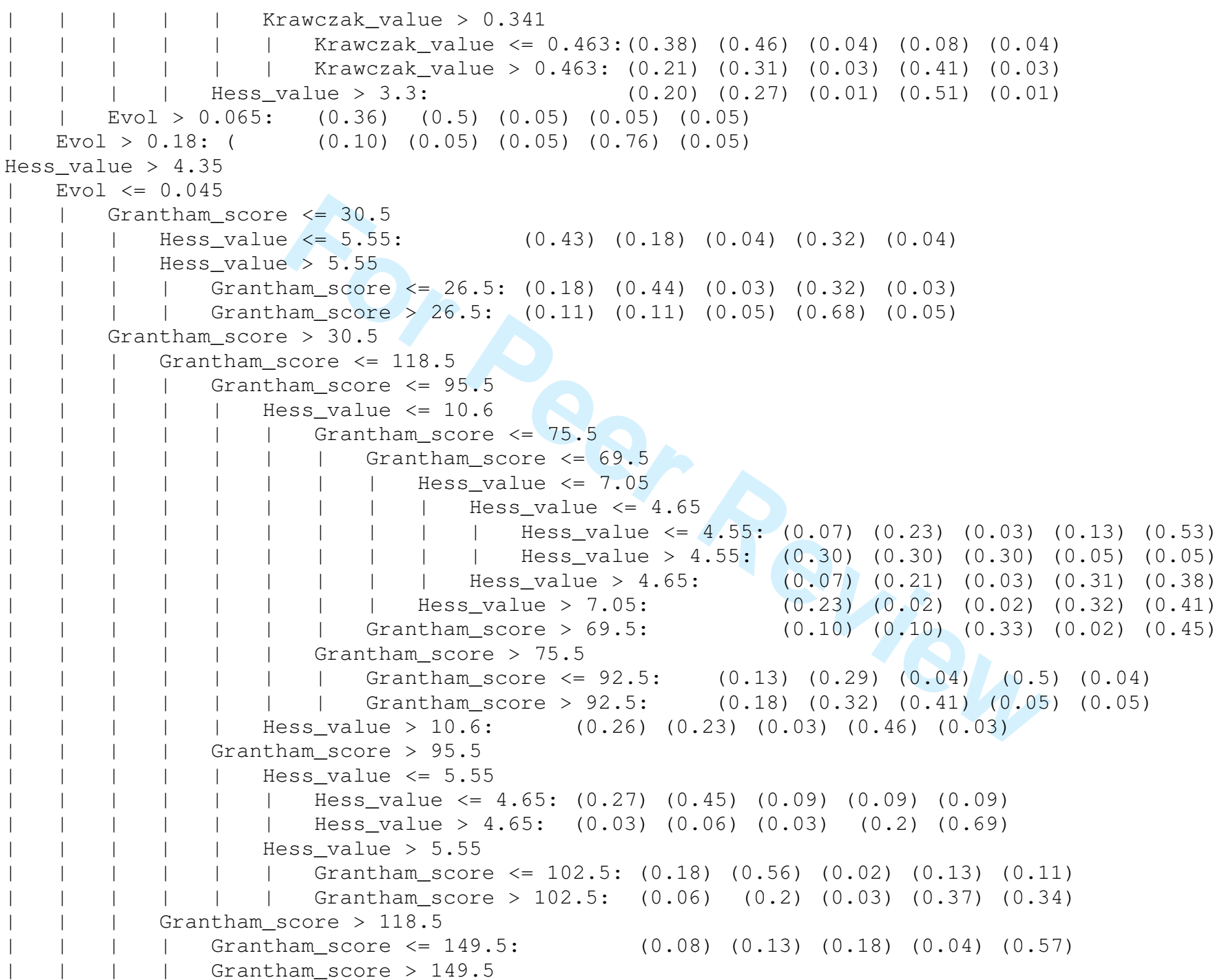




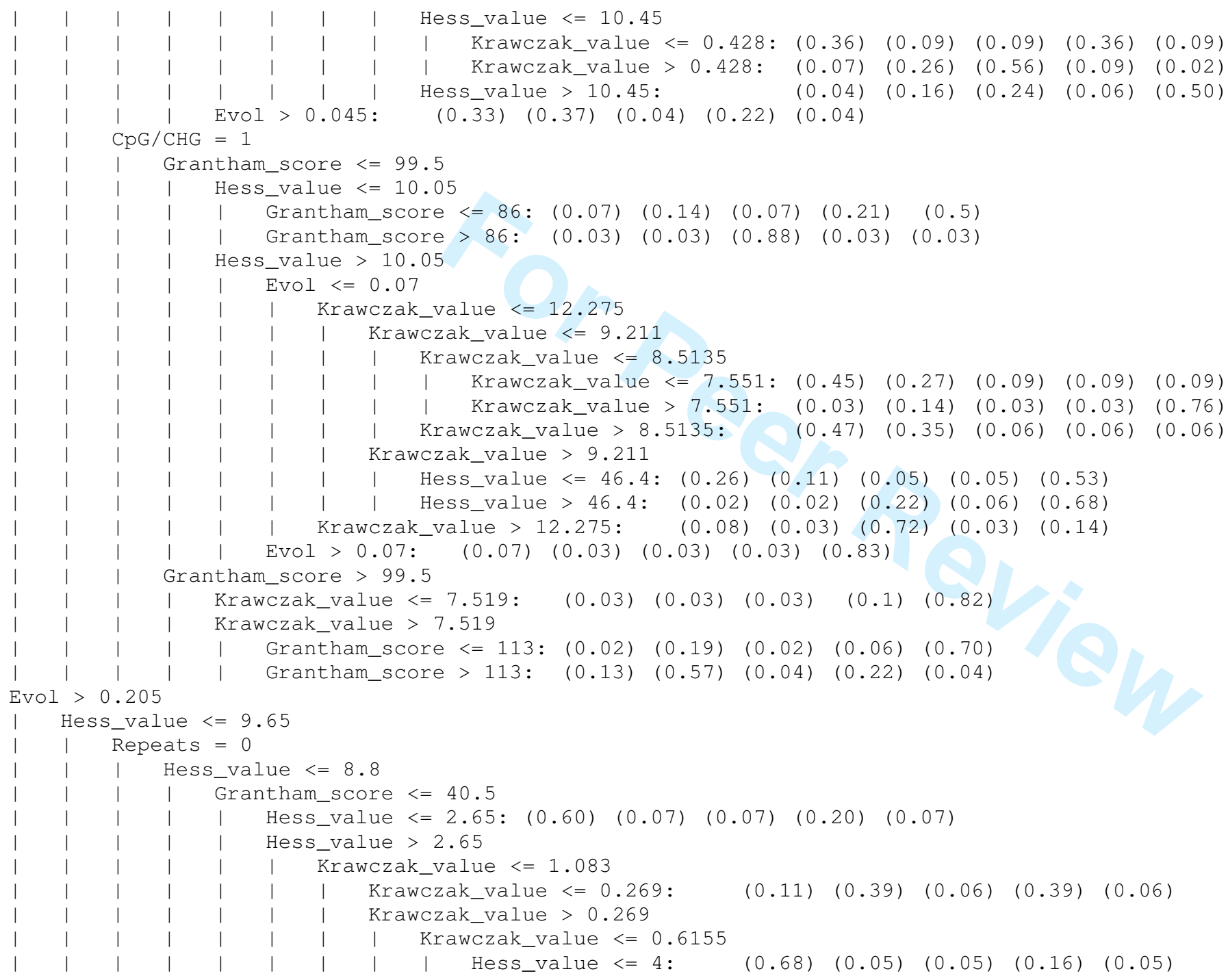




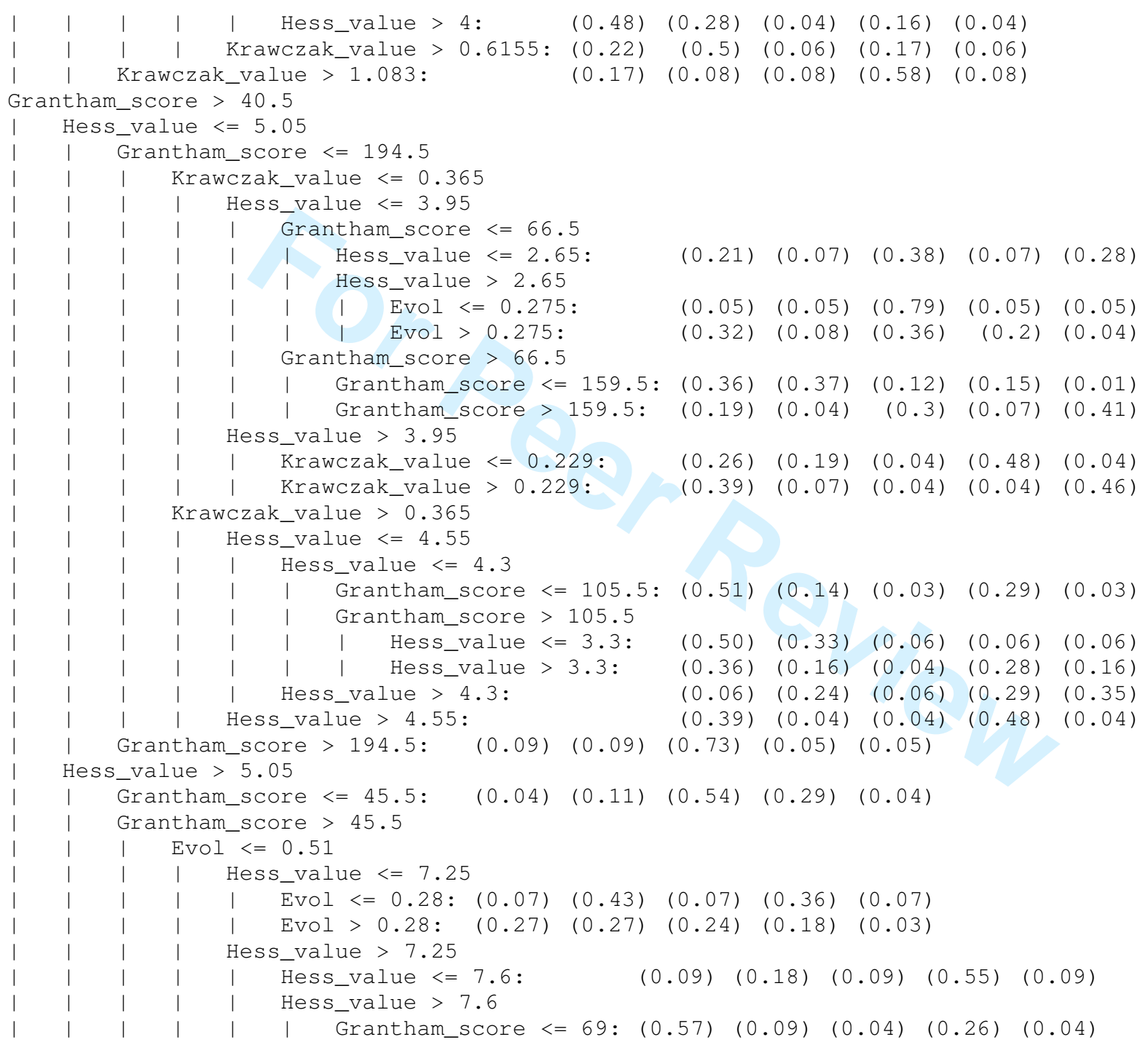




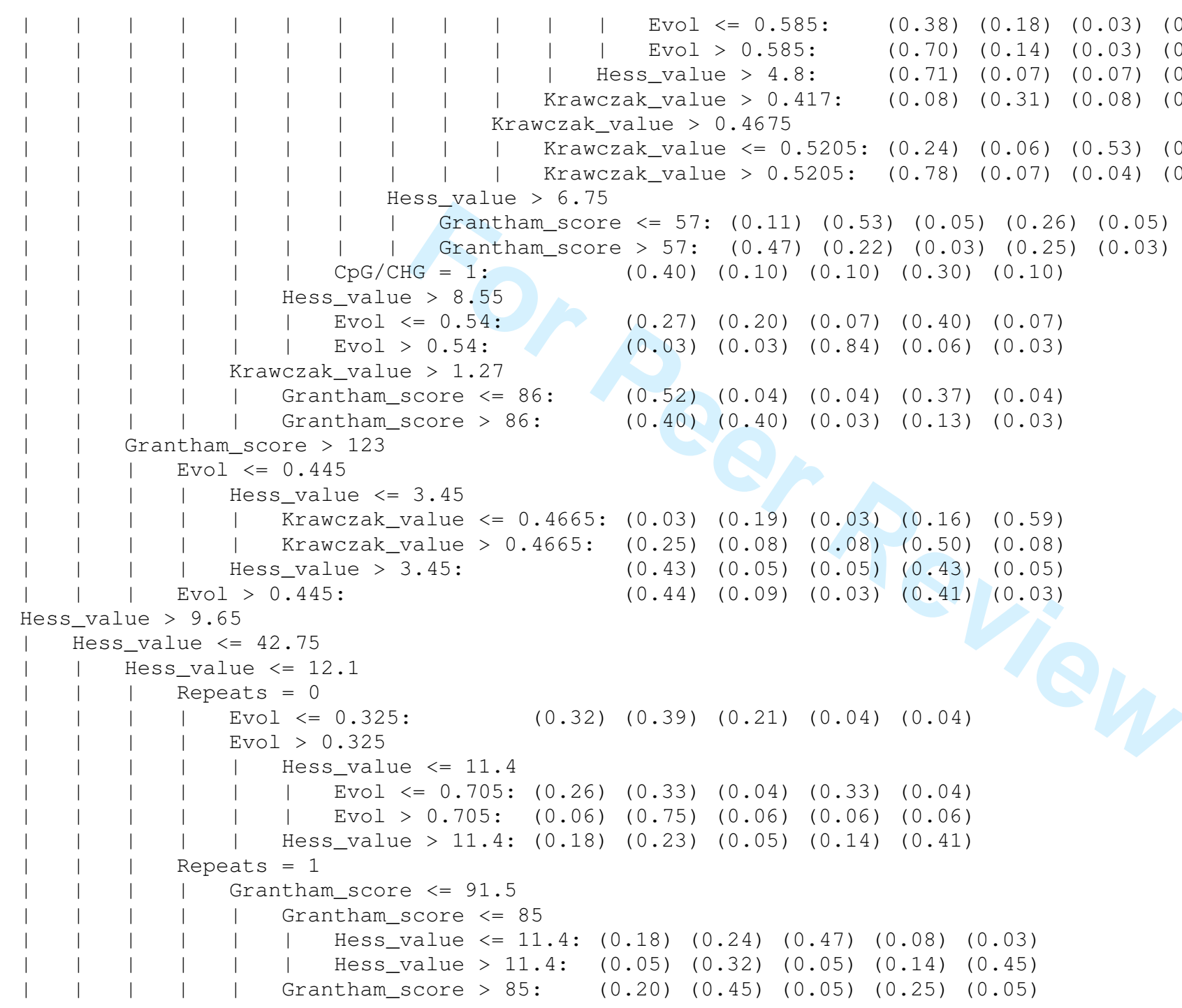




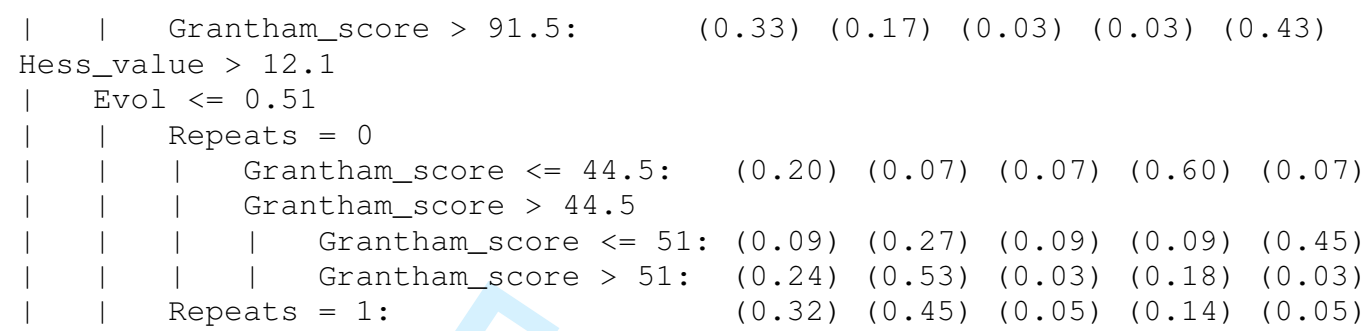

2797
1633

0.5392

0.1878

0.3177 
Root relative squared error

Total Number of Instances

$===$ Detailed Accuracy By Class $===$

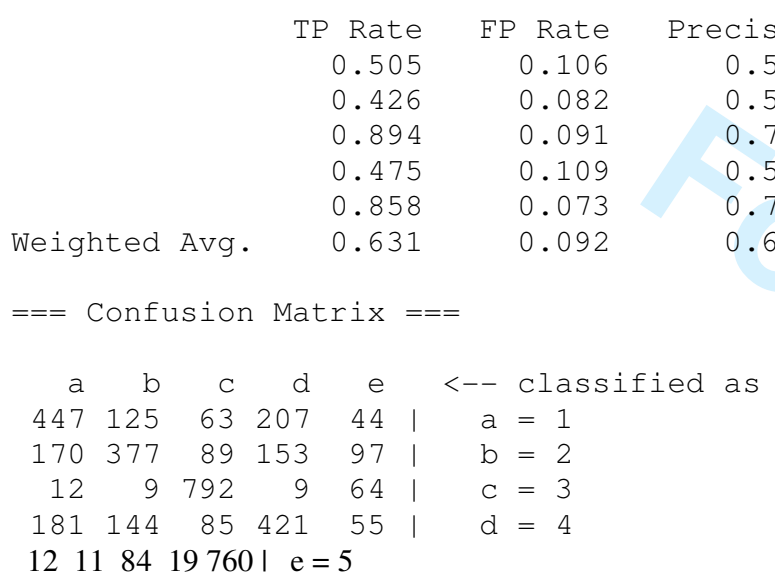

$79.4156 \div$

4430 
Supplementary Table 1. Tumour suppressor gene orthologues used to estimate the degree of evolutionary conservation of the various gene coding sequences

\begin{tabular}{|c|c|c|c|}
\hline Gene & Species & $\begin{array}{l}\text { cDNA sequence } \\
\text { identifier }\end{array}$ & $\begin{array}{l}\text { Protein sequence } \\
\text { identifier }\end{array}$ \\
\hline$A P C$ & $\begin{array}{l}\text { Xenopus laevis } \\
\text { Bos taurus } \\
\text { Rattus norvegicus } \\
\text { Mus musculus }\end{array}$ & $\begin{array}{l}\text { U64442.1 } \\
\text { XM_865627.1 } \\
\text { NM_012499.1 } \\
\text { NM_007462.1 }\end{array}$ & $\begin{array}{l}\text { AAB41671.1 } \\
\text { XP_870720.1 } \\
\text { NP_036631.1 } \\
\text { NP_031488.1 }\end{array}$ \\
\hline ATM & $\begin{array}{l}\text { Gallus gallus } \\
\text { Xenopus laevis } \\
\text { Rattus norvegicus } \\
\text { Sus scrofa } \\
\text { Canis familiaris } \\
\text { Mus musculus }\end{array}$ & $\begin{array}{l}\text { XM_417160.1 } \\
\text { AY668954.1 } \\
\text { XM_236275.3 } \\
\text { AY587061 } \\
\text { XM_845871.1 } \\
\text { NM_007499 }\end{array}$ & $\begin{array}{l}\text { XP_417160.1 } \\
\text { AAT72929.1 } \\
\text { XP_236275.3 } \\
\text { AAT01608.1 } \\
\text { XP_850964.1 } \\
\text { NP_031525.1 }\end{array}$ \\
\hline$B R C A 1$ & $\begin{array}{l}\text { Gallus gallus } \\
\text { Xenopus laevis } \\
\text { Bos taurus } \\
\text { Rattus norvegicus } \\
\text { Canis familiaris } \\
\text { Mus musculus }\end{array}$ & $\begin{array}{l}\text { NM_204169.1 } \\
\text { AF416868.1 } \\
\text { NM_178573.1 } \\
\text { NM_012514.1 } \\
\text { NM_001013416.1 } \\
\text { NM_009764.2 }\end{array}$ & $\begin{array}{l}N P \_989500.1 \\
A A L 13037.1 \\
N P \_848668.1 \\
N P \_036646.1 \\
N P \_001013434.1 \\
N P \_033894.2\end{array}$ \\
\hline$B R C A 2$ & $\begin{array}{l}\text { Gallus gallus } \\
\text { Danio rerio } \\
\text { Bos taurus } \\
\text { Rattus norvegicus } \\
\text { Canis familiaris } \\
\text { Mus musculus }\end{array}$ & $\begin{array}{l}\text { NM_204276.1 } \\
X M \_690042.1 \\
X M \_583622.2 \\
\text { NM_031542.1 } \\
\text { NM_001006653.4 } \\
\text { NM_009765.1 }\end{array}$ & $\begin{array}{l}N P \_989607.1 \\
X P \_695134.1 \\
X P \_583622.2 \\
N P \_113730.1 \\
N P \_001006654.2 \\
N P \_033895.1\end{array}$ \\
\hline $\mathrm{CDH} 1$ & $\begin{array}{l}\text { Xenopus laevis } \\
\text { Danio rerio } \\
\text { Bos taurus } \\
\text { Rattus norvegicus } \\
\text { Canis familiaris } \\
\text { Mus musculus }\end{array}$ & $\begin{array}{l}\text { BC068940.1 } \\
\text { NM_131820.1 } \\
\text { NM_001002763.1 } \\
\text { NM_031334.1 } \\
\text { XM_536807.2 } \\
\text { NM_009864.1 }\end{array}$ & $\begin{array}{l}\text { AAH68940.1 } \\
N P \_571895.1 \\
N P \_001002763.1 \\
N P \_112624.1 \\
X P \_536807.2 \\
N P \_033994.1\end{array}$ \\
\hline$C D K N 2 A$ & $\begin{array}{l}\text { Gallus gallus } \\
\text { Takifugu rubripes } \\
\text { Bos taurus } \\
\text { Rattus norvegicus } \\
\text { Canis familiaris } \\
\text { Mus musculus }\end{array}$ & $\begin{array}{l}\text { NM_204433.1 } \\
\text { AJ250231.1 } \\
X M \_868375.1 \\
\text { NM_031550.1 } \\
X M \_538685.2 \\
\text { AF044336.1 }\end{array}$ & $\begin{array}{l}\text { NP_989764.1 } \\
C A C 12808.1 \\
X P \_873468.1 \\
N P \_113738.1 \\
X P \_538685.2 \\
A A C 08963.1\end{array}$ \\
\hline$N F 1$ & $\begin{array}{l}\text { Gallus gallus } \\
\text { Takifugu rubripes } \\
\text { Rattus norvegicus } \\
\text { Canis familiaris } \\
\text { Mus musculus }\end{array}$ & $\begin{array}{l}\text { XM_415914.1 } \\
\text { AF064564.2 } \\
\text { NM_012609.1 } \\
\text { XM_537738.2 } \\
\text { NM_010897.1 }\end{array}$ & $\begin{array}{l}\text { XP_415914.1 } \\
\text { AAD15839.1 } \\
\text { NP_036741.1 } \\
\text { XP_537738.2 } \\
\text { NP_035027.1 }\end{array}$ \\
\hline$N F 2$ & $\begin{array}{l}\text { Gallus gallus } \\
\text { Danio rerio } \\
\text { Bos taurus } \\
\text { Rattus norvegicus } \\
\text { Canis familiaris } \\
\text { Mus musculus }\end{array}$ & $\begin{array}{l}\text { NM_204497.2 } \\
\text { NM_212951.1 } \\
\text { XM_611643.2 } \\
\text { XM_341248.2 } \\
\text { XM_534729.2 } \\
\text { NM_010898.2 }\end{array}$ & $\begin{array}{l}\text { NP_989828.2 } \\
\text { NP_998116.1 } \\
\text { XP_611643.2 } \\
\text { XP_341249.2 } \\
\text { XP_534729.2 } \\
\text { NP_035028.2 }\end{array}$ \\
\hline PTCH1 & $\begin{array}{l}\text { Xenopus laevis } \\
\text { Gallus gallus } \\
\text { Danio rerio } \\
\text { Meriones unguiculatus } \\
\text { Rattus norvegicus } \\
\text { Mus musculus }\end{array}$ & $\begin{array}{l}\text { AF302765.1 } \\
\text { NM_204960.1 } \\
\text { NM_130988.1 } \\
\text { AB188226.1 } \\
\text { NM_053566.1 } \\
\text { NM_008957.1 }\end{array}$ & $\begin{array}{l}\text { AAK15463.1 } \\
\text { NP_990291.1 } \\
\text { NP_571063.1 } \\
\text { BAE78534.1 } \\
\text { NP_446018.1 } \\
\text { NP_032983.1 }\end{array}$ \\
\hline PTEN & Xenopus laevis & AF144732.1 & AAD46165.1 \\
\hline
\end{tabular}




\begin{tabular}{|c|c|c|c|}
\hline & $\begin{array}{l}\text { Gallus gallus } \\
\text { Bos taurus } \\
\text { Canis familiaris } \\
\text { Rattus norvegicus } \\
\text { Mus musculus }\end{array}$ & $\begin{array}{l}\text { XM_421555.1 } \\
\text { XM_613125.2 } \\
\text { NM_001003192.1 } \\
\text { NM_031606.1 } \\
\text { NM_008960.2 }\end{array}$ & $\begin{array}{l}\text { XP_421555.1 } \\
\text { XP_613125.2 } \\
\text { NP_001003192.1 } \\
\text { NP_113794.1 } \\
\text { NP_032986.1 }\end{array}$ \\
\hline$R B 1$ & $\begin{array}{l}\text { Gallus gallus } \\
\text { Rattus norvegicus } \\
\text { Canis familiaris } \\
\text { Mus musculus } \\
\text { Oncorhynchus mykiss } \\
\text { Notophthalmus viridescens }\end{array}$ & $\begin{array}{l}\text { NM_204419.1 } \\
\text { XM_344434.2 } \\
\text { XM_534118.2 } \\
\text { NM_009029.1 } \\
\text { AF102861.1 } \\
\text { Y09226.1 }\end{array}$ & $\begin{array}{l}\text { NP_989750.1 } \\
\text { XP_344435.2 } \\
\text { XP_534118.2 } \\
\text { NP_033055.1 } \\
\text { AAD13390.1 } \\
\text { CAA70428.1 }\end{array}$ \\
\hline STK11 & $\begin{array}{l}\text { Xenopus laevis } \\
\text { Danio rerio } \\
\text { Rattus norvegicus } \\
\text { Raja erinacea } \\
\text { Canis familiaris } \\
\text { Mus musculus }\end{array}$ & $\begin{array}{l}\text { U24435.1 } \\
\text { NM_001017839.1 } \\
\text { XM_234900.2 } \\
\text { AF486831.1 } \\
\text { XM_542206.2 } \\
\text { NM_011492.1 }\end{array}$ & $\begin{array}{l}\text { AAC59904.1 } \\
\text { NP_001017839.1 } \\
\text { XP_234900.2 } \\
\text { AAL92113.1 } \\
\text { XP_542206.2 } \\
\text { NP_035622.1 }\end{array}$ \\
\hline TP53 & $\begin{array}{l}\text { Gallus gallus } \\
\text { Danio rerio } \\
\text { Bos taurus } \\
\text { Rattus norvegicus } \\
\text { Canis familiaris } \\
\text { Mus musculus }\end{array}$ & $\begin{array}{l}\text { NM_205264.1 } \\
\text { NM_131327.1 } \\
\text { NM_174201.2 } \\
\text { NM_030989.1 } \\
\text { NM_001003210.1 } \\
\text { NM_011640.1 }\end{array}$ & $\begin{array}{l}\text { NP_990595.1 } \\
\text { NP_571402.1 } \\
\text { NP_776626.1 } \\
\text { NP_112251.1 } \\
\text { NP_001003210.1 } \\
\text { NP_035770.1 }\end{array}$ \\
\hline$T S C 1$ & $\begin{array}{l}\text { Gallus gallus } \\
\text { Danio rerio } \\
\text { Bos taurus } \\
\text { Rattus norvegicus } \\
\text { Canis familiaris } \\
\text { Mus musculus }\end{array}$ & $\begin{array}{l}\text { XM_415449.1 } \\
\text { XM_691747.1 } \\
\text { XM_612846.2 } \\
\text { NM_021854.1 } \\
\text { XM_537808.2 } \\
\text { NM_022887.2 }\end{array}$ & $\begin{array}{l}\text { XP_415449.1 } \\
\text { XP_696839.1 } \\
\text { XP_612846.2 } \\
\text { NP_068626.1 } \\
\text { XP_537808.2 } \\
\text { NP_075025.2 }\end{array}$ \\
\hline TSC2 & $\begin{array}{l}\text { Gallus gallus } \\
\text { Takifugu rubripes } \\
\text { Bos taurus } \\
\text { Rattus norvegicus } \\
\text { Canis familiaris } \\
\text { Mus musculus }\end{array}$ & $\begin{array}{l}\text { XM_414853.1 } \\
\text { AF013614 } \\
\text { XM_581197.2 } \\
\text { NM_012680.2 } \\
\text { XM_537008.2 } \\
\text { NM_011647.2 }\end{array}$ & $\begin{array}{l}\text { XP_414853.1 } \\
\text { AAB86682.1 } \\
\text { XP_581197.2 } \\
\text { NP_036812.2 } \\
\text { XP_537008.2 } \\
\text { NP_035777.2 }\end{array}$ \\
\hline$V H L$ & $\begin{array}{l}\text { Gallus gallus } \\
\text { Danio rerio } \\
\text { Bos taurus } \\
\text { Rattus norvegicus } \\
\text { Canis familiaris } \\
\text { Mus musculus }\end{array}$ & $\begin{array}{l}\text { XM_414447.1 } \\
\text { XM_681176.1 } \\
\text { XM_613870.2 } \\
\text { NM_052801.1 } \\
\text { NM_001008552.1 } \\
\text { NM_009507.2 }\end{array}$ & $\begin{array}{l}\text { XP_414447.1 } \\
\text { XP_686268.1 } \\
\text { XP_613870.2 } \\
\text { NP_434688.1 } \\
\text { NP_001008552.1 } \\
\text { NP_033533.1 }\end{array}$ \\
\hline$W T 1$ & $\begin{array}{l}\text { Xenopus laevis } \\
\text { Gallus gallus } \\
\text { Rattus norvegicus } \\
\text { Canis familiaris } \\
\text { Sus scrofa } \\
\text { Mus musculus }\end{array}$ & $\begin{array}{l}\text { U42011.1 } \\
\text { NM_205216.1 } \\
\text { NM_031534.1 } \\
\text { XM_846479.1 } \\
\text { NM_001001264.1 } \\
\text { NM_144783.1 }\end{array}$ & $\begin{array}{l}\text { AAB53152.1 } \\
\text { NP_990547.1 } \\
\text { NP_113722.1 } \\
\text { XP_851572.1 } \\
\text { NP_001001264.1 } \\
\text { NP_659032.1 }\end{array}$ \\
\hline
\end{tabular}


SupplementaryTable 2. Differences in distribution of parameters for somatic, germline, shared, somatic recurrent and shared recurrent missense mutations. Observed median and/or mean values are shown in brackets. (Note that the higher values correspond to less conserved genes whereas the low values refer to highly conserved ones).

\begin{tabular}{|c|c|}
\hline Parameter & $\begin{array}{c}\text { Observed trend } \\
(\mathbf{p}<0.05)\end{array}$ \\
\hline $\begin{array}{l}\text { Median non-disease } \\
\text { associated mutability rate } \\
\text { according to Hess et al. } \\
{[1994]}\end{array}$ & 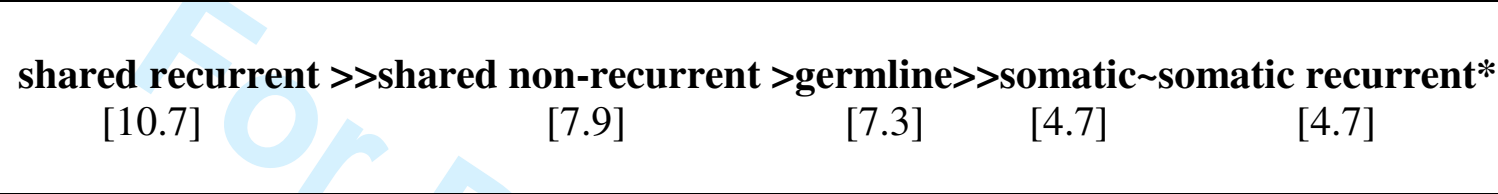 \\
\hline $\begin{array}{l}\text { Median disease-associated } \\
\text { mutability rate according to } \\
\text { Krawczak et al. [1998] }\end{array}$ & 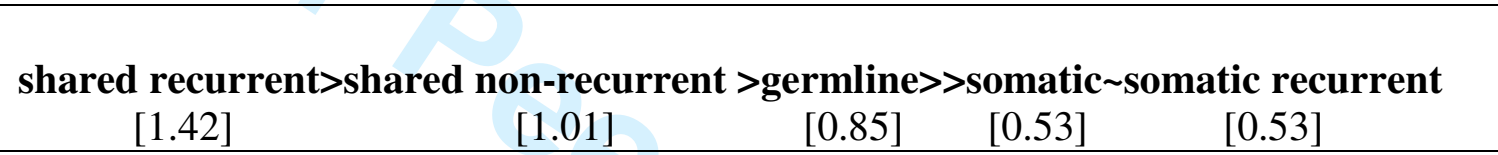 \\
\hline $\begin{array}{l}\text { Mean/median degree of } \\
\text { evolutionary conservation }\end{array}$ & $\begin{array}{ccc}\text { shared recurrent } & <\text { shared non-recurrent } & <<\text { somatic non-recurrent } \\
{[0.072 / 0]} & {[0.138 / 0]} & {[0.265 / 0.24]} \\
& \text { somatic non-recurrent } & >\text { germline } \\
{[0.265 / 0.24]} & {[0.18 / 0]} \\
\end{array}$ \\
\hline Mean Grantham score & $\begin{array}{c}\text { germline >somatic recurrent } \sim \text { somatic non-recurrent } \\
{[93] \quad[85]} \\
\text { shared recurrent } \sim \text { shared non-recurrent }>\text { > somatic recurrent } \\
{[100]}\end{array}$ \\
\hline $\begin{array}{l}\text { Proportion of CpG-located } \\
\text { mutations }\end{array}$ & $\begin{array}{ccccc}\text { shared recurrent } \sim \text { shared }>>\text { germline }>>\text { somatic } & \sim \text { somatic recurrent } \\
{[0.34]} & {[0.21]} & {[0.12]} & {[0.08]} & {[0.05]}\end{array}$ \\
\hline $\begin{array}{l}\text { Proportion of } \mathrm{CpHpG-} \\
\text { located mutations }\end{array}$ & $\begin{array}{ccc}\text { shared recurrent } \sim \text { shared } & \text { > } \\
{[0.098]} & {[0.082]} & {[0.028]} \\
\end{array}$ \\
\hline $\begin{array}{l}\text { Proportion of mutations } \\
\text { located within or in the } \\
\text { vicinity of direct repeats }\end{array}$ & \begin{tabular}{ccc}
\multicolumn{2}{c}{ somatic $>>$ germline $>>$ recurrent somatic } \\
{$[0.07]$} & {$[0.04]$} & {$[0.02]$}
\end{tabular} \\
\hline
\end{tabular}




\begin{tabular}{|c|c|c|}
\hline $\begin{array}{l}\text { Proportion of mutations } \\
\text { located within (or in the } \\
\text { vicinity of) runs of identical } \\
\text { nucleotides }\end{array}$ & \begin{tabular}{cr}
\multicolumn{2}{c}{ somatic $>>$ shared } \\
{$[0.24] \quad[0.05]$} \\
germline $>>$ shared \\
{$[0.20]$} & {$[0.05]$}
\end{tabular} & $\begin{array}{c}\text { somatic }>>\text { shared recurrent } \\
{[0.24] \quad[0.16]} \\
\text { somatic recurrent }>>\text { shared } \\
{[0.21]}\end{array}$ \\
\hline
\end{tabular}

*Inequality shared>germline $>$ somatic implies that a significant difference $(\mathrm{p}<0.05)$ in the corresponding parameter was observed between each pair of mutational spectra, i.e. shared vs germline, shared vs somatic and germline vs somatic. Symbol ' $\sim$ ' denotes the absence of any significant difference between any two mutational spectra with respect to a given parameter. Symbols ' $>>$ ' or ' $<<$ ' indicate experiment-wise statistical significance of the observed inequality whereas symbols ' $<$ ' or ' $>$ ' indicate gene-wise statistical significance. 
Supplementary Table 3. Various parameters of gene-wise somatic and germline missense mutational spectra vs. potential mutational spectra exhibiting either gene-wise $(\mathrm{p}<0.05)$ or experiment-wise differences $(\mathrm{p}<0.05$; shaded in light grey) with respect to the parameters measured.

\begin{tabular}{|c|c|c|c|c|c|c|c|c|c|c|c|c|}
\hline & \multicolumn{2}{|c|}{$\begin{array}{c}\text { Non-disease } \\
\text { associated mutation } \\
\text { rate }\end{array}$} & \multicolumn{2}{|c|}{$\begin{array}{l}\text { Disease-associated } \\
\text { mutation rate }\end{array}$} & \multicolumn{2}{|c|}{$\begin{array}{c}\text { Evolutionary } \\
\text { conservation rate }\end{array}$} & \multicolumn{2}{|c|}{ Grantham score } & \multicolumn{2}{|c|}{$\begin{array}{l}\text { CpG-located } \\
\text { missense } \\
\text { mutations }\end{array}$} & \multicolumn{2}{|c|}{$\begin{array}{c}\text { CpHpG- } \\
\text { located } \\
\text { missense } \\
\text { mutations }\end{array}$} \\
\hline & $\begin{array}{c}\text { Gene } \\
\text { symbol }\end{array}$ & Median & $\begin{array}{c}\text { Gene } \\
\text { symbol }\end{array}$ & Median & $\begin{array}{c}\text { Gene } \\
\text { symbol } \\
\end{array}$ & Median & $\begin{array}{c}\text { Gene } \\
\text { symbol } \\
\end{array}$ & Median & $\begin{array}{c}\text { Gene } \\
\text { symbol } \\
\end{array}$ & $\%$ & $\begin{array}{c}\text { Gene } \\
\text { symbol } \\
\end{array}$ & $\%$ \\
\hline \multirow{8}{*}{ 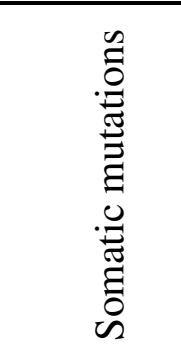 } & & & STK11 & 1.66 & & & & & STK11 & 25 & & \\
\hline & & & PTCH1 & 1.06 & & & & & & & & \\
\hline & $A P C$ & 8.4 & $C D K N 2 A$ & 1.01 & $C D K N 2 A$ & 0.38 & & & $C D K N 2 A$ & 20 & $C D K N 2 A$ & 5.2 \\
\hline & $C D K N 2 A$ & 7.9 & $A P C$ & 0.83 & & & & & & & & \\
\hline & PTEN & 5.6 & PTEN & 0.53 & 0 & & & & & & & \\
\hline & TP53 & 4.6 & TP53 & 0.5 & TP53 & 0.17 & & & $R B 1$ & 18 & TP53 & 2.8 \\
\hline & & & & & VHL & 0.14 & & & BRCA2 & 16 & & \\
\hline & & & & & & & & & PTCHI & 15 & & \\
\hline \multirow{3}{*}{$\begin{array}{l}\text { for all } 17 \\
\text { genes } \\
\text { combined }\end{array}$} & somatic & 4.7 & somatic & 0.53 & somatic & 0 & somatic & 78 & somatic & 8 & somatic & 2.5 \\
\hline & control & 4.1 & control & 0.4 & control & 0.2 & control & 74 & control & 2 & control & 2 \\
\hline & germline & 7.2 & germline & 0.85 & germline & 0 & germline & 94 & germline & 12 & germline & 3 \\
\hline \multirow{11}{*}{ 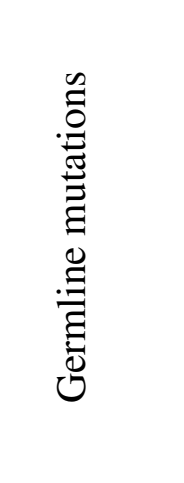 } & & & & & & & & & & & & \\
\hline & TSC2 & 7.2 & & & TSC2 & 0 & & 2 & BRCAl & 7 & BRCAl & 3.6 \\
\hline & $N F 1$ & 7.3 & & & & & $N F 1$ & 98 & & & & \\
\hline & $R B 1$ & 7.6 & & & & & & & $N F 1$ & 7 & & \\
\hline & $A T M$ & 7.9 & $A T M$ & 0.79 & ATM & 0 & $A T M$ & 98 & ATM & 15 & $A T M$ & 3.8 \\
\hline & BRCAI & 7.9 & BRCAI & 0.81 & VHL & 0 & VHL & 99 & BRCAI & 16 & & \\
\hline & BRCA2 & 8.7 & BRCA2 & 0.81 & & & & & $N F 1$ & 18 & & \\
\hline & & & PTEN & 0.92 & & & & & & & TSC2 & 8.1 \\
\hline & & & $R B 1$ & 0.99 & & & & & & & $W T 1$ & 10.8 \\
\hline & & & $N F 1$ & 1.03 & & & & & & & & \\
\hline & & & TSC2 & 1.03 & & & & & & & & \\
\hline
\end{tabular}

John Wiley \& Sons, Inc.20 


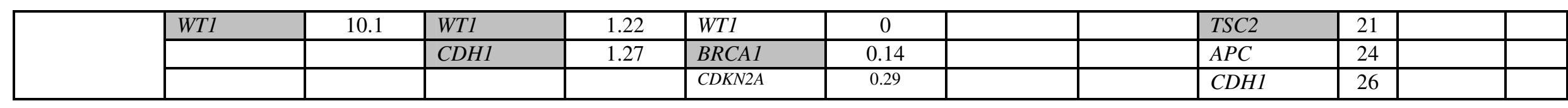


Supplementary Table 4. Summary of mutations occurring in direct repeats of length $\geq 8$ bp in the 17 tumour suppressor genes.

\begin{tabular}{|c|c|c|c|c|c|c|c|c|c|c|c|}
\hline \multirow[b]{2}{*}{$\begin{array}{c}\text { Gene } \\
\text { symbol }\end{array}$} & \multirow{2}{*}{$\begin{array}{l}\text { Proportion } \\
\text { of gene } \\
\text { length } \\
\text { covered } \\
\text { by repeats } \\
(\%)\end{array}$} & \multicolumn{6}{|c|}{ Number of missense mutations found in repeats } & \multicolumn{4}{|c|}{$\begin{array}{l}\text { Number of micro-deletions and micro- } \\
\text { insertions found in repeats }\end{array}$} \\
\hline & & $\begin{array}{l}\text { somatic } \\
\text { non- } \\
\text { recurrent }\end{array}$ & germline & $\begin{array}{c}\text { shared } \\
\text { non- } \\
\text { recurrent }\end{array}$ & $\begin{array}{l}\text { somatic } \\
\text { recurrent }\end{array}$ & $\begin{array}{l}\text { shared } \\
\text { recurrent }\end{array}$ & Total & $\begin{array}{l}\text { somatic } \\
\text { non- } \\
\text { recurrent }\end{array}$ & germline & shared & Total \\
\hline$A P C$ & 4 & 3 & 0 & 0 & 0 & 0 & 3 & 17 & 21 & 1 & 17 \\
\hline ATM & 7 & 2 & 0 & 0 & 0 & 0 & 2 & 0 & 11 & 0 & 0 \\
\hline BRCA1 & 5 & 0 & 9 & 0 & 0 & 0 & 9 & 1 & 8 & 0 & 1 \\
\hline BRCA2 & 2 & 0 & 0 & 0 & 0 & 0 & 0 & 1 & 12 & 0 & 1 \\
\hline CDH1 & 3 & 0 & 0 & 0 & 0 & 0 & 0 & 0 & 1 & 0 & 0 \\
\hline CDKN2A & 17 & 25 & 8 & 3 & 0 & 0 & 36 & 28 & 2 & 0 & 28 \\
\hline NF1 & 7 & 0 & 2 & 0 & 0 & 0 & 2 & 0 & 15 & 0 & 0 \\
\hline NF2 & 3 & 0 & 0 & 0 & 0 & 0 & 0 & 1 & 1 & 0 & 1 \\
\hline PTCH1 & 3 & 0 & 0 & 0 & 0 & 0 & 0 & 0 & 0 & 0 & 0 \\
\hline PTEN & 17 & 7 & 0 & 0 & 4 & 2 & 13 & 20 & 5 & 1 & 20 \\
\hline$R B 1$ & 12 & 0 & 1 & 0 & 0 & 0 & 1 & 2 & 12 & 0 & 2 \\
\hline STK11 & 10 & 0 & 3 & 1 & 0 & 0 & 4 & 0 & 6 & 0 & 0 \\
\hline TP53 & 14 & 24 & 1 & 0 & 13 & 2 & 40 & 21 & 0 & 0 & 21 \\
\hline$T S C 1$ & 5 & 0 & 1 & 0 & 0 & 0 & 1 & 0 & 4 & 0 & 0 \\
\hline TSC2 & 5 & 0 & 10 & 1 & 0 & 0 & 11 & 0 & 6 & 0 & 0 \\
\hline VHL & 6 & 0 & 1 & 0 & 0 & 0 & 1 & 0 & 1 & 0 & 0 \\
\hline$W T 1$ & 7 & 1 & 0 & 0 & 0 & 0 & 1 & 0 & 0 & 0 & 0 \\
\hline TOTAL & 6 & 62 & 36 & 5 & 17 & 4 & 124 & 91 & 105 & 2 & 91 \\
\hline
\end{tabular}

John Wiley \& Sons, Inc.22 
Supplementary Table 5. Summary of mutations occurring in inverted repeats of length $\geq 8 \mathrm{bp}$ in the 17 tumour suppressor genes.

\begin{tabular}{|c|c|c|c|c|c|c|c|c|c|c|c|}
\hline \multirow[b]{2}{*}{$\begin{array}{l}\text { Gene } \\
\text { symbol }\end{array}$} & \multirow{2}{*}{$\begin{array}{c}\text { Proportion } \\
\text { of gene } \\
\text { length } \\
\text { covered } \\
\text { by repeats } \\
(\%)\end{array}$} & \multicolumn{6}{|c|}{ Number of missense mutations found in repeats } & \multicolumn{4}{|c|}{$\begin{array}{l}\text { Number of micro-deletions and micro- } \\
\text { insertions found in repeats }\end{array}$} \\
\hline & & $\begin{array}{l}\text { somatic } \\
\text { non- } \\
\text { recurrent }\end{array}$ & germline & $\begin{array}{c}\text { shared } \\
\text { non- } \\
\text { recurrent }\end{array}$ & $\begin{array}{l}\text { somatic } \\
\text { recurrent }\end{array}$ & $\begin{array}{l}\text { shared } \\
\text { recurrent }\end{array}$ & Total & $\begin{array}{l}\text { somatic } \\
\text { non- } \\
\text { recurrent }\end{array}$ & germline & shared & Total \\
\hline$A P C$ & 6 & 5 & 4 & 1 & 1 & 0 & 5 & 21 & 27 & 2 & 50 \\
\hline ATM & 13 & 1 & 14 & 0 & 0 & 0 & 1 & 1 & 16 & 0 & 17 \\
\hline BRCA1 & 6 & 0 & 15 & 0 & 0 & 0 & 0 & 0 & 22 & 1 & 23 \\
\hline BRCA2 & 7 & 3 & 1 & 0 & 0 & 0 & 3 & 1 & 27 & 0 & 28 \\
\hline $\mathrm{CDH1}$ & 5 & 0 & 1 & 0 & 0 & 0 & 0 & 1 & 0 & 0 & 1 \\
\hline CDKN2A & 8 & 30 & 5 & 6 & 2 & 1 & 30 & 13 & 2 & 1 & 16 \\
\hline$N F 1$ & 11 & 0 & 3 & 0 & 0 & 0 & 0 & 1 & 24 & 0 & 25 \\
\hline NF2 & 10 & 1 & 3 & 0 & 0 & 0 & 1 & 11 & 6 & 0 & 17 \\
\hline PTCH1 & 5 & 1 & 0 & 0 & 0 & 0 & 1 & 0 & 2 & 0 & 2 \\
\hline PTEN & 6 & 10 & 1 & 1 & 4 & 1 & 10 & 9 & 2 & 0 & 11 \\
\hline$R B 1$ & 16 & 4 & 5 & 1 & 0 & 0 & 4 & 7 & 28 & 0 & 35 \\
\hline STK11 & 13 & 1 & 5 & 0 & 1 & 0 & 1 & 1 & 9 & 0 & 10 \\
\hline TP53 & 5 & 13 & 0 & 0 & 51 & 9 & 13 & 53 & 2 & 0 & 55 \\
\hline TSC1 & 5 & 0 & 1 & 0 & 0 & 0 & 0 & 0 & 7 & 0 & 7 \\
\hline TSC2 & 9 & 0 & 6 & 0 & 0 & 0 & 0 & 1 & 13 & 0 & 14 \\
\hline$V H L$ & 12 & 9 & 8 & 1 & 1 & 0 & 9 & 36 & 15 & 2 & 53 \\
\hline WT1 & 7 & 0 & 2 & 0 & 0 & 0 & 0 & 0 & 0 & 0 & 0 \\
\hline TOTAL & 9 & 78 & 74 & 10 & 60 & 11 & 78 & 156 & 202 & 6 & 364 \\
\hline
\end{tabular}

John Wiley \& Sons, Inc. 23 
Supplementary Table 6. Summary of mutations occurring within symmetric repeats of length $\geq 8 \mathrm{bp}$ in the 17 tumour suppressor genes.

\begin{tabular}{|c|c|c|c|c|c|c|c|c|c|c|c|}
\hline \multirow[b]{2}{*}{$\begin{array}{c}\text { Gene } \\
\text { symbol }\end{array}$} & \multirow{2}{*}{$\begin{array}{l}\text { Proportion } \\
\text { of gene } \\
\text { length } \\
\text { covered } \\
\text { by repeats } \\
(\%)\end{array}$} & \multicolumn{6}{|c|}{ Number of missense mutations found in repeats } & \multicolumn{4}{|c|}{$\begin{array}{l}\text { Number of micro-deletions and micro- } \\
\text { insertions found in repeats }\end{array}$} \\
\hline & & $\begin{array}{l}\text { somatic } \\
\text { non- } \\
\text { recurrent }\end{array}$ & germline & $\begin{array}{c}\text { shared } \\
\text { non- } \\
\text { recurrent }\end{array}$ & $\begin{array}{l}\text { somatic } \\
\text { recurrent }\end{array}$ & $\begin{array}{l}\text { shared } \\
\text { recurrent }\end{array}$ & Total & $\begin{array}{l}\text { somatic } \\
\text { non- } \\
\text { recurrent }\end{array}$ & germline & shared & Total \\
\hline$A P C$ & 16 & 5 & 2 & 0 & 2 & 0 & 9 & 58 & 87 & 6 & 151 \\
\hline ATM & 32 & 2 & 11 & 0 & 0 & 0 & 13 & 2 & 43 & 0 & 45 \\
\hline BRCA1 & 20 & 1 & 30 & 0 & 0 & 0 & 31 & 0 & 82 & 2 & 84 \\
\hline BRCA2 & 18 & 6 & 18 & 0 & 0 & 0 & 24 & 2 & 79 & 3 & 84 \\
\hline$C D H 1$ & 24 & 4 & 0 & 0 & 0 & 0 & 4 & 5 & 8 & 0 & 13 \\
\hline CDKN2A & 24 & 49 & 13 & 5 & 2 & 0 & 69 & 35 & 7 & 1 & 43 \\
\hline NF1 & 31 & 1 & 20 & 0 & 0 & 0 & 21 & 2 & 85 & 2 & 89 \\
\hline NF2 & 24 & 6 & 3 & 0 & 1 & 0 & 10 & 49 & 12 & 3 & 64 \\
\hline PTCH1 & 23 & 5 & 8 & 1 & 0 & 0 & 14 & 5 & 23 & 0 & 28 \\
\hline PTEN & 44 & 27 & 3 & 1 & 9 & 0 & 40 & 42 & 13 & 1 & 56 \\
\hline$R B 1$ & 48 & 3 & 10 & 1 & 0 & 0 & 14 & 4 & 41 & 1 & 46 \\
\hline STK11 & 33 & 3 & 6 & 0 & 2 & 0 & 11 & 1 & 20 & 1 & 22 \\
\hline TP53 & 30 & 60 & 2 & 1 & 132 & 23 & 218 & 147 & 1 & 0 & 148 \\
\hline$T S C 1$ & 23 & 0 & 3 & 0 & 0 & 0 & 3 & 0 & 27 & 0 & 27 \\
\hline TSC2 & 23 & 0 & 13 & 0 & 0 & 0 & 13 & 1 & 29 & 0 & 30 \\
\hline VHL & 17 & 3 & 9 & 2 & 0 & 2 & 16 & 25 & 7 & 2 & 34 \\
\hline$W T 1$ & 26 & 0 & 6 & 0 & 0 & 0 & 6 & 3 & 4 & 0 & 7 \\
\hline TOTAL & 25 & 175 & 157 & 11 & 148 & 25 & 516 & 381 & 568 & 22 & 971 \\
\hline
\end{tabular}

John Wiley \& Sons, Inc.24 
Suplementary Table 7. Occurrence of missense mutations in repeats/runs of identical nucleotides and/or $\mathrm{CpG} / \mathrm{CpHpG}$ oligonucleotides

\begin{tabular}{|c|c|c|c|c|c|}
\hline \multirow[b]{2}{*}{$\begin{array}{l}\text { Type of } \\
\text { Repeats }\end{array}$} & \multirow[b]{2}{*}{$\begin{array}{c}\text { Type of } \\
\text { mutational } \\
\text { spectrum }\end{array}$} & \multicolumn{3}{|c|}{ Number of mutations } & \multirow[b]{2}{*}{$\begin{array}{c}\text { Remaining } \\
\text { number of } \\
\text { mutations }\end{array}$} \\
\hline & & $\begin{array}{l}\text { exclusively in } \\
\text { repeats/runs }\end{array}$ & $\begin{array}{l}\text { exclusively in } \\
\mathrm{CpG} / \mathrm{CpHpG}\end{array}$ & $\begin{array}{c}\text { in both } \\
\text { repeats/runs } \\
\text { and } \\
\text { CpG/CpHpG }\end{array}$ & \\
\hline \multirow{6}{*}{ Runs } & $\begin{array}{l}\text { somatic } \\
\text { non- } \\
\text { recurrent }\end{array}$ & 184 & 58 & 24 & 618 \\
\hline & germline & 151 & 100 & 27 & 608 \\
\hline & $\begin{array}{l}\text { somatic } \\
\text { recurrent }\end{array}$ & 167 & 46 & 18 & 636 \\
\hline & $\begin{array}{l}\text { shared non- } \\
\text { recurrent }\end{array}$ & 5 & 28 & 0 & 69 \\
\hline & $\begin{array}{l}\text { shared } \\
\text { recurrent }\end{array}$ & 10 & 38 & 5 & 59 \\
\hline & potential & 32861 & 3902 & 765 & 111495 \\
\hline \multirow{6}{*}{ Direct } & $\begin{array}{l}\text { somatic } \\
\text { non- } \\
\text { recurrent }\end{array}$ & 52 & 72 & 10 & 750 \\
\hline & germline & 31 & 122 & 5 & 728 \\
\hline & $\begin{array}{l}\text { somatic } \\
\text { recurrent }\end{array}$ & 14 & 61 & 3 & 789 \\
\hline & $\begin{array}{l}\text { shared non- } \\
\text { recurrent }\end{array}$ & 3 & 26 & 2 & 71 \\
\hline & $\begin{array}{l}\text { shared } \\
\text { recurrent }\end{array}$ & 2 & 41 & 2 & 67 \\
\hline & potential & 5252 & 4431 & 236 & 139104 \\
\hline
\end{tabular}




\section{Page 139 of 141}

Human Mutation

\begin{tabular}{|l|l|c|c|c|c|}
\hline Inverted & $\begin{array}{l}\text { somatic } \\
\text { non- } \\
\text { recurrent }\end{array}$ & 65 & 69 & 13 & 737 \\
\cline { 2 - 6 } & germline & 64 & 117 & 10 & 695 \\
\cline { 2 - 6 } & $\begin{array}{l}\text { somatic } \\
\text { recurrent }\end{array}$ & 55 & 59 & 5 & 748 \\
\cline { 2 - 6 } & $\begin{array}{l}\text { shared non- } \\
\text { recurrent }\end{array}$ & 8 & 26 & 2 & 66 \\
\cline { 2 - 6 } & $\begin{array}{l}\text { shared } \\
\text { recurrent }\end{array}$ & 7 & 39 & 4 & 62 \\
\cline { 2 - 6 } Symmetric & $\begin{array}{l}\text { sotential } \\
\text { somatic } \\
\text { non- } \\
\text { recurrent }\end{array}$ & 10790 & 4314 & 353 & 133566 \\
\cline { 2 - 6 } & germline & 140 & 110 & 20 & 647 \\
\cline { 2 - 6 } & $\begin{array}{l}\text { somatic } \\
\text { recurrent }\end{array}$ & 137 & 53 & 11 & 619 \\
\cline { 2 - 6 } & $\begin{array}{l}\text { shared non- } \\
\text { recurrent }\end{array}$ & 7 & 24 & 4 & 67 \\
\cline { 2 - 6 } & $\begin{array}{l}\text { shared } \\
\text { recurrent }\end{array}$ & 16 & 34 & 9 & 53 \\
\cline { 2 - 6 } & potential & 28646 & 3752 & 915 & 115710 \\
\hline
\end{tabular}

John Wiley \& Sons, Inc. 26 
Supplementary Table 8. Truncating vs. non-truncating lesions

\begin{tabular}{|c|c|c|c|c|c|c|c|c|c|c|}
\hline Gene & & Missense & Nonsense & $\begin{array}{l}\text { Micro- } \\
\text { deletions }\end{array}$ & $\begin{array}{c}\text { Micro- } \\
\text { insertions }\end{array}$ & $\begin{array}{l}\text { Micro- } \\
\text { indels }\end{array}$ & $\begin{array}{c}\text { Non-truncating } \\
\text { lesions }\end{array}$ & $\begin{array}{l}\text { Truncating } \\
\text { lesions }\end{array}$ & $\begin{array}{l}\text { Ratio of non-truncating } \\
\text { to truncating lesions }\end{array}$ & $\begin{array}{c}\text { Ratio of } \\
\text { truncating } \\
\text { somatic to } \\
\text { truncating } \\
\text { germline } \\
\text { lesions }\end{array}$ \\
\hline \multirow{2}{*}{$A P C$} & Somatic & 39 & 79 & 152 & 44 & 3 & 39 & 278 & 0.14 & \multirow{2}{*}{0.46} \\
\hline & Germline & 23 & 180 & 299 & 115 & 12 & 23 & 606 & 0.04 & \\
\hline \multirow{2}{*}{$A T M$} & Somatic & 11 & 7 & 4 & 1 & 0 & 11 & 12 & 0.92 & \multirow{2}{*}{0.05} \\
\hline & Germline & 76 & 75 & 122 & 35 & 14 & 76 & 246 & 0.31 & \\
\hline \multirow{2}{*}{ BRCAI } & Somatic & 6 & 9 & 9 & 5 & 0 & 6 & 23 & 0.26 & \multirow{2}{*}{0.05} \\
\hline & Germline & 170 & 121 & 259 & 85 & 12 & 170 & 477 & 0.36 & \\
\hline \multirow{2}{*}{$B R C A 2$} & Somatic & 21 & 1 & 8 & 4 & 0 & 21 & 13 & 1.62 & \multirow{2}{*}{0.03} \\
\hline & Germline & 86 & 76 & 247 & 90 & 11 & 86 & 424 & 0.20 & \\
\hline \multirow{2}{*}{$\mathrm{CDH1}$} & Somatic & 15 & 7 & 13 & 2 & 0 & 15 & 22 & 0.68 & \multirow{2}{*}{0.69} \\
\hline & Germline & 19 & 11 & 12 & 8 & 1 & 19 & 32 & 0.59 & \\
\hline \multirow{2}{*}{ CDKN2A } & Somatic & 198 & 18 & 77 & 25 & 8 & 198 & 128 & 1.55 & \multirow{2}{*}{4.74} \\
\hline & Germline & 62 & 7 & 11 & 7 & 2 & 62 & 27 & 2.30 & \\
\hline \multirow{2}{*}{$N F 1$} & Somatic & 2 & 11 & 16 & 3 & 0 & 2 & 30 & 0.07 & \multirow{2}{*}{0.07} \\
\hline & Germline & 83 & 115 & 221 & 105 & 8 & 83 & 449 & 0.18 & \\
\hline \multirow{2}{*}{$N F 2$} & Somatic & 23 & 42 & 182 & 28 & 6 & 23 & 258 & 0.09 & \multirow{2}{*}{2.22} \\
\hline & Germline & 20 & 43 & 55 & 16 & 2 & 20 & 116 & 0.17 & \\
\hline \multirow{2}{*}{ PTCH1 } & Somatic & 14 & 9 & 14 & 6 & 1 & 14 & 30 & 0.47 & \multirow{2}{*}{0.28} \\
\hline & Germline & 24 & 27 & 42 & 32 & 8 & 24 & 109 & 0.22 & \\
\hline \multirow{2}{*}{ PTEN } & Somatic & 226 & 56 & 152 & 51 & 4 & 226 & 263 & 0.86 & \multirow{2}{*}{3.21} \\
\hline & Germline & 45 & 28 & 29 & 22 & 3 & 45 & 82 & 0.55 & \\
\hline$R B 1$ & Somatic & 25 & 27 & 34 & 12 & 3 & 25 & 76 & 0.33 & 0.30 \\
\hline
\end{tabular}




\begin{tabular}{|c|c|c|c|c|c|c|c|c|c|c|}
\hline & Germline & 37 & 76 & 117 & 53 & 11 & 37 & 257 & 0.14 & \multirow{3}{*}{0.17} \\
\hline \multirow{2}{*}{ STK11 } & Somatic & 20 & 10 & 5 & 1 & 1 & 20 & 17 & 1.18 & \\
\hline & Germline & 30 & 27 & 47 & 24 & 3 & 30 & 101 & 0.30 & \\
\hline \multirow{2}{*}{ TP53 } & Somatic & 1229 & 96 & 512 & 238 & 0 & 1229 & 846 & 1.45 & \multirow{2}{*}{24.89} \\
\hline & Germline & 94 & 10 & 16 & 5 & 3 & 94 & 34 & 2.76 & \\
\hline \multirow{2}{*}{ TSC1 } & Somatic & 2 & 1 & 1 & 0 & 0 & 2 & 2 & 1.00 & \multirow{2}{*}{0.02} \\
\hline & Germline & 7 & 37 & 53 & 25 & 4 & 7 & 119 & 0.06 & \\
\hline \multirow{2}{*}{$T S C 2$} & Somatic & 2 & 1 & 3 & 2 & 1 & 2 & 7 & 0.29 & \multirow{2}{*}{0.03} \\
\hline & Germline & 89 & 74 & 110 & 46 & 3 & 89 & 233 & 0.38 & \\
\hline \multirow{2}{*}{ VHL } & Somatic & 88 & 15 & 180 & 44 & 1 & 88 & 240 & 0.37 & \multirow{2}{*}{1.82} \\
\hline & Germline & 143 & 27 & 63 & 37 & 5 & 143 & 132 & 1.08 & \\
\hline \multirow{2}{*}{ WT1 } & Somatic & 1 & 3 & 4 & 3 & 0 & 1 & 10 & 0.10 & \multirow{2}{*}{0.37} \\
\hline & Germline & 40 & 14 & 8 & 4 & 1 & 40 & 27 & 1.48 & \\
\hline \multirow{2}{*}{ Total } & Somatic & 1922 & 392 & 1366 & 469 & 28 & 1922 & 2255 & 0.85 & \multirow{2}{*}{0.65} \\
\hline & Germline & 1048 & 948 & 1711 & 709 & 103 & 1048 & 3471 & 0.30 & \\
\hline
\end{tabular}

